\title{
7 Egalitäre Elitenbildung: Die Universität Dar es Salaam
}

Akademisches Lehrpersonal wird normalerweise unter Begriffen wie „EntwicklungsexpertInnen“ und „EntwicklungshelferInnen“ nicht subsumiert; in historischen Forschungen zur Entwicklungsarbeit blieb Universitätspersonal bisher ausgeschlossen. Dafür gibt es keinen plausiblen Grund. Viele der expatriates an der Universität Dar es Salaam kamen durch spezifisch entwicklungspolitische Kanäle (wie Abkommen über Technische Hilfe bzw. Kulturell-Wissenschaftliche Zusammenarbeit) und mit spezifisch entwicklungspolitischen Intentionen nach Tansania. Sie bauten Studiengänge und Lehrstühle mit auf, beeinflussten Inhalte und wirkten in Personalentscheidungen, Ressourcenallokation oder politischen Debatten mit und wurden dabei selbst in ihrem intellektuellen und beruflichen Werdegang geprägt. Für Tansania wiederum war die personelle Unterstützung ein Schlüssel, um self-reliance im Bildungswesen $\mathrm{zu}$ erreichen - insbesondere an der einzigen Universität des Landes, die wie kaum eine andere Institution die Hoffnungen auf Entwicklung, Sozialismus und Eigenständigkeit symbolisierte.

Als die ersten kleinen Gruppen von DozentInnen aus der BRD und der DDR ihre Lehrtätigkeit an der Universität Dar es Salaam aufnahmen, befand sich diese gerade in ihrer nationalheroischen Phase. Neun Jahre nach der Eröffnung als College im Verbund mit den ostafrikanischen Hochschulen Makerere (Uganda) und Nairobi (Kenia) wurde die Universität 1970 zu einer eigenständigen nationalen Institution. Immer neue Institutsgebäude und Wohnhäuser wurden errichtet, das wissenschaftliche Personal und die Leitungspositionen stetig nationalisiert und die ersten tansanischen Professoren berufen. Die Universität stand symbolisch für den erfolgreich verlaufenden Emanzipationsprozess des Nationalstaates, wie der Rektor ${ }^{1}$ Pius Msekwa 1970 in seiner Eröffnungsrede verkündete:

The establishment of a University in a country is clearly a sign of growth and maturity; and that, I know, is how the people of Tanzania view the establishment of the University of Dar es Salaam. It means that our nation has now reached a stage where it can produce its high

1 Pius Msekwa und seine Nachfolger waren nominell Vice Chancellor, der tansanische Präsident hatte die Position des Chancellor. In der Praxis übernahm der jeweilige Vice Chancellor aber alle Aufgaben eines Rektors.

๑ OpenAccess. ๑ 2021 Eric Burton, publiziert von De Gruyter. (cc) BY Dieses Werk ist lizenziert unter der Creative Commons Attribution 4.0 International Lizenz. https://doi.org/10.1515/9783110705621-010 
level manpower in circumstances and under conditions wholly decided, and guided, by the National Ethic. ${ }^{2}$

Einen Punkt spielte Msekwa in seiner Eröffnungsrede bewusst herunter: Die Bedingungen, die Universität nach strikt nationalen Gesichtspunkten auszurichten, waren vielleicht besser als in den Jahren zuvor, aber immer noch nicht günstig. In materieller und auch personeller Hinsicht war die Universität von externen Gebern abhängig. Zum Zeitpunkt der Eröffnung als nationale Bildungseinrichtung am 29. August 1970 kam das wissenschaftliche Personal aus 30 Ländern, darunter Tansania (85 Personen), Großbritannien (62), USA (20), Kanada (11), Nigeria (9), Schweden (8), Dänemark und Kenia (je 7). Hinzu kamen auch eine Lehrkraft aus der BRD und zwei aus der DDR. ${ }^{3}$ Entsandte aus kommunistischen Ländern waren also eindeutig in der Unterzahl, aber auch unter den anderen ausländischen Lehrkräften fanden sich Linksliberale und MarxistInnen, die von Tansanias „revolutionärem Potenzial“" angelockt wurden.

Die Universitätsleitung stellte den Campus bisweilen als einem dritten Raum zwischen Ost und West dar, wo streitende Ideologien koexistieren und gar konvergieren konnten. Chief Kunambi schwärmte 1968 bei einem Besuch an der Leipziger Karl-Marx-Universität vom internationalen Flair des University College Dar es Salaam, es sei eine richtiggehende „kleine UN“, wo „die Vertreter von Ost und West, darunter den beiden deutschen Staaten, zusammenkommen und ohne Probleme zu einem Ganzen zusammenwachsen" könnten. ${ }^{4}$ Kunambis ostdeutsche Gesprächspartner teilten diese Vision der Konvergenz freilich nicht, und tatsächlich war die Universität schon 1968 kein Hort der Eintracht, sondern eine Arena, in der globale und nationale Interessengegensätze aufeinanderprallten. Der Campus war ein Raum, in dem sich die Widersprüche des tansanischen Sozialismus (siehe Kapitel 2) verdichteten und verschärften. Die Allianzen und Konfliktlinien waren dabei aber deutlich komplexer als nur jene zwischen „Ost“ und „West“, sie umfassten ideologische und theoretische Gräben an der

2 Appendix E, Vice-Chancellor's Speech for the Inauguration Ceremony 29th August 1970, in: UDSM, A Report on the Activities of the University of Dar es Salaam for the Year 1970-71, Dar es Salaam 1971, S. 265.

3 University of Dar es Salaam, A Report on the University of Dar es Salaam for the Year 1970 - 71, Dar es Salaam 1971, S. 271. Weitere Lehrkräfte kamen aus Ungarn (6), Uganda und Frankreich (je 5), Australien und Ägypten (je 4), Norwegen (3), Malawi, Guyana und Indien (je 2), Neuseeland, Bulgarien, Sudan, Niederlande, Irland, Schweiz, Tschechoslowakei, Jamaika, Italien, Burma und Pakistan (je 1).

4 UAL, DIB 164, Wienhold, Bericht über den Besuch von Chief Kunambi, Registrar of the University College Dar es Salaam, Leipzig, 12.1.1969, UAL, DIB 164, Bl. 34-36. 
Schnittstelle von Entwicklung und Dekolonisierung genauso wie Rivalitäten auf globaler, nationaler, institutioneller und persönlicher Ebene.

Die Geschichte der Universität Dar es Salaam ist bisher noch weitgehend der Erinnerungsliteratur überlassen geblieben, die von Perspektiven aktivistischer bzw. „radikaler“ TansanierInnen und expatriates einerseits und dem Blickwinkel ehemaliger Rektoren und leitender Universitätsangestellter andererseits dominiert wird. ${ }^{5}$ Auch in historischen und bildungswissenschaftlichen Werken über den tansanischen Hochschulbetrieb kommen diese beiden Perspektiven immer wieder zum Vorschein. Politische Auseinandersetzungen, Proteste und Demonstrationen werden entweder als progressives, aber von den Eliten unterdrücktes Potenzial gedeutet, oder aber als eher lästige Probleme identifiziert, die durch bedächtige Führung gelöst wurden. ${ }^{6}$ Vereinzelte historische Forschungen wie die hervorragende, aber unveröffentlichte Arbeit von Michelle Elise Bourbonniere, stellen die Debatten um eine sozialistische Umgestaltung der Universität im Gefolge der Arusha Declaration in den Vordergrund. ${ }^{7}$ Die bisherigen Schilderungen der Geschichte der Universität Dar es Salaam und erst recht die umfangreiche Erinnerungsliteratur haben sich damit vor allem an den Funken schlagenden Debatten um Radikalismus und Sozialismus abgearbeitet. Neben diesen zentralen Fragen der Politisierung bzw. „Sozialisierung“ ist allerdings die Ökonomisierung des Universitätsbetriebs aus dem Blick geraten. Diese lässt sich besonders gut an der Ingenieurwissenschaftlichen Fakultät aufzeigen.

Dieses Kapitel diskutiert die Entwicklungsarbeit im Universitätssektor und trägt gleichzeitig zu einer Geschichte der Universität Dar es Salaam als Raum nationaler und globaler Auseinandersetzungen bei. Der Schwerpunkt der Darstellung liegt auf den 1970er und 1980er Jahren. In den Jahren nach 1973 sollte die DDR mit konstant fünf bis sechs Lehrkräften an der Universität die größte Gruppe aus den kommunistischen Ländern stellen. Die BRD trat finanziell wie personell

5 Von denen einige im Folgenden zitiert werden, u. a. von Karim F. Hirji, John Saul und Issa Shivji. Unter den Rektoren haben Pius Msekwa und Matthew Luhanga Erinnerungen an ihre Amtszeit vorgelegt.

6 Beispiele für marxistische Analysen sind Manfred A. Bienefeld, Planning People, in: J. F. Rweyemamu u. a., Hg., Towards Socialist Planning, Dar es Salaam 1972, S.166-199; Issa G. Shivji, Intellectuals at the Hill. Essays and Talks 1969-1993, Dar es Salaam 1993. Aus Sicht leitender Universitätsfunktionäre sind die meisten Beiträge in bzw. von T. S. A. Mbwette/Abel G. M. Ishumi, Hg., Managing University Crises, Dar es Salaam 2000; Matthew Laban Luhanga/Daniel J. Mkude, Hg., Higher Education Reforms in Africa. The University of Dar es Salaam Experience, Dar es Salaam, Tanzania 2003; Philemon Andrew K. Mushi, History and Development of Education in Tanzania, Dar es Salaam, Tanzania 2009.

7 Michelle Elise Bourbonniere, Debating Socialism on the Hill. The University of Dar es Salaam, 1961-1971, MA Thesis, Halifax, N. S. 2007; Ivaska, Cultured States, Kap. 3 
ab 1970 stärker in Erscheinung und wurde durch die Technische Hilfe für die 1973 eröffnete Ingenieurwissenschaftliche Fakultät zu einer materiell wie personell maßgeblichen Präsenz am Campus.

Hinter dem gemeinsamen proklamierten Ziel, Tansanias tertiäres Bildungswesen zu stärken, standen unterschiedliche Interventionslogiken, die Möglichkeiten und Strategien der beiden deutschen Staaten widerspiegeln. Die DDR setzte durch die Entsendung von GesellschaftswissenschaftlerInnen auf die ideologische Beeinflussung angehender Führungskräfte und das „Halten“ einmal erkämpfter Stellen, um die jungen Nationalstaaten auf dem nicht kapitalistischen Entwicklungsweg zu unterstützen ${ }^{8}$, während die BRD mit materiellen und personellen Mitteln die technokratische Ausbildung von Fachkräften in einer modernisierungstheoretischen Perspektive verfolgte (also freilich auch eine Form ideologischer Beeinflussung, wenngleich nicht in der Selbstwahrnehmung der meisten Akteure), in der sich die ausländischen Fachkräfte mit der Zeit überflüssig machen sollten. Wichtig ist dabei der Blick auf den Alltag, denn in dem ereignisgeschichtlichen Fokus auf Proteste und Verbote, sozialistische und nationalistische Richtungswechsel wurde die Kontinuität der Ausbildungstätigkeit die für den Großteil der Lehrenden und Studierenden die Hauptsache war vernachlässigt.

Das Kapitel skizziert zuerst die Politisierung des akademischen Feldes, d.h. die Einbindung der Universität und des akademischen Feldes in die tansanische Politik - wobei es hier verschiedene Meinungen gab, wie diese Einbindung sich auswirken sollte. Nach 1967 wurde die Universität schrittweise zu einer Institution umfunktioniert, die der staatlichen Entwicklungsstrategie zu dienen hatte. Eine zentrale Herausforderung blieb dabei, die Elitenbildung - wie sie durch die universitäre Bildung betrieben wurde - mit egalitaristischen Prinzipien in Einklang zu bringen. Die BRD allerdings betrieb im Rahmen ihrer Unterstützung der Ingenieurwissenschaftlichen Fakultät eine Unterwanderung der egalitaristischen Prinzipien von Ujamaa. Die entsendenden DDR-Stellen wiederum hofften, dem Marxismus-Leninismus an der Universität stärkere Geltung zu verschaffen. Die Auslandskader hatten allerdings oft Schwierigkeiten, sich in den ideologischen Kämpfen am Campus wirkungsvoll zu positionieren. Wenn sie Maßnahmen setzen wollten, die über ein bloßes Lückenfüllen im Lehrbetrieb hinausgingen, waren BRD- wie DDR-Entsandte immer auf Allianzen vor Ort angewiesen.

8 UAL, DIB 164, „Die Hochschulbeziehungen der Karl-Marx-Universität Leipzig zu den arabischen und afrikanischen Ländern bis 1975“, o.D. [ca. 1968], Bl. 14. 


\subsection{Konfliktlinien: Anspruch und Realität der anti-elitären Elitenbildung}

Obwohl Dar es Salaam ursprünglich als gänzlich unpassender Standort für eine Universität gesehen wurde - eine britisch dominierte Arbeitsgruppe beklagte 1960 vor allem das „warme, Faulheit induzierende Klima“, das ein effizientes Arbeiten unmöglich machen würde - setzte sich die Küstenstadt doch gegen Alternativvorschläge wie Arusha oder Morogoro durch. ${ }^{9}$ Die Universität Dar es Salaam widerlegt jeden Klimadeterminismus, denn von hier sollte der politischen Elite des Landes bald frischer Wind und auch die eine oder andere steife Brise entgegenwehen. Errichtet auf einer Anhöhe, von der sich das acht Meilen entfernte Stadtzentrum Dar es Salaams und die Weiten des Indischen Ozeans überblicken ließen, drückte jedoch schon die Lage der Universität für viele die Abschottung von der Bevölkerung, Bildungsdünkel und intellektuellen Elitismus aus. ${ }^{10}$

Deutlichster Ausdruck dieses Elitismus war der Marsch von 412 Studierenden im Oktober 1966, mit dem gegen die Verpflichtung von UniversitätsabsolventInnen zum National Service protestierten. ${ }^{11}$ Der National Service war bereits Jahre zuvor gegründet worden, neu war allerdings die Forderung, dass auch Studierende nach ihrem Abschluss einen fünfmonatigen Dienst leisten und für weitere anderthalb Jahre in einem gemeinnützigen Amt nur $40 \%$ des üblichen Gehalts erhalten sollten. ${ }^{12}$ Die Studierenden verstanden sich, das belegen ihre Schlachtrufe und Slogans auf den Plakaten, als gebildete Elite, die der politischen Elite den Kampf ansagte. ${ }^{13}$ In einer Pressemeldung nach der Demonstration hetzte die TANU gegen die ,arm-chair philosophers on the Hill who have succumbed to be used as tools of neo-colonial intrigues“, und beschuldigte sie der "slyness of Lucipher“, koloniale Teile-und Herrsche-Taktiken zu verwenden, um die Nation zu spalten. ${ }^{14}$ Hier lässt sich Bourdieus theoretische Einsicht übertragen, dass „die Besitzer von Bildungskapital am stärksten zur Ungeduld und zur Revolte gegen die Privilegien der Besitzer von politischem Kapital neigen“; sie sind es auch, die

9 CCMA, NP/003, S. N. Eliufoo, „Memorandum on the Choice of Site for a University in Tanganyika“, 25.4.1960; Übersetzung EB.

10 Eckert, Herrschen und Verwalten, S. 249.

11 Der Protestmarsch war kein isoliertes Ereignis, sondern stellte die Kulmination bereits laufender öffentlicher Debatten dar. Angefeuert wurde er auch durch die Berichterstattung in der tansanischen Presse über studentische Proteste in anderen Ländern, darunter Indonesien und Algerien. Siehe Ivaska, Of Students, S. 97.

12 Eckert, Herrschen und Verwalten, S. 250.

13 Andrew M. Ivaska, Of Students, „Nizers,“ and a Struggle over Youth. Tanzania’s 1966 National Service Crisis, in: Africa Today 51/3 (2005), S. 83-107, hier: S. 98.

14 CCMA, ADM/549, TANU Press Release 28.10.1966, S. 2. 
„die egalitären oder meritokratischen Glaubensbekenntnisse, die die Grundlage der [...] beanspruchten Legitimität bilden“, gegen die Besitzer politischen Kapitals selbst wenden. ${ }^{15}$ Damit ist die eine Konfliktlinie abgesteckt: Inhaber kulturellen Kapitals, die sich Sonderbedingungen aushandeln wollten, gegen die Inhaber politischen Kapitals, von denen gerade in den 1960er-Jahren viele keine höheren Bildungsabschlüsse aufweisen konnten. Nyerere und andere PolitikerInnen positionierten sich (hierin durchaus vergleichbar mit dem SED-Regime, für das der folgende Begriff geprägt wurde) als „,anti-elitäre Eliten““. ${ }^{16}$

Während politische Kriterien und egalitaristische Ansprüche in der ersten Hälfte der 1970er-Jahre an der Universität ernsthaft debattiert und in Ansätzen umgesetzt wurden, wie unten genauer diskutiert wird, führten wirtschaftliche Probleme in den Jahren darauf zu einem Exodus des Lehrpersonals, das gerade erst weitgehend „tansanisiert“ worden war, sowie einer zunehmenden, schleichenden Ökonomisierung. Allein von 1977 bis Mitte der 1980er verließen über einhundert Universitätsangestellte den Campus; meist, um in Tansania oder im Ausland Stellen mit besseren Einkommensmöglichkeiten anzutreten. ${ }^{17}$ Die bleibenden Lehrkräfte diversifizierten angesichts sinkender Reallöhne und ökonomischer und damit existenzieller Unsicherheit ihre Einkommensquellen und versuchten zudem, die Rahmenbedingungen ihrer Tätigkeit möglichst flexibel zu gestalten. Wie ein Bericht der Universität 1993 zurückblickend feststellte: „For many of the staff of the university, the sheer necessity for survival meant that all the academic activities - teaching, research and attainment of knowledge - became secondary or tertiary activities. “18 Einige dieser Strategien unterminierten allerdings die Grundsätze der Universität und des leadership code, sodass eine Formalisierung ausbleiben musste. Eine weitere Konfliktlinie bestand also zwischen den ökonomischen Interessen des (einheimischen) Lehrpersonals und den egalitaristischen Anforderungen, die Nebeneinnahmen verboten. Einzelpersonen und Institute waren auf Geber angewiesen, die allerdings meist nur noch kleinere und kurzfristige Projekte finanzierten. ${ }^{19}$ Im Zuge der Suche nach Geldern verlor das politische Feld auf dem Campus zunehmend an Einfluss, das ökonomische

15 Bourdieu, Praktische Vernunft, S. 31. Bourdieu bezieht sich hier auf die DDR Ende der 1980er Jahre.

16 Peter Hübner, Antielitäre Eliten?, in: ders., Hg., Eliten im Sozialismus: Beiträge zur Sozialgeschichte der DDR, Köln 1999, S. 9-36.

17 Tripp, Changing the Rules, S. 40.

18 UDSM, Institutional Transformation Process: UDSM 2000, Dar es Salaam 1993, S. C3, zit. n. David Wield, Coordination of Donors in African Universities, in: Higher Education Policy 10/1 (1997), S. 41-54, hier: S. 43.

19 Wield, Coordination, S. 43, 46. 
Feld durchsetzte das akademische Feld immer mehr. Dem war allerdings eine Periode der Politisierung vorangegangen.

\section{Der Campus und das politische Feld}

Die Debatten über Sozialismus - wie er in Tansania und anderen Ländern tatsächlich war, wie er in Zukunft sein sollte und wie er umgesetzt werden konnte, reichten weit über die Universität hinaus und fanden ebenso in Zeitungen, Bars, Hotels und Schulen statt. Die Universität war jedoch ein Epizentrum dieser Diskussionen, die wiederum nicht nur auf Seminare und formelle Anlässe beschränkt waren, sondern auch in der Mensa im Rahmen einer gelegentlichen baraza (ähnlich spontanen teach-ins) und beim coffeeshop geführt wurden. ${ }^{20}$ Die Präsenz der Befreiungsbewegungen und Besuche von Stokeley Carmichael, C. L. R. James oder Angela Davis machten Dar es Saalam darüberhinaus zu einem Brennpunkt radikaler intellektueller Kreise und eines transnationalen politischen Aktivismus. ${ }^{21}$ Neben der US-amerikanischen Bürgerrechtsbewegung diskutierte man „on the Hill“ lebhaft die chinesische Kulturrevolution, verdammte die USIntervention in Vietnam und zog Theorien von Kwame Nkrumah, Amílcar Cabral, Frantz Fanon und natürlich Marx und Lenin zur Deutung von Ereignissen heran; bald kamen die lateinamerikanischen Dependenztheorien hinzu und wurden vom Guyaner Walter Rodney mit How Europe Underdeveloped Africa auf den afrikanischen Kontinent ihrer einflussreichsten Anwendung zugeführt. ${ }^{22}$ Diese Debatten waren - da viele Lehr- und Forschungsbeauftragte gleichzeitig Beratungsaufgaben für die Regierung übernahmen oder sogar in politische Positionen überwechselten - auch über das akademische Feld hinaus praxisrelevant. Der dritte Entwicklungsplan mit seinen Industrialisierungsplänen etwa war stark von der Dependenztheorie geprägt. Jene tansanischen InterviewpartnerInnen, die diese Zeit als Lehrende und Studierende miterlebt hatten, erinnerten sich voller Nostalgie an die feurigen Debatten der damaligen Zeit.

Die Durchmischung und Kreuzung diversester Erfahrungen, Ansichten und Ideologien konnte durchaus absurde Blüten treiben, die ein beredtes Zeugnis für

20 Bourbonniere, Debating Socialism on the Hill, S. 6; Ivaska, Of Students, 104; Interview \#31, DDR-Universitätsexperte.

21 Ivaska, Movement Youth, S. 188.

22 So u. a. Issa Shivji in einem Interview: Marc Wuyts, Issa Shivji, in: Development and Change 39/6 (2008), S. 1079-1090. Siehe auch Immanuel R. Harisch, Facets of Walter Rodney's Pan-African Intellectual Activism during his Dar es Salaam Years, in: Stichproben. Wiener Zeitschrift für kritische Afrikastudien 20/38 (2020), S. 101-129. 
die Vielfalt des intellektuellen Lebens in Dar es Salaam abgeben. So bemühte sich der Historiker Rodney inständig, die Kompatibilität von Ujamaa und (nicht-doktrinärem) Marxismus-Leninismus herbeizuargumentieren. In seiner Vorlesung über die Oktoberrevolution stellte er dar, wie die Bedingungen in Russland zur Zeit der Oktoberrevolution den zeitgenössischen in Tansania ähnelten und Tansania, wie die Sowjetunion, graduell zu einem eigenen sozialistischen Weg finden würde. ${ }^{23}$ Nach Rodneys euphorischer Vorlesung hörten die Studierenden dann den Tschechen Zbiniak Maly, für den die russische Revolution - gerade im Kontext der Niederschlagung des Prager Frühlings - ein „kolossales Desaster“ darstellte, das die Demokratie in seinem Heimatland zerstört hatte. ${ }^{24}$ Diese Konstellation - dass die, die ein kommunistisches Systems am eigenen Leib erlebt hatten, skeptisch waren, während jene, die vom Realsozialismus fasziniert waren, ihn nur aus der Ferne oder bei kurzfristigen Besuchen erlebt hatten - war nicht selten. Auch andere DozentInnen aus Osteuropa äußerten sich, zumindest unter vier Augen, skeptisch über sozialistische Transformationspolitiken. Der westdeutsche Politikwissenschaftler Ansprenger erinnert sich an die Äußerung eines polnischen Kollegen: „Ich habe jetzt Kollektivierung der Bauern drei Mal erlebt in Russland, in Polen nach 1945, in Ghana unter Nkrumah; ich sehe nicht ein, warum es hier in Tanzania besser laufen soll...“.25

Somit ist es auch wenig verwunderlich, wenn DAAD-Generalsekretär Hubertus Scheibe berichtete, dass er die Sorgen über die Präsenz von WissenschaftlerInnen aus Osteuropa - „die keineswegs alle, wie die Amerikaner behaupten, Kommunisten“ waren, wie er feststellte - nicht teilte. ${ }^{26}$ Nicht nur in Bezug auf Ideen und Personen war die Universität ein global vernetztes Drehkreuz, auch die materiellen Quellen wurden bewusst diversifiziert - nicht zuletzt, weil Großbritannien nach dem Abbruch der diplomatischen Beziehungen 1965 alle Leistungen

23 Davon ist jedenfalls auszugehen, zieht man folgenden Text heran: Walter Rodney, Tanzanian Ujamaa and Scientific Socialism, in: The African Review: A Journal of African Politics Development and International Affairs 1/4 (1971), S. 61-76. Detailliert zu Rodney in Dar es Salaam siehe auch Immanuel Harisch, Walter Rodney's Dar es Salaam Years, 1966-1974: How Europe Underdeveloped Africa, Tanzania’s Ujamaa, and Student Radicalism at „the Hill“', Masterarbeit, Wien 2017.

24 So die Erinnerung eines britischen Kollegen von Maly: John McCracken, Terry Ranger: A Personal Appreciation, in: Journal of Southern African Studies 23/2 (1997), S. 175-185, hier: S. 179; Übersetzung EB.

25 Ansprenger, Politische Geschichte Afrikas, S. 115-116.

26 BArch Koblenz, B 212/30032, DAAD-Generalsekretär Scheibe, Reisebericht, Dar es Salaam, 3.6.9.1967, S. 2. 
zeitweilig eingefroren hatte. ${ }^{27}$ Scheibe vermerkte nach einem Aufenthalt im September 1967, die „ganze Welt“ sei an der Finanzierung der Universität beteiligt. ${ }^{28}$ Neben den ostafrikanischen Regierungen und der East African Community trugen Großbritannien und US-amerikanische Stiftungen einen Großteil der laufenden Kosten. Die BRD unterstützte den Bau der Aula, die USA lieferten Bücher für die von China erbaute Bibliothek, die Ford Foundation und die Rockefeller Foundation übernahmen die Gehälter zahlreicher westlicher DozentInnen und Stipendien für tansanische NachwuchsakademikerInnen.

Die westliche Herkunft von einem Großteil des Personals bot immer wieder Anlass für Kritik von links. So demonstrierte die marxistisch orientierte Studierendenvereinigung United African Students Revolutionary Front (USARF) ${ }^{29} 1967$ gegen die „imperialistische Infiltration“ durch DozentInnen aus westlichen Ländern und besetzte 1969 die Rechtsfakultät mit der Forderung, die dort tätigen USProfessoren abzusetzen und die Fakultät sofort mit Personal aus sozialistischen Ländern zu besetzen und schnellstmöglich zu „ostafrikanisieren“. ${ }^{30}$ Der von nationalistischen und radikal linken Kreisen immer wieder ins Feld geführte Vorwurf, dass es sich bei westlichem Lehrpersonal um „trojanische Pferde“ handele, betraf nicht nur die Lehrinhalte: Mehrere US-amerikanische Lehrkräfte entpuppten sich tatsächlich als CIA-Spione. ${ }^{31}$ Die linke Kritik vom Campus spielte der politischen Elite dabei manchmal in die Hände, stellte die Hegemonie von Ujamaa aber auch. 1969 etwa hieß es im Editorial der ersten Ausgabe der studentischen Zeitschrift Cheche, der Neokolonialismus habe sich unter dem Deckmantel verschiedener „Sozialismen“ eingeschlichen, die sich als „afrikanisch“, „arabisch“ und „pragmatisch“ ausgaben. Die AutorInnen maßen intellektuellen Diskussionen höchste Bedeutung bei und betonten, dass das „Gravitationszentrum des Befreiungskampfes“ an der „ideologischen Front“ liege. ${ }^{32}$ USARF-Mitglieder hielten sich aber nicht nur mit Debatten auf. Sie besuchten Ujamaa-Dörfer, arbeiteten bei self-reliance-Aktivitäten mit und sammelten Spenden für Befrei-

27 Bertram B.B. Mapunda, Infrastructure, in: Isaria N. Kimambo u.a., Hg., In Search of Relevance: A History of the University of Dar es Salaam, Dar es Salaam 2008, 60-82, hier: 76-78. 28 BArch Koblenz, B 212/30032, DAAD-Generalsekretär Scheibe, Reisebericht, Dar es Salaam, 3.6.9.1967, S. 1.

29 Diese ging selbst aus dem Socialist Club hervor, an dem Studierende aus verschiedenen afrikanischen Ländern - darunter Uganda, Äthiopien, Malawi, Kenia, Tansania - sowie Walter Rodney teilnahmen. Shivji, Intellectuals at the Hill, S. 133.

30 Aminzade, Race, S. 187; Appendix E in Karim F. Hirji, Cheche: Reminiscences of a Radical Magazine 2010.

31 Einer der CIA-Agenten war Steve Lucas. Siehe auch John S. Saul, Revolutionary Traveller. Freeze-Frames from a Life, Winnipeg 2009, S. 414; Saul, Planning for Socialism in Tanzania, S. 11. 32 Editorial, in: Cheche 1 (1969), S. 1, Übersetzung E. B. 
ungsbewegungen. ${ }^{33} 1970$ wurde die USARF durch die Universitätsleitung mit der Begründung verboten, dass der Name Cheche („Funke“, in doppelter Anlehnung an Nkrumahs Spark und Lenins Iskra) ebenso wie die von der Organisation vertretene Ideologie den „russischen Sozialismus“ propagiere und damit im tansanischen Ujamaa nicht duldbar sei. Das Verbot zeigt, dass Studierende und ihre Kritik von den Herrschenden als ernst zu nehmende Bedrohung wahrgenommen wurden. ${ }^{34}$ Spätere Reinkarnationen linker Publikationen und Organisationen waren enger mit der Jugendorganisation der Partei verknüpft, deren Mitglieder am Campus sich allerdings ebenfalls von der Parteilinie in Richtung marxistischer Klassenanalyse entfernten.

\section{Sozialismen im Universitätsalltag}

Die Erinnerungsliteratur vermittelt bisweilen den Eindruck, der gesamte Campus habe konstant unter politischer Hochspannung gestanden. Von den meisten BRDund DDR-InterviewpartnerInnen wurden die Studierenden jedoch im Gegensatz dazu als äußerst diszipliniert, fleißig und Autorität anerkennend charakterisiert; bisweilen auch, was ähnliche Verhaltensweisen nur negativ wendet, als karriereund prüfungsfixiert, obrigkeitshörig und unselbstständig. Gerade die vermeintliche Unselbstständigkeit kann aber auch als Strategie gelesen werden, die eigene Laufbahn nicht zu gefährden. Im Kontrast zu diesen Schilderungen über disziplinierte (bzw. obrigkeitshörige) Studierende stehen Erzählungen (teils in denselben Interviews) über Proteste, Streiks und Demonstrationen, mit denen Studierende eine Verbesserung ihrer Situation forderten, aber auch die Universitätsleitung oder die Korruption der politischen Elite kritisierten: „Unruhen gab’s immer“, wie ein ehemaliger DDR-Auslandskader sich erinnerte. ${ }^{35}$

Karim Hirji, damals selbst unter den AktivistInnen, schätzt retrospektiv mit Blick auf das Jahr 1970, dass nur 5 Prozent der damals etwa 1.500 Studierenden als radikal bezeichnet werden konnten; 10 Prozent sah er als politisch aktiv im begrenzten ideologischen wie praktischen Rahmen der TANU und TYL; die verbleibenden 85 Prozent verteilten sich auf eine kleine Gruppe von ,die-hard reactionaries“, die den Sozialismus verabscheuten, und die überwältigende Mehrheit, die weder links noch rechts einzuordnen gewesen sei und sich so weit

33 Karim F. Hirji, Not So Silent A Spark, in: Karim F. Hirji, Hg., Cheche: Reminiscences of a Radical Magazine, Dar es Salaam 2010, S. 53-63, hier: S. 60.

34 Hirji, Not So Silent A Spark.

35 Interview \#99, DDR-Universitätsexperte. 
wie möglich aus politischen Fragen herausgehalten habe. ${ }^{36}$ Während der relativ kleine Teil marxistischer Lehrkräfte und Studierender einen unversöhnlichen Gegensatz zwischen individuellem Karrieredenken und der sozialistischen Entwicklung Tansanias sah, betrachtete der Großteil der Studierenden eigenes und kollektives Vorankommen als zwei Seiten derselben Medaille. Das eigene Wissen würde allen zugutekommen, aber natürlich auch eine gewisse Eliteposition und damit einen Abstand zum Gros der Bevölkerung herstellen. Diese elitäre Ausrichtung war, so der an der Universität unterrichtende Politikwissenschaftler Manfred Bienefeld 1972, angesichts einer Reihe von Faktoren nicht auszumerzen. Das Internatsleben war sozial exklusiv, Bildungswesen und manpower planning hochselektiv und Bildung blieb der Königsweg zu mehr Einkommen, Status und Macht. ${ }^{37}$ Der Alltag bestand also keineswegs nur in politischer Diskussion und Protest und spielte sich wohl häufig so ab, wie in Abbildung 7.1 idealisiert dargestellt: eine konzentrierte und ergebnisorientierte Lernatmosphäre, in der die internationalen Lehrkräfte sich in den Dienst der Universität als Ausbildungsinstitution stellten.

Abbildung 7.2, ebenso einem Universitätsbericht entnommen, ist eine geradezu paradigmatische Darstellung der Besonderheiten, die linke westliche Intellektuelle nach Tansania zogen. Die Fotografie zeigt Universitätspersonal, wie es beim Bau einer Kindertagesstätte im Namen von self-reliance selbst Hand anlegt. Angeleitet vom Rektor Msekwa persönlich gaben sich die Intellektuellen - um Ali Mazruis satirische, aber treffende Kritik zu paraphrasieren - ihren romantischen Vorstellungen von körperlicher Arbeit hin und nahmen Schubkarre und Schaufel mit derselben Einstellung in die Hand, mit der Marie Antoinette in den prächtigen Parkanlagen bei Paris die Bäuerin mimte. ${ }^{38}$ Die ungelenk wirkende Person mit Sonnenbrille und strahlend weißer Kleidung in der linken Bildhälfte belegt in unfreiwillig komischer Manier die rein symbolhafte Natur dieser self-relianceAktion, in der es nicht um Effizienz, sondern um eine sichtbare Beteiligung der intellektuellen Elite an manueller Arbeit ging. Derartige Akte sollten Anerkennung für die breite Bevölkerung und die von ihr verrichtete, meist körperlich anstrengende Arbeit vermitteln. Die Originalbildunterschrift lautet „University staff led by the Vice Chancellor help to build the U.W.T. nursery school“, wobei „led by the Vice Chancellor“ auf die tansanisch-nationale Souveränität verweist, während die lakonische Referenz auf die anderen Abgebildeten - „university staff“ - ihre Herkunft unmarkiert lässt, aber im Zusammenspiel mit dem Bild

36 Karim F. Hirji, Tribulations of an Independent Magazine, in: Karim F. Hirji, Hg., Cheche: Reminiscences of a Radical Magazine 2010, S. 35-51, hier: S. 42.

37 Bienefeld, Planning People, S. 178-180.

38 Mazrui, Tanzaphilia, S. 24. 


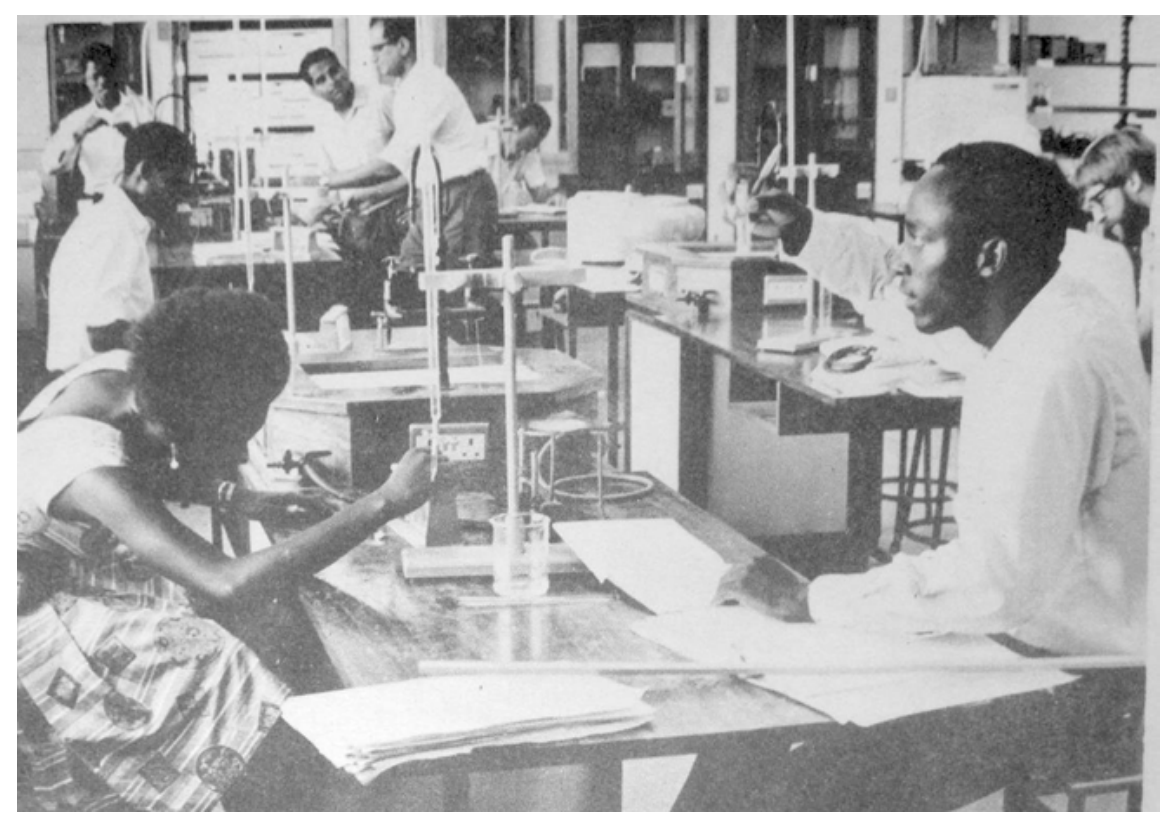

Abbildung 7.1: Chemiepraktikum für SekundarschullehrerInnen (Quelle: UDSM, A Report on the Activities of the University of Dar es Salaam for the Year 1971-72, Dar es Salaam 1973, 76)

offensichtlich nahelegt, dass hier expatriates den tansanischen Prinzipien und Strategien Folge leisten. Auch Bildunterschriften anderer Fotografien in den Universitätsberichten gehen nicht darauf ein, dass Lehrkräfte mit nicht-tansanischer oder zumindest nicht-afrikanischer Herkunft abgebildet sind. Derartige Bilder spiegelten in erster Linie die Perspektive der nationalen Elite: Expatriates hatten ErfüllungsgehilfInnen für das self-reliance-Vorhaben zu sein, die Studierenden sollten diszipliniert lernen und sich ebenso wie das Lehrpersonal in den Dienst des Staates und der nationalen Entwicklungsaspirationen stellen.

Die erste wichtige Etappe in der Politisierung der Universität war die Konferenz mit dem vielsagenden Titel The Role of University of UDSM in Socialist Tanzania im März 1967, also zwei Monate nach der Deklaration von Arusha. ${ }^{39}$ In seiner Eröffnungsrede hob College-Leiter Chagula hervor, dass die Konferenz ohne die Proteste der Studierenden gegen den National Service im Vorjahr wohl nicht einberufen worden wäre. Die Diskussionen sollten Möglichkeiten aufzeigen, wie die Universität sozial und politisch vollständig in die Struktur (fabric) der

39 Siehe hierzu auch Bourbonniere, Debating Socialism on the Hill, S. 67-77, 97-101. 


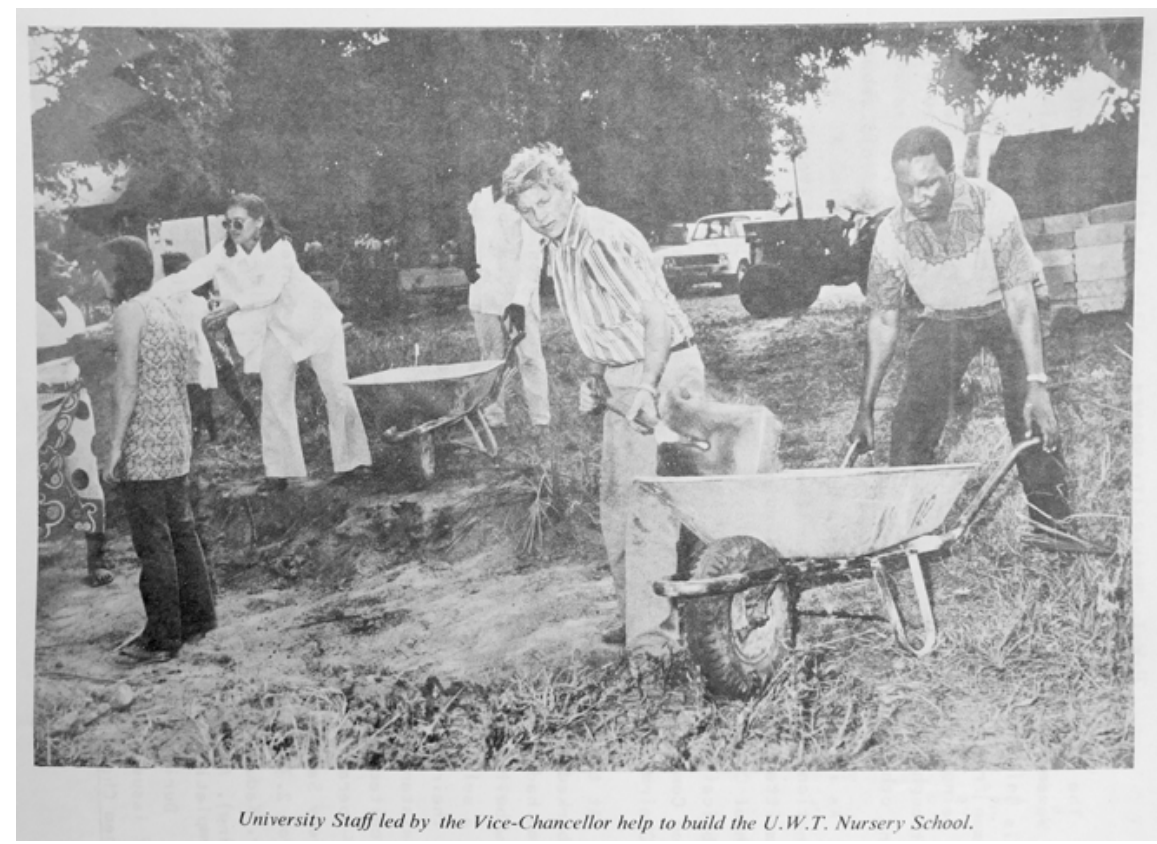

Abbildung 7.2: Self-reliance als akademische Praxis: Universitätspersonal unter der Leitung des Dekans Pius Msekwa beim Bau der U.W.T. Nursery School (Quelle: UDSM, A Report on the Activities of the University of Dar es Salaam for the Year 1974-75, Dar es Salaam 1976, 130)

Nation eingebunden werden könne. ${ }^{40}$ „Politische Bildung“ mit einem Fokus auf tansanischen Sozialismus sollte für alle (tansanischen) Studierenden Pflicht werden und auch praktisches Engagement - z.B. in den Massenorganisationen und self-reliance-Aktivitäten - umfassen. In den Sozialwissenschaften seien vom Sozialismus überzeugte oder aus sozialistischen Ländern kommende Lehrkräfte zu bevorzugen..$^{41}$ Bis 1967 hatte die Universität ihr Personal vor allem über nichttansanische Institutionen wie das IntraUniversity Council und den Overseas

40 CCMA, 570, The Role of the University of College Dar es Salaam in Socialist Tanzania, Address by Principal Dr.W. K. Chagula on the occasion of the opening session of „A Conference on the Role of the University College, Dar es Salaam in a Socialist Tanzania“, 11.3.1967, Dar es Salaam.

41 CCMA, 570, The Role of the University of College Dar es Salaam in Socialist Tanzania, Draft Recommendations of the Conference on the Role of the University College, Dar es Salaam in a Socialist Tanzania, 12.3.1967, Dar es Salaam. Dabei bestand über den ersten Punkt weitgehend Einigkeit, während die Bevorzugung von sozialistischen Lehrkräften in den Berichten der jeweiligen Komitees nicht explizit erwähnt wird. Die Komiteeberichte sind im selben Konvolut enthalten. 
Educational Service rekrutiert und politischen Überzeugungen keine Bedeutung beigemessen.

\section{Prekäre Positionen}

Ab 1967 wurde das Ideal der Blockfreiheit auch am Campus wirksam. Um ein Gegengewicht zur massiven westlichen Präsenz zu schaffen, wurden gezielt die ersten Lehrkräfte aus kommunistischen Staaten rekrutiert, anfangs in erster Linie aus der Tschechoslowakei, Ungarn und Polen, also Ländern, die als kritisch gegenüber der sowjetischen Linie galten. ${ }^{42} 1973$ entsandte die Universität Dar es Salaam zusätzlich zur üblichen Ausschreibung offener Stellen in nationalen und internationalen Zeitungen erstmals Rekrutierungsdelegationen, die nicht nur in Großbritannien und Indien, sondern auch in sieben osteuropäischen Ländern Halt machten..$^{43}$ Die erste Station hier war die DDR. Delegationsleiter Ibrahim Kaduma, Leiter des Institute of Development Studies, bemängelte, „dass in Anbetracht des ,gemeinsamen sozialistischen Weges unserer Länder` die DDR und die anderen sozialistischen Länder [...] noch nicht im ausreichenden Maße Hilfe leisteten“. ${ }^{44}$ Trotz des expliziten Rufes nach sozialistischen ExpertInnen, auch vonseiten Nyereres, stieß die DDR mit ihren konkreten Angeboten auf wenig Zuspruch. Die Universitätsverwaltung bremste den Zuwachs aus dem sozialistischen Lager aus, womöglich aus einer pro-westlichen oder anti-sowjetischen Haltung heraus, teils aber sicher auch aus pragmatischer Beachtung der Interessen westlicher Geber. Inwiefern zum Beispiel Vertreter der BRD in Gesprächen direkten Druck ausübten oder es sich um eher indirekten Einfluss und vorauseilenden Gehorsam handelte, der die Universitätsverwaltung dazu brachte, der DDR den Zugang zu erschweren, ist anhand der eingesehenen Quellen nicht zu klären. Dokumentiert sind jedoch mannigfaltige Verzögerungsstrategien. Dazu gehörten Rückmeldungen, dass die Qualifikation der vorgeschlagenen Kader nicht genüge oder die Bewerbungsunterlagen mehrerer DDR-Lehrkräfte verloren gegangen seien; in einem Fall wurden zwei BewerberInnen zu einem Interview in die tan-

42 Tamás Gerőcs, To Be Bravely Critical of Reality: An Interview with Tamás Szentes, in: Review of African Political Economy, 8.11.2018. roape.net/2018/11/08/to-be-bravely-critical-to-reality-aninterview-with-tamas-szentes/ (Zugriff: 23.6.2020).

43 UDSM, A Report on the Activities of the University of Dar es Salaam for the Year 1973-74, Dar es Salaam 1975, S. 9.

44 UAL, DIB 144, Wienhold, Bericht über den Besuch einer Delegation der Universität Dar es Salaam, 5.9.1974, S. 2. 
sanische Botschaft in Bonn gebeten, was für die DDR natürlich vollkommen inakzeptabel war. ${ }^{45}$

Universitätsrektor Pius Msekwa - 1970 vom TANU-Hauptquartier zum Hill versetzt, um dort die Nationalisierung und Ausrichtung der Universität entsprechend Parteivorgaben voranzutreiben - bedauerte diese „Versehen“, machte der DDR aber keinerlei Zugeständnisse. Parallel war er damit beschäftigt, mit BRDVertretern die Eröffnungsfeier der Ingenieurwissenschaftlichen Fakultät vorzubereiten und intensiv um die persönliche Teilnahme vom Minister für wirtschaftliche Zusammenarbeit Eppler zu werben. ${ }^{46}$ Hinzu kam die neue Qualifizierungspolitik, die den Einfluss der sozialistischen Staaten an der Universität weiter verringern sollte: „Es werden grundsätzlich keine Genehmigungen zur weiteren Qualifizierung von Angehörigen der Universität in den sozialistischen Staaten mehr erteilt“, berichteten zwei ostdeutsche Dozenten: „Wer in den sozialistischen Staaten studiert hat, muß in der Regel erst im Lande arbeiten oder wird zum weiteren Studium in westliche imperialistische Staaten delegiert. “47 Die meisten tansanischen AbsolventInnen aus sozialistischen Ländern in Übersee wurden tatsächlich nicht an der Universität tätig. Diese Situation sollte sich bis Ende der 1980er-Jahre nicht ändern. 1988/89 hatte über die Hälfte des akademischen Personals (53\% von 892 Personen) mindestens einen Abschluss aus einem westlichen Land; 13\% hatten sogar ausschließlich an westlichen Universitäten studiert. Gerade einmal 6\% hatten Abschlüsse aus sozialistischen Staaten in Übersee. Die 16 Personen (2\%), die sowohl östlich und westlich des Eisernen Vorhangs akademische Abschlüsse erreicht hatten, waren allesamt für ihre höheren Abschlüsse gen Westen gezogen - was die These einer „Westorientierung“ der Migrations- und Bildungswege (siehe Kapitel 4) erhärtet. Das weitere akademische Personal, darunter vor allem Nachwuchskräfte, hatte ausschließlich in Ostafrika studiert (39\%, 352 Personen). In der Universitätsleitung (Senior Officers) war weder 1989 noch 1974 eine einzige Person mit einem Abschluss aus einem RGW-Land vertreten. ${ }^{48}$

45 BArch Berlin, DR 3/2. Schicht/B 1383a, Aktennotiz über Gespräch mit Msekwa, Dar es Salaam, 25.2.1974; ebd., Aktennotiz über Gespräch mit Msekwa, Dar es Salaam, 17.12.1973; ebd., Oelschlägel (DDR-Botschaft) an Lojewski (MHF), Dar es Salaam, 28.11.1973.

46 BArch Koblenz, B 213/33043, Bildungshilfe Technische Fakultät Heft 6, Wagner (FoE UDSM) an BRD-Botschaft, Dar es Salaam, 4.6.1974.

47 BArch Berlin, DR 3/2. Schicht/ B 1449/1b, DDR-Universitäts-Experten R. A. und B. an Lojewski (MHF), Dar es Salaam, 29.1.1974.

48 Diese Ausführungen basieren auf eigenen Berechnungen auf der Grundlage der Informationen im UDSM Calendar 1988/89. Der Vereinfachung halber wurden hier z. B. auch Universitäten in Indien den kapitalistischen Ländern zugeordnet; sozialistische Länder bezeichnet nur die staatssozialistischen Länder des RGW, China etc. 
DDR-Botschafter Helmut Matthes reagierte Anfang 1974 offensiv auf die Umgehungsstrategien der Universitätsverwaltung. Da er keine Möglichkeit mehr sah, bei der „reaktionäre[n] Führung“ der Universität Änderungen zu bewirken, nahm er den Umweg über die Diplomatie. Das war riskant, da er damit die Beziehung zur Universitätsleitung empfindlich verschlechtern konnte. Matthes intervenierte an höchster Stelle, nämlich bei Nyerere persönlich, und plötzlich wurden die DDR-Angebote innerhalb weniger Tage bestätigt. ${ }^{49}$ Die DDR bot fast ausschließlich Kader für den Bereich der Sozial- und Geisteswissenschaften an, da im technischen Bereich die „Beherrschung der BRD“ als unantastbar erachtet wurde und für die mehrmals erbetene Entsendung von Lehrkräften im Bereich der Medizin die Kapazitäten der DDR genauso begrenzt waren wie Tansanias Bedeutung für Ost-Berlin. ${ }^{50}$ Da auch in der Politikwissenschaft und der Soziologie gerade erstere war sehr westlich orientiert - bis 1990 keine DDR-Lehrkräfte untergebracht werden konnten, waren die wichtigsten Nischen die Entwicklungsforschung sowie die Wirtschafts- und Rechtswissenschaften, also Bereiche, wo auch tansanisches Lehrpersonal präsent war, das Sympathien für den Realsozialismus und eine Vorliebe für marxistische Theorieangebote hegte. ${ }^{51}$

Angesichts der behäbigen Planungsmaschinerie und des Mangels an geeigneten Auslandskadern war es für die DDR entscheidend, rechtzeitig - also viele Monate vor der offiziellen Ausschreibung - über freie und frei werdende Stellen informiert zu werden. Hier machten sich Netzwerke bezahlt, in die die DDR zuvor investiert hatte. Hinweise lieferten nicht nur Diplomaten anderer RGW-Länder, ${ }^{52}$ sondern auch tansanische Absolventen ostdeutscher Universitäten. Kassim Guruli war in dieser Hinsicht der wichtigste Alumnus. Sein Weg hatte ihn noch vor der Unabhängigkeit von Dar es Salaam über Liberia und Guinea in die DDR geführt, wo er in Leipzig ein Grund- und Doktoratsstudium in Ökonomie absolviert und mehrere Jahre als Generalsekretär der SED-freundlichen Union afrikanischer Studenten in der DDR fungiert hatte. Seine Beziehungen zur DDR und seine Sympathie für den Marxismus-Leninismus hatten sich während dieser Jahre gefestigt. Unter dem renommierten ungarischen Ökonomen Tamás Szentes als Leiter des Wirtschaftsinstituts erhielt Guruli eine Stelle und wurde 1973 selbst Leiter dieses Instituts. Schon Szentes hatte Einladungen an die DDR ausgesprochen, und

49 BArch Berlin, DR 3/2. Schicht/B 1383a, Matthes (DDR-Botschafter) an Förster (MHF), Dar es Salaam, 28.11.1974.

50 Ebd., Matthes (DDR-Botschafter) an Förster (MHF), Dar es Salaam, 20.4.1973.

51 BArch Berlin, DR 3/2. Schicht/B 1514, Klinkert (DDR-Botschafter) an Heidorn (MHF), Dar es Salaam, 10.12.1985.

52 PAAA, C 773/74, Zeise (HPA), Aktennotiz über ein Gespräch mit dem Handelsrat der VR Bulgarien, Dar es Salaam, 11.5.1972, Fol. 18. 
Guruli lancierte die freundlichen Beziehungen weiter, so etwa 1974, als er die Botschaft über anstehende Ausschreibungen informierte. ${ }^{53}$

Die Position Gurulis war allerdings, wie die anderer marxistischer Lehrkräfte mit offenen Sympathien für die osteuropäischen Länder oder Antipathien für Ujamaa, prekär. Gurulis Versuche, weitere Kräfte auf einer ähnlichen politischen Linie nach Dar es Salaam zu lotsen, sind damit auch zu verstehen als eine Strategie, die eigene Position zu sichern und z.B. Mehrheiten in Entscheidungsgremien durchsetzen zu können. Gegen Gegenwind von ganz oben waren diese Absicherungsmaßnahmen aber ungenügend. Guruli musste später überraschend die Leitung des Institute of Development Studies abgeben, die er 1973 ebenfalls kurz übernommen hatte. Obwohl er zeitweise den Vorsitz der TANU-Zweigstelle an der Universität innehatte, wurde er 1977 auf eine unwirksame Beamtenposition versetzt und verstarb wenige Jahre später. ${ }^{54}$ Diese Versetzung war Teil einer offensichtlichen politischen Intervention in die akademische Freiheit.

Ebenso aufs Abstellgleis geschoben wurden sechs weitere Wissenschaftler, darunter mehrere mit Abschlüssen aus RGW-Ländern sowie der Dekan der Fakultät für Geistes- und Sozialwissenschaften Arnold Temu, der ebenfalls die DDR besucht hatte und offen die Rekrutierung von WissenschaftlerInnen aus kommunistischen Ländern mit der Begründung gefordert hatte, dass nur diese die richtigen Lehren vermitteln könnten. ${ }^{55}$ Der Marxist Temu hatte es sich mit der Universitätsleitung (und Nyerere) vor allem durch seine Parteinahme für protestierende StudentInnen verscherzt. Er verließ Tansania kurz nach seiner Demütigung für mehrere Jahrzehnte und setzte seine akademische Laufbahn im Exil fort. ${ }^{56}$

Auch ausländische Lehrkräfte, die die „wissenschaftliche Anwendung“ des Sozialismus gefordert oder anderweitig probiert hatten, Ujamaa weiter nach „links“ zu manövrieren, bekamen fallweise keine Vertragsverlängerung angeboten. ${ }^{57}$ Einige der verwaisten Lehrveranstaltungen gingen dann in die Verantwortung von DDR-DozentInnen über. Diese hüteten sich seit jeher, Ujamaa offen zu kritisieren; das Deutungsmonopol lag letztendlich beim tansanischen Staat, in dessen Diensten man stand. 1969 berichtete der damals einzige DDR-Kader an der

53 BArch Berlin, DR 3/2. Schicht/B 1383a, Oelschlägel (DDR-Botschaft) an Förster (MHF), Dar es Salaam, 4.9.1974.

54 Coulson, Tanzania, S. 274-275.

55 UAL, DIB 164, Epperlein, Bericht über die Betreuung von Dr. Temu vom University College Daressalam (Tanzania), o.D. [April 1970], o.O., Bl. 44-45.

56 Saul, Revolutionary Traveller, S. 55.

57 Coulson, Tanzania, S. 274-275; siehe auch Bourbonniere, Debating Socialism on the Hill, S. 8; Interview \#31, DDR-Universitätsexperte. 
Universität, ein Theaterwissenschaftler ohne jede Afrikaerfahrung, jegliche Frontalkritik an der Politik sei „[f]ür Expatriates selbstverständlich unmöglich“ und „für die wenigen Tansanier offensichtlich sehr prekär“. ${ }^{58}$ Die Unterstützung „progressiver Kollegen“ sei ebenfalls riskant, weil man sich dadurch die Feindschaft westlicher und konservativer tansanischer Führungskräfte zuziehen könne. ${ }^{59}$

Die DDR-Hoffnungen auf politische Wirksamkeit richteten sich folglich vor allem auf die Lehr- und Organisationstätigkeit und insbesondere die Entsendung von Lehrkräften an das Institute of Development Studies (IDS), das als ideologische Leitinstitution an der Universität gegründet wurde. Das IDS wurde ein Biotop für DDR-Auslandskader, wo sie eine große Zahl von HörerInnen erreichten. Alle Studierenden der Universität Dar es Salaam - gleich welches Fach sie studierten hatten hier historische Einführungen in die vorkoloniale und koloniale Geschichte, aber auch theoretische Kurse in Politischer Ökonomie und Marxistischer Philosophie in den ersten zwei Jahren ihres Bachelor-Studiums zu belegen. Mit seinem obligatorischen Charakter glich das IDS den ideologischen Pflichtfächern an osteuropäischen Universitäten, wenngleich die Kanonisierung des Stoffes keinesfalls derart dogmatisch war, sondern ein ganzes Spektrum marxistischer und postkolonialer Ansätze avant la lettre umfasste. ${ }^{60}$ Die Entstehungsgeschichte des IDS veranschaulicht die Aushandlungsprozesse über die Politisierung der Universität im Anschluss an die Deklaration von Arusha.

\section{Die Gründung des Institute of Development Studies}

Die Initiative für die Gründung eines interdisziplinären Kurses zu Entwicklungsfragen ging auf eine als Group of Nine bekannt gewordene Gruppe von Dozenten zurück. Sie forderten 1967 im Rahmen der bereits erwähnten Tagung The Role of University of UDSM in Socialist Tanzania eine Neuorientierung der Sozialwissenschaften von separaten Disziplinen hin zur praxisorientierten Interdisziplinarität, also einen gemeinsamen Studiengang mit thematischen statt disziplinären Spezialisierungen. Die radikale Gruppe um John Saul, Lionel Cliffe, Sol Piccioto, Giovanni Arrighi, Grant Kamenju, Walter Rodney und anderen bestand aus

58 BArch Berlin, DR 3/2. Schicht/B 1449/1b, F., Bericht aufgrund meiner Tätigkeit in Tanzania / University College Dar es Salaam, o.D. [ca. 1969], S. 12.

59 Ebd., S. 16.

60 Siehe zu postkolonialen Perspektiven avant la lettre: Clemens Pfeffer, Missionshistoriographie post 1968. Postkoloniale Perspektiven avant la lettre, in: Sebastian Pittl, Hg., Theologie und Postkolonialismus. Ansätze - Herausforderungen - Perspektiven. Regensburg 2018, S. 191-218. 
marxistischen Lehrkräften, die sich dem Ziel verschrieben, der Universität einen gleichermaßen sozialistischen wie auch an tansanische Verhältnisse angepassten Charakter zu verleihen. ${ }^{61}$ Kamenju, ein Kenianer, war das einzige ostafrikanische Mitglied dieser Gruppe. Diese Spannung zwischen einem zumindest teilweise national und tansanisch gedachten Projekt und „ausländischer“ Initiative sollte dem Vorhaben später zum Verhängnis werden. Vorerst konnte die Gruppe mithilfe weiterer AnhängerInnen ihre Anträge und Lehrplanentwürfe mit knappen Mehrheiten durch die universitären Entscheidungsgremien manövrieren. Wie die radikalen Studierenden schienen auch die marxistischen Lehrkräfte ihre Ideen nicht nur mittels Überzeugungskraft, sondern teilweise durch einen aggressiven, einschüchternden Argumentationsstil durchgesetzt zu haben. ${ }^{62}$

Gegenkräfte - die darauf abzielten, Curricula und disziplinäre Trennungen beizubehalten und damit auch ihre eigenen Einflusssphären absichern wollten verwässerten die Vorschläge allerdings und stutzten die Reformen bis 1972 auf ein entradikalisiertes Minimum zurück. Insbesondere die erste Generation tansanischer Rückkehrer aus Übersee, vor allem aus den USA, stellte sich dieser radikalen Umwälzung entschieden entgegen. Sie übernahmen Leitungsfunktionen an Instituten sowie Fakultäten, stellten immer größere Anteile im Senat und hatten wenig Interesse daran, ihre einflussreichen Posten und disziplinären Reiche samt dem dazugehörigen institutionellen Kapital aufzugeben. Nationalisierungsdiskurse, seit Ende der 1960er an Bedeutung gewinnend, spielten ihnen zusätzlich in die Hände, sodass die Reformversuche als ausländische Intervention und Bedrohung tansanischer Autorität gebrandmarkt werden konnten. ${ }^{63}$ Bei den Initiatoren, die gehofft hatten, in Tansania eine völlig neue akademische Kultur zu schaffen, die an westlichen Universitäten nicht realisierbar war, machte sich Ernüchterung breit: „Many of the expatriates felt betrayed, and either departed quietly or found that their contracts were not renewed. "64 Dafür war keinesfalls immer nur die Universität verantwortlich, John Saul etwa bekam den Vertrag vonseiten seiner kanadischen Entsendeorganisation gekündigt, wurde aber kurz

61 Saul, Revolutionary Traveller, S. 29-33. Kurzbiographien der Beteiligten finden sich bei Ivaska, Cultured States, S. 148-149.

62 So erinnerte sich Eric Helleiner, der einer eher „pragmatischen“ Sozialismus bevorzugte. Siehe seine vielsagenden Zitate und ähnliche Einschätzungen in einer Studentenpublikation in Bourbonniere, Debating Socialism on the Hill, S. 98, 130.

63 Vgl. Saul, Revolutionary Traveller, S. 59: „Amidst growing tension, our efforts were, at one extremely tempestuous faculty meeting, at last rejected (a meeting in which, for the very first time in seven years in Tanzania, I heard a very opportunist and highly rhetorical brand of black-nationalist racism directed against some of us rather than any substantive argument).“

64 Coulson, Tanzania, S. 272-273. 
darauf von der Universität mit einem lokalen Vertrag wieder eingestellt. ${ }^{65}$ Die Existenzberechtigung der Universität schien jedenfalls, so Coulson, doch nicht darin zu liegen, zum Epizentrum sozialer Transformationen zu werden: „Its economic function was, and continued to be, to train a privileged class of technicians, managers, and administrators. Those who argued for socialism would be tolerated only so long as they did not expose the weaknesses of the state.“66

Der Gruppe gelang es jedoch, einen holistischen, interdisziplinären Kurs mit historisch-marxistischer Ausrichtung zu etablieren. ${ }^{67}$ Dieser Kurs sollte den Widerspruch zwischen der Rolle der Universität als Produktionssttätte von high level manpower und dem egalitaristischen Projekt von Ujamaa auflösen und alle Studierenden mit einer gemeinsamen, kapitalismuskritischen Wissensbasis um die geschichtlichen und globalen Hintergründe der tansanischen Abhängigkeit ausstatten. 1971 erfolgte die Gründung des Department of Development Studies, das 1973 zum eigenständigen Institut, dem Institute of Development Studies (IDS) umfunktioniert wurde. Die proklamierte Hauptaufgabe des Instituts - „to instil into the students of this University [...] the commitment to the Ideals [sic] of the Party by giving them proper tools of analysis“68 - verwies ganz klar auf die Führungsrolle der Partei. Sämtliche tansanischen InterviewpartnerInnen stimmten mit dieser Definition mehr oder weniger überein und sahen das IDS als „Ujamaa-Zentrum“ der Universität. Vermeintliche Versuche von Westdeutschen, auf die Lehrplangestaltung Einfluss zu nehmen, schienen entweder wenig Wirkung gehabt oder sich der bestehenden sozialistischen Ausrichtung eingepasst zu haben, wie ein DDR-Bericht 1972 vermerkte. ${ }^{69}$ Schon Mitte der 1970er-Jahre wirkte sich die ökonomische Krise auch am IDS negativ aus. Ressourcen-, Literatur- und Personalmangel führten dazu, dass nur wenige Forschungen ${ }^{70}$ durchgeführt werden konnten und - aufgrund des verpflichtenden Charakters für alle Studierenden - das Betreuungsverhältnis in den Lehrveranstaltungen mit 1:100 das

65 Saul, Revolutionary Traveller, S. 43.

66 Coulson, Tanzania, S. 276.

67 Der britische Marxist Lionel Cliffe übernahm die Leitung dieses Programms erst, nachdem mehrere ostafrikanische Lehrkräfte abgelehnt hatten. Bourbonniere, Debating Socialism the Hill, S. 103; Shivji, Intellectuals at the Hill, S. 133-134.

68 CCMA, THQ/C/E.20/7, I.D.S. Board Paper No. B/14/1975, Statement on Institute of Development Studies 1976/77 Estimates; vgl. Interview mit Pius Msekwa, Dar es Salaam, 23.11.2014.

69 UAL, DIB 164, Angaben zum Hochschulwesen in Tansania, Leipzig, 11.12.1972, Bl. 89.

70 Ein Teil der knappen Forschungsgelder kam allerdings ironischerweise einem (moderat linken) GTZ-Experten der Ingenieursfakultät zugute, der mit britischen und indischen Kollegen eine Studie über die tansanische Industrie durchführte - vollständig finanziert vom IDS. (Interview \#122, GTZ-Experte) 
schlechteste an der ganzen Universität war. ${ }^{71}$ Dem Institut, das die Rolle einer ideologischen Leitinstitution einnehmen sollte, fehlte die materielle Basis: Westliche Geber zeigten kein Interesse und gleichzeitig war die gewollte Symbolkraft des Instituts als Herzstück der ideologischen Eigenständigkeit und Abhängigkeitsüberwindung kaum geeignet Gebern hier eine Dominanz einzuräumen, wie sie etwa die BRD an der Ingenieurwissenschaftlichen Fakultät ausübte. Offene Stellen sollten zudem soweit irgend möglich mit tansanischen Lehrkräften besetzt werden. ${ }^{72}$ Da diese allerdings, sofern sie bereits höhere Qualifikationen hatten, häufig den Weg nach Westeuropa und in die USA suchten, blieben expatriates- unter ihnen auch DDR-Entsandte - ein wichtiger Einfluss am IDS.

\subsection{Politisierungsversuche: DDR-DozentInnen an der Universität Dar es Salaam}

Der Handlungsspielraum und Einfluss von DDR-Lehrkräften an der Universität Dar es Salaam war von verschiedenen Variablen abhängig. Hier muss einerseits differenziert werden zwischen verschiedenen Fakultäten und Instituten, andererseits verschoben sich auch die Kräfteverhältnisse zwischen Universität, politischen Autoritäten und Gebern. Obwohl politische Auseinandersetzungen die größte Rolle in DDR-Berichten spielen, werden auch die Auswirkungen der Wirtschaftskrise und der persönlichen Überlebensstrategien bei den tansanischen KollegInnen offensichtlich.

\section{Das IDS als geschützter ideologischer Raum}

Die günstigste Situation für die Tätigkeit im Sinne der DDR-Direktiven herrschte am IDS, wo die „Propagierung“ (oder zumindest Behandlung) des MarxismusLeninismus im Lehrprogramm verankert war und somit eine stabile Legitimationsplattform für die ungestörte und uneingeschränkte Lehre der entsprechenden Theorien bestand. ${ }^{73}$ Die DDR-Professorin Hannelore Petsch konnte sich sogar als Koordinatorin des M.A.-Kurses etablieren und betreute wie spätere DDR-Ent-

71 CCMA, THQ/C/E.20/7, I.D.S. Board Paper No. B/14/1975, Statement on Institute of Development Studies 1976/77 Estimates.

72 Ebd., Minutes of the 11th Board Meeting of the Institute of Development Studies, 7.1.1976. 73 BArch Berlin, DR 3/2. Schicht/B 1514, Klinkert (DDR-Botschafter) an Heidorn (MHF), Dar es Salaam, 10.12.1985. 
sandte einen guten Teil der Master-Studierenden, von denen einige auch aus dem Parteiapparat stammten. ${ }^{74}$

Unter der Leitung des DDR-Rückkehrers Guruli und seinen Nachfolgern, dem Partei-Hardliner Ibrahim Kaduma (der aber 1977 als Vice Chancellor auch für die Versetzung Gurulis und anderer Kräfte verantwortlich war) und dem in Moskau ausgebildeten Juristen Haroub Othman, bildete das IDS einen geschützten Raum für die DDR-Entsandten. Das lag allerdings, gerade im Fall von Kaduma, nicht an einer Präferenz für den Marxismus-Leninismus. In den Augen von DDR-Wissenschaftlern galt Kaduma aufgrund seiner Nationalisierungsrhetorik als „kleinbürgerlich-konservativ“, außerdem war er zuvor als Staatssekretär im Finanzministerium für die Beziehungen mit westlichen Staaten zuständig gewesen. ${ }^{75}$ Kaduma zufolge hatte Nyerere für das IDS den Auftrag gegeben, die tansanischen Werte $\mathrm{zu}$ vermitteln und verschiedene Wege zum Sozialismus $\mathrm{zu}$ diskutieren. ${ }^{76}$ Kaduma schien das IDS jedoch in eine Parteiinstitution wie das Kivukoni College transformieren $\mathrm{zu}$ wollen, was Nyerere $\mathrm{zu}$ weit ging. ${ }^{77}$ Zugleich vertrat Kaduma eine in Bezug auf den Sozialismus undogmatische Position, da er einerseits dem wissenschaftlichen Nachwuchs Besuche in kommunistischen Staaten ermöglichte, andererseits die Neuanstellung von AbsolventInnen aus sozialistischen Ländern vermied und eine pragmatische Aneignung verschiedener Ideen forderte: „It will be naïve to think that using ,capitalist methods“ to achieve socialist goals is a crime “. ${ }^{78}$ Kadumas Nachfolger Othman hatte nach einem Aufenthalt in China und seinem Jurastudium in der Sowjetunion in den 1960er Jahren und in den 1980er Jahren auch weitere Aufbaukurse zur Entwicklungsforschung in Den Haag und London absolviert. Als aktivistischer Intellektueller intervenierte er häufig in politische Debatten; als IDS-Vorstand versuchte er, in eigenen Worten, „to make the institute academically sound and politically relevant without it

74 CCMA, THQ/C/E.20/7, Board Paper No. B/14/1975; Interview \#121, DDR-Universitätsexperte. 75 UAL, DIB 164, Arnold, Vermerk über DSM-Delegation, Leipzig, 26.8.1974, Bl. 214-215; UAL, DIB 550, Wienhold, [unleserlich] zur postgradualen Ausbildung von Nachwuchslehrkräften des gesellschaftswissenschaftlichen Grundstudiums der Universitäten Dar es Salaam und Mogadischu im Rahmen eines 3-Monate-Intensiv-Kurses an der KMU Leipzig, o.O., 22.10.1974, Bl. 183. 76 So Kaduma 2004 in einem Interview, zitiert in Isaria N. Kimambo, Establishment of the University of Dar es Salaam, in: Isaria N. Kimambo u.a., Hg., In Search of Relevance: A History of the University of Dar es Salaam, Dar es Salaam 2008, S. 152-169, hier: S. 162.

77 Coulson, Tanzania, S. 274-275.

78 CCMA, THQ/C/E.20/7, Kaduma, Perspective of the Institute of Development Studies, S. 3; DIB 550, Wienhold, [unleserlich] zur postgradualen Ausbildung von Nachwuchslehrkräften des gesellschaftswissenschaftlichen Grundstudiums der Universitäten Dar es Salaam und Mogadischu im Rahmen eines 3-Monate-Intensiv-Kurses an der KMU Leipzig, o.O., 22.10.1974, Bl. 184. 
being an ideological arm of the state or the party“ ${ }^{79}$ Othman trat laut einem DDRDozenten 1986 als Leiter in Erscheinung, der den DDR-Lehrkräften ,,,akademische Freiheit‘ gewährt[e] und sie zu ,aggressive[m] ‘ Auftreten ermutigt[e]“. ${ }^{80}$ Dabei scheint es aber auch geblieben zu sein, denn gleichzeitig, so ein Bericht aus dem Jahr 1985, blieben überall an der Universität, auch am IDS, DDR-Kräfte von vielen Workshops ausgeschlossen, wurden nicht für die Übernahme zentraler Funktionen herangezogen und erhielten auch keinerlei Vorzugsinformationen. ${ }^{81}$

Ein Großteil des tansanischen Lehrpersonals war zu dieser Zeit vorrangig auf der Jagd nach Forschungsgeldern, Stipendien und Weiterbildungsangeboten westlicher Sponsoren. Gastaufenthalte in Europa und Nordamerika konnten „das 10- bis 15-Fache des [...] monatlichen Professorengehaltes“ in Dar es Salaam einbringen und immer mehr Doktoratsstudierende, die westwärts zogen, gaben offen zu, dass nicht die Qualifikation, sondern „die Möglichkeit, sich während dieser Zeit materielle Werte anzuschaffen, der ausschlaggebende Faktor“ für einen Auslandsaufenthalt war. ${ }^{82}$ Othman selbst wollte während mehrmonatiger England-Aufenthalte sein Amt niederlegen und sich der administrativen Überfrachtung entledigen. Der stellvertretende Institutsdirektor - DDR-Dozent A. Kurtz - hielt allerdings am Prinzip (siehe Kapitel 5.4) fest, dass solche Machtpositionen von tansanischer Seite besetzt bleiben sollten und übernahm den Posten dann lediglich interimsmäßig. ${ }^{83} 1988$ klagte der Leiter der DDR-Universitätsgruppe aber, dass Othman im institutionellen Tauziehen zwischen „progressiven“ und „reaktionären“ KollegInnen nicht Stellung beziehe. ${ }^{84}$ Um die Nachfolge Othmans kämpften auf der einen Seite H. M. Mlawa, der in Sussex promoviert hatte und sich - laut DDR-Bericht - entschieden gegen die weitere Rekrutierung von Lehrkräften aus kommunistischen Ländern und Verbreitung marxistischer

79 Haroub Othman, From Law to Development Studies: A View from Tanzania, in: The Institute of Development Studies, Annual Report 1986 / Handbook 1987, Sussex 1987, 56 - 57.

80 BArch Berlin, DR 3/2. Schicht/B 1514, K., Abschlußbericht über den Einsatz in der VR Tansania (September 82 bis Dezember 85), Zwickau, 3.2.1986.

81 BArch Berlin, DR 3/2. Schicht/B 1514, Spezialistengruppe des MHF an der Universität Dar es Salaam, Zur Situation an der Universität Dar es Salaam (Fortschreibung der Analyse vom April 1984), Dar es Salaam, Oktober 1984.

82 UAL, DIB 550, Studienjahresanalyse 1988/89 der Uni-Gruppe Daressalaam, 30.5.1989, Bl. 20; BArch Berlin, DR 3/2. Schicht/B 1514, Spezialistengruppe des MHF an der Universität Dar es Salaam, Zur Situation an der Universität Dar es Salaam (Fortschreibung der Analyse vom April 1984), Dar es Salaam, Oktober 1984.

83 BArch Berlin, DR 3/2. Schicht/1514, K. (Staatl. Leiter der Universitätsgruppe DSM), Jahresanalyse 1986/87, Dar es Salaam, 20.7.1987-.

84 Ebd., K. (Staatl. Leiter der Universitätsgruppe DSM), Jahresanalyse 1987/88, Dar es Salaam, 14.4.1988. 
Theorien einsetzte, und auf der anderen Seite eine Gruppe um Ernest Maganya (der seinen Doktortitel kurz zuvor in der DDR erhalten hatte) und Kurtz. ${ }^{85}$

Die Annahme des Berichterstatters, dass die Universitäts- und Parteileitung den Institutsvorstand unmöglich dem „Anti-Sozialisten“ Mlawa übertragen könne, erwies sich im Jahr darauf genauso als Trugschluss wie das Urteil über die vermeintlich antikommunistische Haltung Mlawas. Als Mlawa 1989 die Leitung des IDS übernahm, fragte er angesichts des andauernden Exodus tansanischer Lehrkräfte - 12 von 20 planten Auslandsaufenthalte - weiterhin um DDR-ExpertInnen an, auch für das unbesetzte Fach Marxistische Philosophie. Die DDR war jedoch zu keiner Kontingenterhöhung bereit, sodass sich Kurtz dafür einsetzen musste, dass sowohl Marxistische Philosophie als auch Politische Ökonomie als obligatorische Master-Fächer bestehen blieben. Derselbe Berichterstatter befand zudem, dass nun „erstmalig am Institut planmäßig Berufungen von Kollegen entsprechend des erreichten Qualifikationsstandes vorgenommen“ wurden und das Kollegium tatsächliche Mitbestimmung genoss, während Othman für seinen autoritativen Führungsstil ins Kreuzfeuer der Kritik geraten war. ${ }^{86}$ Othman selbst kämpfte vergeblich darum, nach mehreren Abfuhren im In- und Ausland wenigstens von DDR-Seite eine positive Empfehlung für die Berufung auf eine Professur zu bekommen. Die DDR-Dozenten lehnten mit der Begründung ab, dass lediglich drei von zwanzig Publikationen Othmans wissenschaftlichen Standards entsprechen würden. ${ }^{87}$ Die personellen Allianzen am Institut waren also offensichtlich brüchig, teils kurzlebig und sind keinesfalls auf ideologische Orientierungen reduzierbar, wenngleich die Terminologie der DDR-Berichte dies oftmals nahelegt. Othman die Unterstützung zu versagen, war offensichtlich eine Maßnahme der DDR-Dozenten, die Annäherung mit dem konzilianten Mlawa nicht zu gefährden und die eigene „Wissenschaftlichkeit“ vom unwissenschaftlichen Ruf Othmans abzugrenzen.

Wie in Kapitel 4 erwähnt sahen TansanierInnen, die in der DDR studiert hatten, den Marxismus-Leninismus-Unterricht retrospektiv als Pendant zu den Development Studies in Tansania. Die Ähnlichkeit betonten manche DDR-DozentInnen schon in den 1970er-Jahren, gerade in Bezug auf die Zielstellung, denn auch IDS-Direktor Kaduma sah als Hauptfunktion des Instituts, die Entwicklung eines sozialistischen Bewusstseins unter den Studierenden zu fördern. ${ }^{88}$ Über die

\section{Ebd.}

86 UAL, DIB 550, Studienjahresanalyse 1988/89 der Uni-Gruppe Daressalaam, Dar es Salaam, 30.5.1989, Bl. 22.

87 Ebd., Bl. $20-21$.

88 Legère, Als Afrikanist, 34; UAL, DIB 144, Dr. H.-J. Wienhold, Bericht über den Besuch einer Delegation der Universität Dar es Salaam, 5.9.1974, S. 3. 
Funktion hinaus gab es auch inhaltliche Überschneidungen; die Prüfungsfragen in Tansania sahen jenen in der DDR nicht unähnlich. 1976 etwa mussten Studenten der Ingenieurwissenschaften diskutieren, ob (1) die Arbeiterklasse in kapitalistischen Staaten trotz relativ höhere Löhne und zahlreicher Vorteile nach wie vor ausgebeutet wurde, (2) der Kolonialismus eine Zivilisierungsmission umfasste, und (3) Sozialismus die „rationale Wahl“ (ein Begriff, der an einen Text Nyereres erinnerte) für die Mehrheit der Länder der Dritten Welt sei. Andere Aufgabenstellungen bauten auf einem marxistischen Stufenmodell auf und zeichneten die Argumentation bereits teilweise vor: „Outline the positive steps that have been taken so far in Tanzania and those which you suggest to be taken to make worker-peasant alliance class power a reality in the Country [sic]. “89 Prüfungsaufgaben aus dem Jahr 1973 gingen in eine ähnliche Stoßrichtung und verlangten u.a., die Rolle der Arbeit im Übergang von der primitiven Urgesellschaft bis zum Feudalismus zu diskutieren, die russische Oktoberrevolution auf Länder der Dritten Welt anzuwenden (also als übertragbares Modell und nicht als kontingentes historisches Ereignis zu verstehen) und Tansanias Kampf für ökonomische Unabhängigkeit mit dem politischen Befreiungskampf im südlichen Afrika zu verknüpfen. ${ }^{90}$

Die Pflichtliteratur, in der die Antworten auf diese Fragen standen, umfasste einige „sowjetische Klassiker“, „deren Beschaffung von der Buchhandlung allerdings nach Möglichkeit sabotiert“ wurde, wie die Professorin Petsch meinte. ${ }^{91}$ Angesichts von Ressourcenmangel basierte die Lehre am IDS wie an vielen anderen Instituten fast ausschließlich auf selbst produzierten Handouts. Gleichzeitig waren die offiziellen DDR-Ansichten, was ein Klassiker sei, kein Gemeinplatz in Dar es Salaam, wo viele Mao und manche sogar Stalin, der aus dem sowjetischen Heldenpantheon längst verbannt war, zum Kanon zählten. Außerdem standen Fanon, Nkrumah und Cabral auf der Leseliste. ${ }^{92}$ Die Pluralität von Sozialismen war dabei am IDS im Lehrplan verankert: Neben der Oktoberrevo-

89 EAC UDSM, Examinations - Bachelor of Science Engineering, First Year Examinations in Development Studies, Februar 1976.

90 CCMA, THQ/C/E.20/7, Prüfungsfragen im Anhang des Schreibens von Chief Academic Officer UDSM an Mapunda, 18.12.1973.

91 BArch Berlin, DR 3/2. Schicht/B 1449/1b, Petsch an MHF, Bericht über das 1. Halbjahr meiner Tätigkeit an der University of Dar es Salam, Institute of Development Studies (IDS) - August 1974Januar 1975, Dar es Salaam, 20.2.1975, S. 1.

92 BArch Berlin, DR 3/2. Schicht/B 1449/1b, Bericht über Studienreise von Dr. Stoecker, 17.11.9.12.1976, Berlin, 17.12.1976. Siehe auch David Wield/Carol Barker, Science, Technology and Development: Part of a Course in Development Studies for First and Second Year Engineering and Medical Students at the University of Dar Es Salaam, Tanzania, in: Social Studies of Science 8 (1978), S. 385-395. 
lution und Ujamaa wurden auch die Revolutionen in China, Korea, Vietnam und Kuba mit ihren jeweiligen sozialistischen Aufbauversuchen und ihren Beiträgen zu marxistischer Theorie und den Praxen der Befreiungsbewegungen behandelt; in einem Kurs über sozialistische Landwirtschaftssysteme wurden neben Polen, der DDR und der Sowjetunion auch die Systeme Nordkoreas, Chinas und Kubas diskutiert. ${ }^{93}$ Mit dieser Pluralität mussten die DDR-Auslandskader umgehen.

\section{Politische Abgrenzungsarbeit und Stellungskämpfe}

In den Berichten der DDR-DozentInnen finden sich - gleich ob von JuristInnen, Sprachforschern oder DozentInnen in Politischer Ökonomie - immer wieder Selbstpositionierungen gegenüber „linksextremen“, „revisionistischen“ und „rechten“ Theorien, die in Dar es Salaam konkurrierten. ${ }^{94}$ In der Darstellung für DDR-Stellen wurde der Auslandseinsatz zu einem guten Teil als ideologische Reinhaltungs- und Abgrenzungsarbeit geschildert, für die allerdings nicht die DDR-internen Maßstäbe angelegt werden könnten. Petsch berichtete, dass sie zwar „trotzkistische“ und „anarchistische“ Positionen angegriffen habe, es aber zu riskant sei, offen die Stimme gegen den „Maoismus“ zu erheben. ${ }^{95}$

In diesem ideologisch nach wie vor pluralen und umkämpftem Feld mit überlappenden und rivalisierenden Theorien sahen vor allem jene Lehrkräfte, die in der DDR Marxismus-Leninismus unterrichteten und in Tansania am IDS tätig waren, ihre Hauptaufgabe darin, „marxistisches Gedankengut gegen Verfälschungen“ zu schützen und die DDR-Geschichte als Modell einer „schöpferischen Anwendung“ des Marxismus-Leninismus zu propagieren. Der Imperativ, DDRPositionen $\mathrm{zu}$ vermitteln, galt für die Entsandten auch, wenn sie persönliche Sympathien für die Gedanken von Nyerere oder Shivji hegten, und deren Ideen als einen Sozialismus „von unten“ rezipierten. ${ }^{96}$ Studierende wie akademische KollegInnen ließen die idealisierten Darstellungen der DDR, gerade angesichts der wachsenden Erfahrungen mit den Problemen des tansanischen Sozialismus,

93 UDSM, Academic Calendar 1985-1988, S. 62, 311.

94 BArch Berlin, DR 3/2. Schicht/B 1449/1b, B., Tätigkeitsbericht (Halbjahresbericht: Nov. 76-Mai 1977), Dar es Salaam, April 1977.

95 Ebd., Petsch an MHF, „Bericht über das 1. Halbjahr meiner Tätigkeit an der University of Dar es Salam, Institute of Development Studies (IDS) - August 1974-Januar 1975, Dar es Salaam, 20.2. 1975, S. 2.

96 Interview \#118, DDR-Universitätsexperte; BA Berlin, DR 3/2. Schicht/ 1514, Universitätsgruppe der DDR, P.K., Verpflichtungen zum 35. Jahrestag der DDR - Annex zum Arbeitsplan Studienjahr 1984/85, Dar es Salaam. 
natürlich nicht unversehrt; auch die Geschichtsdeutung der DDR wurde hinterfragt. Ein DDR-Historiker, der einen Vortrag über die ,antikoloniale Tradition“ der deutschen Arbeiterbewegung hielt und insbesondere August Bebels Eintreten gegen den deutschen Kolonialismus betonte, stieß ,auf Skepsis und kaum verhohlenen Unglauben“. ${ }^{97}$ Letztlich ging es bei der angetroffenen Skepsis wohl auch weniger um die faktenmäßig richtige Darstellung von Geschichte. Bebels Kolonialkritik ist zwar verbrieft, aber wie die ,antikoloniale Tradition“ der freihandelsorientierten Arbeiterbewegung bestenfalls als ambivalent zu charakterisieren. ${ }^{98}$ Die Skepsis war womöglich darin begründet, dass die vom DDR-Gast postulierte „revolutionäre Potenz der Arbeiterklasse“ in Europa und die Bereitschaft zum antirassistischen Kampf für das Publikum, das größtenteils aus Personal vom IDS und Angehörigen der TANU Youth League bestand, nicht erkennbar war.99

Außerhalb des ideologisch geschützten Raumes beim IDS mussten marxistisch orientierte Lehrprogramme - nicht nur von DDR-Lehrkräften - mit größerem Einsatz verteidigt werden. Da die anderen kommunistischen Staaten kaum Personal entsandten, bedeutete es jedes Mal, wenn die DDR eine Stelle nicht direkt neu besetzte, „faktisch dem Gegner das Feld“ zu überlassen. ${ }^{100}$ Dass es sich hier nicht um grundlosen Alarmismus handelte, zeigt die Tatsache, dass z. B. nach Abreise eines DDR-Ökonoms 1972 die Lehrfächer „Systemvergleich KapitalismusSozialismus“, „Planungserfahrungen sozialistischer Länder“ und „Landwirtschaftliches Genossenschaftswesen sozialistischer Länder“vom Abteilungsleiter widerstandslos gestrichen werden konnten. ${ }^{101}$ Ein Ökonom, der sich im Tätigkeitsbericht 1977 in einer „ständige[n] Konfrontation mit sozialismusfeindlichen Ideologien rechtsextremistischer, bürgerlicher und linksextremistischer Prägung“ positionierte, musste die Literaturauswahl für seinen Kurs vor seinen KollegInnen rechtfertigen. ${ }^{102}$ Laut ihm bestand am Institut zwar die allgemeine Pflicht, dass Lehrprogramme vor dem Kollegium verteidigt werden mussten, allerdings seien nur die „progressiven“ Lehrkräfte tatsächlich zur Verteidigung genötigt worden.

97 BArch Berlin, DR 3/2. Schicht/ B 1449/1b, Bericht über Studienreise von Dr. Stoecker, 17.11.9.12.1976, Berlin, 17.12.1976.

98 Detaillierter hierzu siehe Jörn Wegner, Die Kriegs- und die Kolonialfrage in der britischen und deutschen Arbeiterbewegung im Vergleich 1899-1914, Berlin 2014.

99 BArch Berlin, DR 3/2. Schicht/ B 1449/1b, Bericht über Studienreise von Dr. Stoecker, 17.11.9.12.1976, Berlin, 17.12.1976.

100 Ebd., B 1383a, Bericht der DDR-Universitätsexperten Br., W., Be., Dar es Salaam, 10.1.1973. 101 UAL, DIB 144, Wienhold, Bericht über den Besuch einer Delegation der Universität Dar es Salaam, 5.9.1974, S. 5.

102 BArch Berlin, DR 3/2. Schicht/B 1449/1b, B., Tätigkeitsbericht, Dar es Salaam, April 1977, S. 2. 
Auch der international anerkannte ungarische Ökonomieprofessor Tamás Szentes hatte sich immer wieder mit dem Vorwurf der „Einseitigkeit“ seiner Lehre auseinandersetzen müssen. ${ }^{103}$

In anderen Fällen war zwar das direkte Umfeld wohlwollend gestimmt, aber die Kräfteverhältnisse im größeren Rahmen ungünstig. Die Anstrengungen eines DDR-Juristen, einen stark britisch geprägten Lehrplan mit marxistisch-leninistischen Inhalten zu ersetzen, wurde von der Fakultätsleitung mit dem Argument blockiert, dass dafür im Senat keine Zustimmung zu erwarten sei. ${ }^{104}$ Sein auf DDRund sowjetischer Literatur aufbauendes Lehrprogramm konnte er aber ungestört durchführen; zudem zeigten seine Mitgliedschaften im Fakultätsrat und ihm anvertraute Kommissionsleitungen (wie z. B. zur Umgestaltung einer Vorlesung), dass er fraglos anerkannt war. Einer seiner Nachfolger spielte dann tatsächlich eine wichtige Rolle in der Umstrukturierung der Rechtsfakultät.

Hauptsächlich wurden die DDR-Entsandten von ihren (fast ausnahmslos tansanischen) Vorgesetzten vor allem nach Lehrbedarf eingesetzt und mussten auch in Fächern improvisieren, die sie nie unterrichtet hatten. Ein Ökonom bekam das besonders zu spüren: Er wurde 1976 völlig unvorbereitet mit der Lehre im Fach Accountancy, also „Buchführung amerikanischen Stils“ beauftragt. ${ }^{105}$ Trotz der Ironie dieser Aufgabe ist nicht unbedingt davon auszugehen, dass es sich dabei um eine politische Maßnahme handelte: Die Institutsleiter hatten in erster Linie sicherzustellen, dass die Universität ihrer fachlichen Ausbildungsfunktion gerecht wurde. Außerdem waren Lehrkräfte aus der DDR von manchen Leitungskräften ausdrücklich erwünscht. So forderte der Dekan der Fakultät für Handel und Management, der Jamaikaner K. L. Edwards, 1982 explizit DDR-Kräfte an, um die Einführung in das „sozialistische Rechnungswesen“ an der Universität zu etablieren. ${ }^{106}$ Angesichts der Tatsache, dass die gesamte tansanische Verwaltung auf das westliche System mit einfacher Budgetplanung ausgerichtet und kein praktischer Effekt zu erwarten war, ging die DDR erst gar nicht auf diese Anfrage ein.

103 Ebd., F., Bericht aufgrund meiner Tätigkeit in Tanzania / University College Dar es Salaam, o.O., o.D. [ca. 1969], S. 12-13.

104 Ebd., B., Bericht über meine Tätigkeit an der Universität Dar es Salaam im Studienjahr 1976/ 77, Dar es Salaam, 12.5.1977. Zur Änderung von Lehrplänen an der Rechtsfakultät siehe auch Isaria N. Kimambo, Establishment of Teaching Programmes, in: Isaria N. Kimambo u.a., Hg., In Search of Relevance: A History of the University of Dar es Salaam, Dar es Salaam 2008, S. 107-130, hier: S. $118-121$.

105 BArch Berlin, DR 3/2. Schicht/ B 1449/1b, Bericht über Studienreise von Dr. Stoecker, 17.11.9.12.1976, Berlin, 17.12.1976.

106 BArch Berlin, DR 3/2. Schicht/ 1514, H., Abschlußbericht über den langfristigen Auslandseinsatz in der VR Tansania, Berlin, 29.11.1982, S. 11. 
In Wirtschaft, Recht und Politischer Ökonomie übernahmen viele DDR-Kräfte Lehrveranstaltungen, die auf einen Vergleich von „Ost“ und „West“ bzw. „,bürgerlicher“ und „progressiver“ Theorie angelegt waren. Diese Kurse boten Raum zum Manövrieren. Die Lehrpläne waren meist von marxistischen Lehrkräften (aus den USA oder Westeuropa, der Karibik bzw. anderen afrikanischen Ländern) erstellt worden, die das Fach zuvor unterrichtet hatten. Das somit in Lehrveranstaltungen übersetzte „Bemühen, sich in einer bipolaren Welt zu wissen“, wurde also nicht von DDR-Kräften importiert, sondern vor Ort angetroffen, das vorgefundene Programm als „durchaus sympathisch“ erachtet und dann adaptiert, wie ein DDR-Ökonom erzählte. ${ }^{107}$ Diese Adaption bestand zum Beispiel darin, Beispiele aus der DDR-Geschichte und -Gesellschaft aufzunehmen, die auch für Tansanias aktuelle Entwicklungsfragen relevant waren, darunter Genossenschaften, staatliche Unternehmen, Kollektivierung der Landwirtschaft oder sozialistisches Recht. ${ }^{108}$ Dank derartiger Kurse konnten Entsandte also einerseits die DDR-Erwartung erfüllen, marxistisch-leninistische Positionen zu propagieren, aber sich durch die vergleichende Perspektive (z. B. Vergleichendes Recht) gegen die lokale antikommunistische und nationalistische Kritik absichern, sie würden ausschließlich DDR-Perspektiven lehren. Gleichzeitig waren sie dadurch in der Lage - was eine beträchtliche persönliche Horizonterweiterung bedeutete Theorien kennenzulernen, die in der DDR tabu waren. Ein Ökonom erzählte, er habe Anfang der 1970er-Jahre den dependenztheoretischen Historiker Walter Rodney in Dar es Salaam „persönlich kennen- und schätzen gelernt“ und habe nach seiner Rückkehr versucht, die u. a. von Rodney vertretene Dependenztheorie in die DDR zu importieren:

\footnotetext{
Mir ging's aber darum, dieses hier theoretisch ziemlich abstrakte Studium, wie es abgekürzt wird, ML [Marxismus-Leninismus], aufzulockern, und in seiner Hauptschwäche eigentlich in kritischem Blick zu nehmen, nämlich mit der ungenügenden Praxisverbindung. Die Stärke von Development Studies ist ja gerade die Verbindung von Theorie und Praxis. Ja. Das ist das, was mich dort auch sehr beeindruckt hat. ${ }^{109}$
}

Versuche, diese stärkere Rückbindung der Theorie an die Praxis in die DDR zu exportieren, seien ihm jedoch nicht gelungen. Gänzlich ohne Echo blieben die innovativen Ansätze aus Dar es Salaam jedoch nicht: Diskutiert wurde z. B. Issa Shivjis Theorie der bürokratischen Bourgeoisie. ${ }^{110}$ Die insgesamt aber dennoch

107 Interview \#31, DDR-Universitätsexperte.

108 Ebd.; Interview \#20, DDR-Universitätsexperte.

109 Interview \#31, DDR-Universitätsexperte.

110 Ebd.; vgl. auch Interview \#29, DDR-Soziologe an der Karl-Marx-Universität; UAL, DIB 144, Wienhold, Bericht über den Besuch einer Delegation der Universität Dar es Salaam, 5.9.1974. Die 
limitierte Rezeption der theoretischen Debatten, die in Dar es Salaam geführt wurden, scheint mit Blick auf die biografischen Erwartungen erklärbar: Die meisten DDR-Entsandten hatten aufgrund der definitiv anstehenden Rückkehr in die DDR und einem vorgezeichneten, bereits eingeschlagenen Karriereweg handfeste Gründe, nicht zu sehr von den politischen und ideologischen Vorgaben abzuweichen.

Im Gegensatz zu westlichen Lehrkräften waren die DDR-LektorInnen in eine hierarchisch gegliederte Universitätsgruppe eingebunden, deren Disziplinierungseffekte auch auf die individuelle Tätigkeit abfärbten. Gerade jene DDR-ExpertInnen, die als „Staatliche Leiter“ der Universitätsgruppe eingesetzt wurden, waren in der Regel auch SED-Mitglieder und forderten von den anderen DDRDozentInnen eine offensivere Propagierung des Sozialismus und mehr Engagement in der auslandsinformatorischen Arbeit. Die so Kritisierten wiederum empfanden diese Kader als „Hardliner“ und sprachen ihnen - zumindest retrospektiv in den Interviews - die fachliche Qualifikation ab. ${ }^{111}$ Diese rhetorische Abgrenzung von „Hardlinern“ kann auch im Lichte biografischer Erfahrungen und persönlicher Aversionen gedeutet werden. Ein DDR-Jurist etwa bekam von seinem tansanischen Dekan - einem Rückkehrer aus der BRD - nach Einsatzende eine ausgezeichnete Beurteilung ausgestellt; zusätzlich wurde er in der DDR für die Verdienste im Rahmen seines Auslandseinsatzes für die „höchste Auszeichnung im Hochschulwesen“ nominiert: die Herder-Medaille in Bronze. Ihm zufolge verhinderte der Staatliche Leiter, dass ihm diese Ehre, auf die er „unheimlich stolz gewesen“ wäre, zuteil wurde:

[I]n dem Abschlussbericht standen zwei Sätze. Er hat offensichtlich nicht genug das sozialistische Recht propagiert, indem er viel Westliches gelehrt hat - das ist ja schon, ich musste es ja machen, wenn ich es vergleichend machte, und außerdem wollten die das ja wissen und er hat mehr die Kontakte zu Engländern, Indern und allen anderen ausländischen westlichen Ländern gesucht. Und da war ich raus. Das war's dann mit meiner Medaille. Darüber war ich jahrelang sehr verstimmt. ${ }^{112}$

Dieses Zitat legt nahe, dass das Abhalten von vergleichend angelegten Lehrveranstaltungen immer die Gefahr barg, sich von DDR-Seite Vorwürfe einzuhandeln. Die eigentliche Empörung gilt aber dem Autoritätsverhältnis, in dem die Staatli-

Theorierezeption und -debatten in der DDR selbst können an dieser Stelle nicht behandelt werden; siehe hierzu die Ausführungen sowie Literaturverweise in Felix Brahm/Adam Jones, Afrikanistik, in: Ulrich von Hehl/Uwe John/Manfred Rudersdorf, Geschichte der Universität Leipzig 1409-2009, Leipzig 2009, S. 295-324.

111 Interviews \#20 und \#99, DDR-Universitätsexperten.

112 Interview \#20, DDR-Universitätsexperte. 
chen Leiter der Universitätsgruppen auch bei gänzlich anderer fachlicher Ausrichtung Urteile über die Qualität der Lehre gaben. Auch ein Sprachforscher äußerte Kritik an der Beurteilung der „Pfeife“ - womit er den Staatlichen Leiter meinte - er hätte sich lediglich „bemüht“, Lehrveranstaltungen gut zu gestalten. ${ }^{113}$ Die Erinnerungen sind teils auch als Kritik an der Wissensproduktion über die DDR-Vergangenheit nach $1990 \mathrm{zu}$ lesen. Der Jurist verwahrte sich gegen die Ansicht, Tansania hätte aus dem Westen „fachliche Experten“ und aus der DDR „nur solche Pfeifen bekommen, die ihren politischen Quark [...] erzählen“. Der Einsatz sei nicht „politisch überfrachtet“ gewesen und er habe, so insistierte er, „nicht nur politischen Schnee“ erzählt:

Ich habe also sozusagen aus dem sozialistischen Recht das Idealistische, das Menschliche und das was sie eben für den Ujamaa-Sozialismus hätten gebrauchen können rausgenommen. Nicht das Rigide! Und das scheint mir gelungen zu sein. Und deshalb habe ich mich nie geschämt über das. Das einzige, wenn mich jetzt jemand fragen würde, „Du hast uns so schön informiert, ... warum habt ihr denn das nicht mehr?“ Das ist schwierig zu erklären. Also ich bin nie ein Hardliner gewesen, oder ein politisch Fanatischer. ${ }^{114}$

Auch andere DDR-Entsandte grenzten sich in Interviews von SED-treuen „Hardlinern“ und anderen, vermeintlich „rigideren“ oder „kommunistischeren“ Sozialismen wie in Nordkorea ab und positionierten die DDR (und sich selbst) damit als „gemäßigt“, flexibel und aufgeschlossen. ${ }^{115}$ Eine solche Haltung war in Dar es Salaam auch eine Voraussetzung, um anti-kommunistischen oder anti-sowjetischen Vorurteilen zu begegnen. Der Jurist etwa fand es anfangs schwer, zu seinem Fakultätskollegen eine produktive Beziehung aufzubauen, „weil der dachte, ich bin so ein Russki, auf Deutsch gesagt, so ein russischer Typ. Und das Russische war das Abstoßende“. ${ }^{116}$

Anfang der 1980er-Jahre kam erneut Bewegung in die Konkurrenzverhältnisse zwischen linken Positionen. Teile der tansanischen Führungsriege initiierten ihre Charmeoffensive Richtung Ostblock und Marxismus, um die Ausfälle der westlichen Mittel zu kompensieren. In dieser Phase rückten neomarxistische, marxistisch-leninistische und afrikanisch-sozialistische Parteien etwas zusammen ohne aber zu einer Einheit zu finden. Berichte von einer Konferenz im Jahr 1983 demonstrieren, wo die Potenziale und Grenzen des linken Bündnisses gegen das Wiederaufleben des westlichen Interventionismus lagen. 1983 regten DDR-Lehrkräfte am Institute of Development Studies anlässlich des 100. Todestages von Karl

113 Interview \#99, DDR-Universitätsexperte.

114 Interview \#20, DDR-Universitätsexperte.

115 Interview \#17, DDR-Lehrerexperte.

116 Interview \#20, DDR-Universitätsexperte. 
Marx die Durchführung eines Symposiums unter dem Titel „Marxismus in Afrika“ an, zu dem über 140 TeilnehmerInnen kamen, darunter auch PolitikerInnen und Minister. Die prominentesten Gäste waren Planungsminister Malima (der auch für den Einsatz von DDR-Beratern im Planungsministerium gesorgt hatte) und CCMZentralkomiteemitglied Seif Shariff. ${ }^{117}$ Nyerere war aufgrund der zeitgleich stattfindenden Blockfreienkonferenz in New Delhi an der Teilnahme verhindert. Bei dem Symposium handelte es sich um das allererste explizit marxistische Symposium, das mit offizieller Förderung und Zustimmung der Partei- und Staatsführung durchgeführt wurde, was im Kontext der (bereits in Kapitel 2 dargestellten) Suche der CCM nach ideologischer Erneuerung und Strategien zur Krisenbearbeitung zu sehen ist. Die DDR-Vertretung und die sowjetische Botschaft stellten, ohne öffentlich in Erscheinung zu treten, Papier und marxistische Literatur bereit.

In der üblichen Manier von DDR-Berichten wurde die Diskussion vom Staatlichen Leiter der Universitätsgruppe nicht inhaltlich und chronologisch, sondern anhand theoretischer und ideologischer Gräben nachgezeichnet. Einerseits habe es ein „Aufeinanderprallen“ marxistischer und nicht-marxistischer Standpunkte gegeben, andererseits auch innermarxistische Auseinandersetzungen. Eine Seite, als deren Vertreter die drei anwesenden DDR-Dozenten, Othman und andere Angehörige des IDS genannt werden, habe für die „Reinheit“ der marxistischen Theorie gekämpft und von Tansania gefordert, von den sozialistischen Staaten zu lernen. Die andere Seite habe die marxistische Theorie gegen die aktuelle Politik, die Arusha Declaration und die Ein-Partei-Politik in Stellung gebracht, wobei sich Issa Shivji einmal mehr als „Wortführer und geistiger Lenker“ erwiesen und ,intellektualistische, kleinbürgerliche, idealistische und linksradikal-maoistische“ Auffassungen vertreten habe. Am Ende habe sich die marxistisch-leninistische Theorie aber „durchgesetzt“. Obgleich die CCM und Regierung den wissenschaftlichen Sozialismus und die Prinzipien einer AvantgardePartei noch immer nicht offiziell anerkenne, sei doch ein Bedeutungsgewinn zu verzeichnen. ${ }^{118}$

Issa Shivji scheint nicht nur in diesem Bericht als Leitfigur einer heterodoxen marxistischen Strömung auf. Seine zentrale Rolle in den weit über Tansania hinaus rezipierten theoretischen Debatten etablierte er durch seine 1970 veröffentlichte Analyse The Silent Class Struggle, deren Thesen er später in Class Struggles in Tanzania (1976) weiter ausführte. Shivji argumentierte, dass sich in

117 BArch Berlin, DR 3/2. Schicht/1512, Leiter der Universitätsgruppe L. H., Einschätzung und Auswertung des wissenschaftlichen Symposiums „Marxismus in Afrika“ des IDS der Universität Dar es Salaam (v. 9. und 10.3.1983), Dar es Salaam, 22.3.1983.

118 Ebd., S. 6. 
Tansania eine bürokratische Bourgeoisie herausgebildet hatte, die nicht vom $\mathrm{Ei}^{-}$ gentum der Produktionsmittel, sondern infolge der weitreichenden Nationalisierungen nach der Deklaration von Arusha 1967 von deren Kontrolle profitierte eine Theorie, die also auch für andere staatssozialistische Länder anwendbar war und in mancher Hinsicht mit älteren Kritiken wie etwa jener des trinidadischen Intellektuellen C. L. R. James am sowjetischen „Staatskapitalismus“ einherging. ${ }^{119}$ Tatsächlich wurde die Kritik, dass Tansania de facto kapitalistisch sei, auch an der UdSSR (etwa im Studentenmagazin Maji Maji, dem Nachfolger von Cheche) geübt: die sowjetische Wirtschaft sei durch ausgeprägte Klassengegensätze und die stetige Ausbeutung der Arbeitenden gekennzeichnet und daher als vollständig kapitalistisch zu charakterisieren. ${ }^{120}$ Ab Mitte der 1980er Jahre wurde Shivji in den DDR-Berichten allerdings zunehmend zu den „progressiven“ Kräften gezählt; nicht zuletzt, da er sich stark für den Erhalt marxistischer Positionen an der Universität sowie Arbeiterrechte außerhalb der Universität einsetzte. ${ }^{121}$ Noch in den Interviews aber kamen Meinungen zum Ausdruck wie jene, dass Shivji zwar in Dar es Salaam als progressiv gegolten habe, aber dass „das, was der sagte, [...] mit Sozialismus nichts zu tun“ gehabt habe - so etwa der bereits erwähnte Jurist, der laut eigener Aussage auch eine persönliche Freundschaft mit Shivji gepflegt hatte. ${ }^{122}$

\section{Funktion und Wahrnehmung der DDR-Lehrkräfte}

Die tansanische Seite bat wiederholt um mehr Lehrkräfte, Stipendien und materielle Hilfe von der DDR. Wie andere kommunistische Staaten kam die DDR diesen Forderungen aufgrund fehlenden Interesses kaum nach. Die Verträge, die zwischen der Karl-Marx-Universität und der Universität Dar es Salaam abgeschlossen wurden, sicherten beidseitige Leistungen zu, wobei DDR-VertreterInnen bisweilen berichteten, dass die Gegenseitigkeit illusorisch und Leistungen zugunsten der DDR nicht zu erwarten seien. ${ }^{123}$ Während in einzelnen Fällen DDRDozentInnen auch Stipendien für ein Studium in der DDR vermitteln konnten, scheiterten andere mit Vermittlungsversuchen und folgerten daraus, dass sie „als

119 Siehe z.B. C. L. R. James, State Capitalism and World Revolution, Chicago 1986 [1950].

120 The Soviet Economy - Completely Capitalist?, in: Maji Maji 26 (1976), S. 28-34, hier: S. 34. 121 UAL, DIB 550, Studienjahresanalyse 1988/89 der Uni-Gruppe Daressalaam, 30.5.1989, Bl. 19. 122 Interview \#20, DDR-Universitätsexperte; vgl. Interview \#29, DDR-Soziologe an der Karl-MarxUniversität.

123 UAL, DIB 164, RA, Handschriftliche Memo. o.D. [ca. 1972], Bl. 11-12. 
kleine Lichter“ ohnehin keinen Einfluss ausüben konnten. ${ }^{124}$ In manchen Fällen wurde die Präsenz einer DDR-Fachkraft gar als Risiko für Extraversionsstrategien wahrgenommen, weil z.B. antikommunistische Geber verschreckt werden konnten. So wurde ein DDR-Jurist aus der Besetzung einer Willkommensdelegation für einen US-amerikanischen Gast wieder gestrichen, weil die tansanischen VertreterInnen plötzlich Sorge trugen, „dass der sein Geld wieder mitnimmt“ . ${ }^{125}$

Wie bereits gezeigt beschrieben auch DDR-Experten einige ihrer Landsleute als politische „Hardliner“. Ein ehemaliger Dozent für Politische Ökonomie meinte, dass er mit Sicherheit als „sturer Sozialist“ wahrgenommen worden sei, was aber nicht seinem Selbstbild entsprochen habe. ${ }^{126}$ Andere tansanische und internationale KollegInnen haben gemischt auf die DDR allgemein und auf die individuellen Entsandten reagiert. Die südafrikanische Wissenschaftlerin und Anti-Apartheidaktivistin Ruth First unterrichtete 1975 ein Semester am Wirtschaftsinstitut, das zu dieser Zeit vom in Leipzig promovierten Kassim Guruli geleitet wurde. First sah die DDR-DozentInnen am IDS als den Mittelpunkt einer Clique, die gegen sie intrigierte: „Of course I've been blackballed by that silly crowd at the university which clusters like a cabal round the GDR staff and trainees“ ${ }^{127}$ Der Grund für den Konflikt ist nicht zu identifizieren, aber First vermittelte in ihrem Brief den Eindruck, dass DDR-DozentInnen und -absolventInnen eine wahrnehmbare Gruppe gebildet hatten.

Vonseiten der Universität scheinen die DDR-ExpertInnen willkommen gewesen und ihre Dienste anerkannt worden zu sein - anderweitig lässt sich kaum erklären, dass ihre Verträge so häufig verlängert bzw. aktiv NachfolgerInnen angefordert wurden. Vereinzelte Dokumente wie die Evaluation durch Studierende und externe Evaluierende oder die Abschlussbeurteilung des (nach einem BRDDoktorat zurückgekehrten) Dekans beinhalten Lobpreisungen. Geschätzt wurden z. B. von den Studierenden die Charaktereigenschaften wie „Fleiß und Dynamik“, aber auch die vergleichende Perspektive, die „,bürgerliche“, „,sozialistische“ und „afrikanische“ Sichtweisen auf das Verfassungsrecht näher brachte. ${ }^{128}$ Der bereits erwähnte Jurist wiederum schwärmte für seinen Dekan, er habe „nie einen

124 Interview \#121, DDR-Universitätsexperte.

125 Interview \#20, DDR-Universitätsexperte.

126 Interview \#121, DDR-Universitätsexperte.

127 Barbara Harlow, „Flushed with elation“: Ruth First at the University of Dar es Salaam, 22.9. 2009. pambazuka.org/governance/flushed-elation-ruth-first-university-dar-es-salaam (Zugriff: 13.09.2016).

128 Privatarchiv W. K., Constitutional Law Students an Dean of Faculty of Law, Dar es Salaam, 9.2.1984, Übersetzung EB; siehe auch ebd., diverse „External Examiner’s Reports“ aus dem Jahr 1984. 
Menschen so verehrt und gesehen wie ihn; eine Koryphäe, fachlich; menschlich ein ganz einfacher, für die Wissenschaft Lebender, aber kein Träumer; ein einmaliger Mensch“. ${ }^{129}$ Auch retrospektive Bewertungen, etwa die Wertschätzung für den Sprachforscher Karsten Legère für seine Verdienste um die Erforschung und Aufwertung des Swahili durch tansanische KollegInnen (ausgedrückt in einer Art Rangliste der verdienstvollsten Personen auf diesem Feld aus dem Jahr 2005, wo Legère den 5. Platz einnimmt) wären allein mit politischen Interessenüberlappungen schwer erklärbar. ${ }^{130}$ Eine solche Position gibt es aber auch. Ein 2014 am IDS unterrichtender Tansanier marxistischer Orientierung, der in den 1970erJahren studiert hatte, pries wenig spezifisch die sozialistische Herkunft:

Anybody who came from the East was like, oh, here they are, the products of socialism, and we admired socialism as a model of organizing society as opposed to capitalist development. ${ }^{131}$

Die aus „dem Osten“ entsandten Lehrkräfte schätzte er als fachlich sehr gut ein. Ein tansanischer Jurist meinte im Interview, dass Ostdeutsche der imperialen Vergangenheit Deutschlands generell sehr viel kritischer gegenüberstanden hätten als Westdeutsche; er bezog sich hier vor allem auf DDR-KollegInnen an seiner Fakultät im Gegensatz zu den Westdeutschen an der Ingenieurwissenschaftlichen Fakultät. ${ }^{132}$ Die Allgemeinheit dieser Schilderungen weist wiederum darauf hin, dass zumindest diese beiden keinen engen, persönlichen Kontakt mit DDR-DozentInnen unterhielten. Interviews mit DDR-Entsandten legen ebenfalls nahe, dass diese eher Kontakte mit anderen expatriates denn mit TansanierInnen unterhielten - und das bisweilen in einer Art und Weise, die offiziellen Vorgaben entgegenstand.

Durch derartige persönliche Kontakte, ebenso wie durch konkrete Erfahrungen in Tansania und in westlichen Ländern, mussten Feindbilder revidiert werden. Die bereits beschriebene Diskrepanz zwischen DDR-seitig erwünschten Kontakten einerseits und den realen persönlichen Kontakten andererseits zeigt sich in besonderer Weise am Campus. Ein ehemaliger Dozent für Politische Ökonomie schilderte im Interview seine damalige Überraschung, als er feststellte, dass der Staatliche Leiter - gleichzeitig auch SED-Parteileiter in Dar es Salaam eine Freundschaft mit seinem westdeutschen Nachbarn unterhielt; das Weihnachtsfest wurde dann sogar gemeinsam auf einer westdeutschen Farm und

129 Interview \#20, DDR-Universitätsexperte.

130 Legère, Als Afrikanist, S. 52.

131 Interview \#10, Tansanischer Dozent am IDS.

132 Interview \#14, Tansanischer Dozent an der Rechtsfakultät. 
Missionsstation in den Usambarabergen verbracht. ${ }^{133}$ Mehrere ehemalige „Universitätsexperten“ erwähnten allerdings, von den KollegInnen gerade anfangs „mehr oder weniger isoliert“ gewesen zu sein. ${ }^{134}$ Ein DDR-Ökonom, der Anfang der 1970er-Jahre an der Universität lehrte, erinnerte sich an einen entscheidenden Nachteil gegenüber den westlichen Universitätsangehörigen:

Denn viele von ihnen waren vorher in Ministerien direkt tätig gewesen, bevor sie an die Universität gingen. Kannten also die Mechanismen, die Zusammenhänge, die Hintergründe. Die haben in ihren Lehrveranstaltungen ganz anders Bezug darauf genommen. Oder aber sind umgedreht, nach ihrer Tätigkeit, von der Universität, vom Economic Research Bureau, in Ministerien gegangen. [...] Sie kannten sich, und waren also außerordentlich miteinander mitverbunden. Insofern war man nur mehr oder weniger staunender Beobachter. ${ }^{135}$

Dieses Drehtür-Phänomen zwischen akademischer und ministerieller Welt gab ihnen Vernetzungsmöglichkeiten und einen anderen Bezug zur tansanischen Realität. In den folgenden Monaten konnte sich dieser Ökonom zunehmend in diese internationalen Austauschnetze hineinbegeben und wertvolle Orientierungshilfen bekommen, anderen DDR-DozentInnen gelang das nicht. Im Gegensatz zu anderen ausländischen Lehrkräften waren sie auch kaum in der Lage, selbst zu forschen. Das hatte mehrere Gründe. Fraglos der wichtigste davon ist, dass DDR-Entsandte von ihren Vorgesetzten in erster Linie zur Durchführung von Lehraufträgen eingesetzt wurden, und dies umso umfassender (im Ausmaß von bis zu zwanzig Wochenstunden), als es in den 1980er-Jahren zunehmend an Lehrpersonal mangelte, da TansanierInnen angesichts geschrumpfter Reallöhne ihr Auskommen mit extern (d.h. in der Regel aus westlichen Ländern) finanzierten Consulting-Aufträgen, Forschungen und Auslandsaufenthalten oder auch wirtschaftlichen Tätigkeiten im informellen Sektor suchen mussten. Lucian Msambichaka, der damalige Leiter des Economic Research Bureau der Universität und Absolvent eines DDR-Studiums, gab im Interview zu Protokoll, dass es sogar seine gezielte Personalpolitik gewesen sei, die Not zur Tugend zu machen und einen großen Teil der Belegschaft in dieser ökonomisch schwierigen Zeit zur weiteren Qualifizierung ins Ausland zu schicken. ${ }^{136}$ Der Bericht eines DDR-Dozenten über die hohe Lehrbelastung oszillierte zwischen einer Beschwerde über die Ungleichverteilung der Lehrbelastung einerseits und einer prononcierten

133 Interview \#121, DDR-Universitätsexperte.

134 Ebd.

135 Interview \#31, DDR-Universitätsexperte.

136 Interview mit Laurian Msambichaka, Dar es Salaam, 13.10.2014. Natürlich hatte das ERB selbst keine entsprechende Lehre zu stemmen wie z. B. das IDS oder die Rechtsfakultät, allerdings unterrichtete das Personal vom ERB trotzdem oft in den relevanten Disziplinen. 
Aufopferungsbereitschaft und Verständnis für die Situation der KollegInnen andererseits:

Es scheint an der Universität Dar es Salaam Tradition geworden zu sein, daß die dort im Einsatz befindlichen Kader aus der DDR weitaus mehr Lehrveranstaltungen durchführen als ihre tansanischen bzw. ausländischen Kollegen. [...] Von tansanischer Seite wurde diese Einsatzbereitschaft sehr hoch geschätzt, gab sie doch zahlreichen, besonders jungen tansanischen Wissenschaftlern mehr Zeit, an ihren Forschungsthemen und an ihrer persönlichen Qualifizierung zu arbeiten. ${ }^{137}$

Hinzu kam, dass sich viele DozentInnen erst einarbeiten mussten, so wie eine Juristin, die „in Tansania ein für [sie] völlig neues Fachgebiet“ unterrichtete. ${ }^{138}$ Wenn sie sich für Forschungszwecke vom Lehrbetrieb entbinden lassen wollten und dafür sogar schon die Zustimmung der Institutsleitung erworben hatten, pochten DDR-Botschaft oder andere Stellen in der Entsendehierarchie auf die Erfüllung der Vertragspflicht (die allerdings durchaus Forschungstätigkeiten einschloss) und verwiesen auf „Sicherheitserfordernisse“, die Reisen ins Inland verunmöglichen würden. ${ }^{139}$

Folglich konnten sich die meisten DDR-Entsandten kaum durch Forschung profilieren, aber im Rahmen ihrer Lehrtätigkeit eine beachtliche Multiplikatorwirkung entfalten. 1987 hatten mehr als 1.100 StudentInnen, darunter 80 Prozent aller Studierenden im ersten und zweiten Semester, Vorlesungen der sechs DDRExperten absolviert. ${ }^{140}$ Der von der DDR gewünschte Effekt wurde jedoch ab Mitte der 1980er-Jahre dadurch gemindert, dass das IDS zwar von seiner Konzeption her das ideologische Zentrum der Universität darstellen sollte, praktisch hingegen „Qualität und Ruf des IDS [...] im Sinken begriffen“ waren und neben dem akademischem Personal auch immer mehr Studierende verbreitet „Unverständnis über Sinn und Zweck von Development Studies“ ausdrückten und forderten, dass das IDS konstruktive Änderungsvorschläge anstelle von ideologischer Kritik leisten solle. ${ }^{141}$

137 BArch Berlin, DR 3/2. Schicht/1514, H., Abschlußbericht über den langfristigen Auslandseinsatz in der VR Tansania, Berlin, 29.11.1982, S. 6.

138 Ebd., O., Abschlussbericht, Leipzig, 19.8.1988, S. 4.

139 Ebd., Böhme (DDR-Botschaft) an MHF, Dar es Salaam, 17.10.1985.

140 Ebd., K. (Staatl. Leiter der Universitätsgruppe DSM), Jahresanalyse 1986/87, Dar es Salaam, 20.7.1987, S. 2.

141 Ebd., DDR-Hochschullehrergruppe an der Universität Dar es Salaam, Zur Situation an der Universität Dar es Salaam, April 1984; ebd., K. (Staatl. Leiter der Universitätsgruppe DSM), Jahresanalyse 1986/87, Dar es Salaam, 20.7.1987, S. 6. 
1990 erhielt der Leiter der DDR-Expertengruppe in Dar es Salaam aus der DDR die Erlaubnis für sein Vorhaben, jene Bücher in der Handbibliothek, „die aus Sicht der gesellschaftlichen Entwicklung in der DDR nicht mehr zu nutzen“ waren, zu vernichten. ${ }^{142}$ Die geänderten globalen und nationalen Kräfteverhältnisse in den 1980er Jahren führten auch an der zeitweise stark links und marxistisch orientierten Rechtsfakultät und anderen Lehrstühlen zu einer (keineswegs vollständigen) „Entpolitisierung“ von Forschung und Lehrinhalten - was in der Regel einem Zurückdrängen marxistischer Theorien und WissenschaftlerInnen gleichkam und das Ersetzen linker Kräfte wie dem Dekan Kaniwanyi, der auch zu Delegationsreisen in die DDR gereist war, durch den BRD-Absolventen Costa Mahalu an der Rechtsfakultät bedeutete. Lediglich einer von fünf DDR-Dozenten - der Produktionslehre an der betriebswissenschaftlichen Fakultät unterrichtete wurde 1990 von der BRD als ,integrierter Experte“ (und damit einer Verdopplung der Bezüge) übernommen. Alle anderen Positionen hielten dem BMZ-Kriterium der „entwicklungspolitischen Förderungswürdigkeit“ nicht stand und wurden wie häufig an den Universitäten in der DDR - ,abgewickelt““ ${ }^{143}$ Im Gegensatz zur DDR, deren Kooperation mit der Universität Dar es Salaam auf den Personalaustausch beschränkt blieb, realisierte die BRD auch umfassende materielle Transfers - insbesondere beim Aufbau der Ingenieurwissenschaftlichen Fakultät, der sich über fast zwei Jahrzehnte hinzog.

\section{3 Ökonomisierung: Die Ingenieurwissenschaftliche Fakultät und BRD-Entwicklungspersonal}

Awadhi Mawenya, der erste tansanische Dekan der Ingenieurwissenschaftlichen Fakultät (1976-1982 im Amt) meinte im Interview, dass der Aufbau der Ingenieurwissenschaftlichen Fakultät erstaunlich schnell gelungen und dieser Erfolg vor allem in der politischen Enthaltsamkeit begründet gewesen sei: „Politics was out of the question, we left it to the colleagues up on the hill. I think this is why we developed very fast. " ${ }^{144}$ So klar dieser Satz auf den ersten Blick scheint, so viele Fragen stellen sich beim zweiten. Handelte es sich um eine apolitische Haltung (die durchaus einen politischen Effekt hat) in einem politisierten Umfeld? In welcher Hinsicht konnte sich die Fakultät der Politisierung und den Debatten entziehen? Im Zentrum stand dabei die Debatte, ob und inwieweit der

142 UAL, DIB 550, Leiter der Betreuungsstelle für Experten MHF an Direktor für IB der KMU, 8. 2. 1990, Bl. 7.

143 Interview \#30, DDR-Universitätsexperte.

144 Interview mit Awadhi Mawenya, Dar es Salaam, 7.10.2014. 
Ingenieursfakultät - die im Vergleich mit den anderen Fakultäten am Campus relativ spät gegründet wurde - im Kontext egalitärer Ujamaa-Politik ein Sonderstatus zukommen durfte.

\section{Die globalen Wurzeln einer tansanischen Fakultät}

Die Etablierung der Fakultät ist im Zusammenhang mit den tansanischen Bemühungen zur Planung von manpower development zu sehen, die sich besonders auf den höheren Bildungsebenen auswirkten. Ende der 1960er-Jahre wurde die projizierte Lücke zwischen Bedarf und Angebot an technischem Personal auf mittlerer als auch auf hoch qualifizierter Ebene immer größer. Überseestudien und die Kooperation mit der Fakultät in Nairobi wurden zunehmend als ungenügend angesehen, um den stetig steigenden Personalbedarf der Entwicklungspläne $\mathrm{zu}$ decken und eine genuin nationale Personalplanung absichern zu können, sodass die tansanische Führung beschloss, einen ingenieurwissenschaftlichen Studiengang im Land zu etablieren. Eine erste, international zusammengesetzte Arbeitsgruppe unter der Leitung des sowjetischen Professors S. A. Shumovsko lieferte ihre Studie über den Aufbau einer technischen Fakultät 1969 ab. ${ }^{145}$ Auf Grundlage der Empfehlungen dieser Studie führte die Regierung Gespräche mit möglichen Gebern. Die Sowjetunion lehnte ab, aber Entwicklungsminister Eppler verkündete bei einem Tansaniabesuch 1970, dass die BRD bereit sei, bei der Etablierung behilflich zu sein. Tansania schien erfolgreich das westdeutsche Prestige- und Profilierungsbedürfnis im Kontext der Systemkonkurrenz angestachelt zu haben: Die Botschaft hatte 1969 stolz berichtet, Nyerere habe die BRD angefragt, „da er die deutsche Technik für die beste hält. Dies mag mit ein Grund sein, weshalb das Projekt der technischen Fakultät, für das die UdSSR ihre Hilfe angeboten hatte, jetzt nicht dieser, sondern der Bundesrepublik angetragen wird." ${ }^{146}$ Es ist jedoch unwahrscheinlich, dass die UdSSR zu diesem Zeitpunkt tatsächlich bereit gewesen wäre, ein Mammutprojekt wie den Aufbau einer technischen Fakultät in Tansania anzugehen und $\mathrm{zu}$ ähnlichen günstigen Bedingungen wie die BRD anzubieten - vor allem, da Tansania zu dieser Zeit nicht zu den zentralen Verbündeten zählte und Mitte 1968 mit der Kritik an der Niederschlagung des Prager Frühlings (siehe Kapitel 2.1) deutlich auf Distanz zu Moskau gegangen war.

145 URT, Annual Manpower Report to the President 1969, Dar es Salaam 1970, S. 18. 146 BArch Koblenz, B 102/86803, Bd. 3, BRD-Botschaft an AA, Dar es Salaam, 2.10.1969. 
Eppler schlug vor, das Projekt als multilaterale Kooperation anzulegen. Tansania lehnte dies mit dem Verweis auf schlechte Erfahrungen mit multilateralen Arrangements ab, was dazu führte, dass die BRD - wie auch im Fall des regionalen Entwicklungsprogramms in Tanga (siehe Kapitel 8) - deutlich umfangreichere Zusagen machte und sehr viel mehr Verantwortung übernahm als ursprünglich angedacht. ${ }^{147}$ Der anfangs geplante Etat von 14 Millionen DM sollte sich bis zum Projektende mehr als verfünffachen. Die Ausgaben der BRD beliefen sich bis 1990 auf über 100 Millionen DM, wobei mehr als ein Drittel der Gesamtsumme für Personalkosten (d.h. vor alles deutsches Personal) und fast ein Zehntel für die Counterpartausbildungen aufgewendet wurde; Investitionen in Bau und Ausrüstung flossen ebenfalls zu einem guten Teil an westdeutsche Unternehmen (Tabelle 7.1).

Tabelle 7.1: Ausgaben der BRD für die Förderung der Ingenieurwissenschaftlichen Fakulität Dar es Salaam bis 1990 (Quelle: BMZ, B 213/48201, Ing.-Fakultät Heft 25, J. R. Masuha (Dekan FoE), Continued Cooperation with the FRG - A Brief to the Vice-Chancellor, Januar 1989)

\begin{tabular}{lrr}
\hline Posten & Ausgaben in Mio. DM & Anteil an Gesamtsumme \\
\hline Personal & 34,4 & $34,0 \%$ \\
Bau & 27,9 & $27,6 \%$ \\
Ausrüstung & 20,5 & $20,3 \%$ \\
Counterpartausbildung & 9,8 & $9,7 \%$ \\
Projektverwaltung & 8,6 & $8,5 \%$ \\
\hline Gesamt & 101,2 & $100 \%$ \\
\hline
\end{tabular}

Die entwicklungspolitische Hochschulförderung durch die BRD hatte ihren Anfang bereits 1959 mit dem Aufbau einer Technischen Hochschule in Madras (Indien) genommen. Die in Indien erprobte Bauweise für derartige Institutionen kam dann auch in Tansania und in anderen Ländern zum Einsatz. ${ }^{148}$ Ab 1970 machte die BRD Hochschulförderung zu einem Kernstück ihrer Konzeption für die zweite Entwicklungsdekade. Die Interventionslogik ging über das Ziel, eine akademische Elite aufzubauen, weit hinaus: Hochschulen sollten zur „Stärkung der Planungsund Organisationsfähigkeit der Entwicklungsländer, Strukturverbesserung in

147 Privatarchiv Awadhi Mawenya, Klaus-Wolfgang Bieger/Dietrich Goldschmidt/Wolfgang Kreuser, The Establishment of an Engineering Faculty at the University of Dar es Salaam in Cooperation with the Federal Republic of Germany, Hannover/Berlin/Köln, Dezember 1970 [im Folgenden: Bieger u.a., Engineering Faculty], S. 4.

148 DAAD-Archiv, B 212/91255, German Aid to Education (German Educational Cooperation) Draft for European Aid Donor's Conference, 12.-13.5.1986. 
ländlichen Regionen, Ausweitung und Diversifizierung des gewerblichen Sektors, Bekämpfung von Arbeitslosigkeit [...] und Verbesserung der allgemeinen Lebensbedingungen“ beitragen. ${ }^{149}$ Ein zentraler Teil der BRD-Konzeption war, die Fakultät nicht isoliert zu fördern, sondern ganze „Ausbildungsketten“ zu etablieren, sodass auch genügend qualifizierte Arbeitskräfte mittlerer Stufe vorhanden sein sollten. In Tansania umfasste die „Ingenieurspyramide“ dann die Aufnahme von Lehrlingen in halbstaatlichen Unternehmen, wo BRD-Berater tätig waren (vgl. Kapitel 6.3), die Ausbildung mittlerer Fachkräfte am Technical College in Dar es Salaam, wo u.a. DED-Entwicklungshelfer arbeiteten, sowie den Aufbau eines zweiten Technical College in Arusha im Norden Tansanias (die Sowjetunion sollte später ein drittes im Süden in Mbeya hinzufügen). ${ }^{150}$ Die Fakultät bildete nur die Spitze dieser Pyramide. Innerhalb des Schwerpunkts der Hochschulförderung errang die Ingenieurwissenschaftliche Fakultät der Universität Dar es Salaam schnell den Ruf als „bedeutendste[s] GTZ-Projekt auf dem Hochschulsektor in Afrika“ und galt Mitte der 1980er-Jahre als „Markstein der deutschen entwicklungspolitischen Zusammenarbeit“. ${ }^{151}$ Neben Madras und Curitiba war Dar es Salaam damit eins der Aushängeschilder für westdeutsche Entwicklungsarbeit, Ingenieurkunst und Wirtschaftskraft.

Kurz nach Epplers Besuch legte ein dreiköpfiges Team aus der BRD eine weitere Studie vor, die auf den Ergebnissen der Studie von 1969 aufbaute. Einer der Autoren der Studie, Wolfgang Kreuser, war zuvor am Indian Institute of Technology in Madras und der Ingenieursfakultät in Kairo tätig gewesen und nahm in Dar es Salaam als Projektleiter und Dekan eine machtvolle Doppelfunktion ein. Bereits in der Studie hieß es, der Dekan müsse aus der BRD kommen, um die „angemessene Verwendung“ deutscher Gelder sicherzustellen. ${ }^{152}$ Während diese Funktion einerseits die Rechenschaft gegenüber den SteuerzahlerInnen sicherstellen sollte, war sie andererseits auch eine Möglichkeit, bundesdeutsche Interessen durchzusetzen. In derselben Studie kam auch das wirtschaftliche Motiv zum Vorschein, „Studenten an deutschen Maschinen und Normen auszubilden. “153

149 Wolfgang Küper, Bildungsförderung - ein Schwerpunkt der Entwicklungshilfe, in: Auslandskurier 11 (1977), S. 18-23, hier: S. 19.

150 DAAD-Archiv, B 212/91395/1, KAS (Bereich IIS-Auslandsinformation), Erfolge und Grenzen deutscher Entwicklungspolitik (Teil 2), 15.6.1984.

151 Küper, Bildungsförderung, 22; DAAD-Archiv, B 212/91255, Rede zur 50. Sitzung des Arbeitskreises Fachkontakte Hochschulförderung, Eschborn, 11.3.1986, S. 9.

152 Privatarchiv Awadhi Mawenya, Bieger u.a., Engineering Faculty, S. 74.

153 Ebd., S. 3. 
Die tansanische Seite versuchte nun, dem westdeutschen Einfluss durch die Diversifizierung der Geberstruktur begegnen - wie Eppler es bereits vorgeschlagen hatte. Im BMZ bemerkte man, dass es aus „politischen Gründen wichtig“ sei, „ein sich anbahnendes deutsches Übergewicht in der personellen Besetzung der Fakultät (ca. 30 Lehrkräfte und Experten) durch eine Internationalisierung zu vermindern“. ${ }^{154}$ Als erstes zeigte sich die Schweiz zu einem umfassenden finanziellen und personellen Engagement bereit, außerdem beteiligten sich im Laufe der Jahre auch die Niederlande, Norwegen und UNESCO. ${ }^{155}$ Die BRD blieb jedoch die dominante Kraft in diesem zunehmend komplexen Geflecht beteiligter Staaten und Agenturen.

In der Anwerbung des bundesdeutschen Personals spielten etablierte Netzwerke die größte Rolle. Die GAWI rekrutierte eine Reihe von Fachkräften, von denen einige bereits in Madras oder Kairo gearbeitet hatten bzw. direkt von dort nach Dar es Salaam versetzt wurden; auch weiteres Personal aus der BRD kam „handverlesen“ aus dem „Dunstkreis von Kreuser“. ${ }^{156}$ Im Gegensatz zu den DDRLehrkräften an der Universität hatten die meisten GAWI- bzW. GTZ-Experten an der Ingenieurwissenschaftlichen Fakultät also bereits Vorerfahrungen in der internationalen Entwicklungsarbeit. Laut einem Interviewpartner, der selbst auf Geheiß von Kreuser aus Kairo nach Dar es Salaam versetzt wurde, handelte es sich bei ihm, dem ersten Dekan Kreuser und anderen damals um einen Kreis von Anthroposophen und Rotariern, die humanitäre und theosophische Motive als Antrieb für ihre Tätigkeit anführten. ${ }^{157}$

\section{Studieren und Lehren im Zeitalter der Dependenz}

Das anfängliche Kerngeschäft der Fakultät war der Lehrbetrieb, der 1973 aufgenommen wurde. Ein Jahr darauf, mit Abschluss der wichtigsten Bauarbeiten, wurde die offizielle Eröffnung gefeiert. Während die Errichtung der physischen Strukturen grosso modo plangerecht über die Bühne gegangen war, kam der

154 BArch Koblenz, B 213/7661, Bildungshilfe Technische Fakultät Heft 6, Wiegmann an StS, Bonn, 26.3.1973.

155 BArch Koblenz, B 213/33056, Bildungshilfe Technische Fakultät Heft 10, W. Küper (GTZ), Protokoll einer Besprechung am 28.11.1975 an der Ingenieurfakultät, Dar es Salaam, 29.11.1975, S. 3.

156 Interview \#101, GTZ-Experte und -Projektleiter; Interview \#122, GTZ-Experte.

157 Interview \#101, GTZ-Experte und -Projektleiter. 
Lehrbetrieb nur schleppend in Gang, worunter in erster Linie die Studenten ${ }^{158} \mathrm{zu}$ leiden hatten. 1974 verfassten dreizehn Studenten anlässlich ihrer drohenden Exmatrikulation aus Leistungsgründen ein offenes Memorandum an den Universitätssenat, in dem sie eingangs die Abhängigkeit der Fakultät von der BRD problematisierten:

[W]e are almost totally depe[n]dent on the good will, staff, the expertise and machinery of West Germany in the creation of this important faculty. It is for this reason that this is yet another technological dependence which will tie Tanzania to the technologies and the machines of West Germany and which will produce Tanzanians capable of servicing imported technologies rather than of producing locally designed and locally built technologies. ${ }^{159}$

Hierbei handelte es sich ursprünglich nicht um die eigenen Worte der Studierenden, sondern ein Zitat aus einem Schreiben des Vorsitzenden des Universitätsrats, Amon J. Nsekela. ${ }^{160}$ Politische self-reliance-Diskurse und dependenztheoretische Diskussionen hatten am Campus ihren Höhepunkt erreicht und das Bewusstsein für mehrdimensionale Abhängigkeitsstrukturen geschärft. Laut einem DDR-Bericht hatten Walter Rodney, Issa Shivji und Gerhard Tschannerl, aber auch marxistische Westdeutsche an der Universität schon 1973 in öffentlichen Debatten eine Verbindung zwischen der Unterstützung für die Fakultät einerseits und der BRD-Politik gegenüber Südafrika und Portugal andererseits hergestellt und schwere Bedenken ob der zu erwartenden ökonomischen und politischen Folgen angemeldet. ${ }^{161}$ Außerdem gab es an der Universität selbst einen Erinnerungsort für Tansanias Versuch, sich von der Abhängigkeit von der BRD zu emanzipieren: Nyereres Reaktion auf die Anwendung der Hallstein-Doktrin durch die BRD im Jahr 1965 hatte dazu geführt, dass das Auditorium Maximum der

158 Die ersten zwei Frauen nahmen im akademischen Jahr 1977/78 ein Ingenieursstudium an dieser Fakultät auf.

159 Amon J. Nsekela (Chairman of the University Council), Communication from the Chair Council Memorandum No. 18.9, zit. nach BArch Koblenz, B 213/33043, Bildungshilfe Technische Fakultät Heft 6, An Open Memorandum to the Senate Regarding the Faculty of Engineering, 2.4. 1974, S. 1.

$160 \mathrm{Zu}$ Nsekelas Biografie - die zahlreiche leitende Positionen in der tansanischen Verwaltung, Politik und Wirtschaft umfasst - siehe Amon S. Nsekela, Socialism and Social Accountability in a Development Nation. Problems in the Transformation of the Tanzanian Economy and Society, Nairobi 1978.

161 PAAA, MfAA, B 279/74, DDR-Experte B. an Matthes (DDR-Botschafter), Dar es Salaam, 30.8. 1973. Gerhard Tschannerl führt seine Position, dass politische Entscheidungen über „Expertenentscheidungen“ stehen sollten, detailliert aus in: Gerhard Tschannerl, Rural Water Supply in Tanzania: Is Politics or Technique in Command?, in: Andrew Coulson, Hg., African Socialism in Practice. The Tanzanian Experience, Nottingham 1979, S. 86-105. 
Universität, die mit BRD-Mitteln errichtete Nkrumah Hall, vorerst unvollendet geblieben war und erst 1970 in einem symbolischen Akt der Wiederannäherung zwischen beiden Regierungen komplettiert wurde. ${ }^{162}$

Auch Jahre später waren diese Vorfälle nicht vergessen. Die Befürchtung mancher, mit der neuen Fakultät in der peripheren Rolle gefangen und an die BRD als Vertreterin des globalen Nordens gekettet zu bleiben, wurden nun zusätzlich von den Argumenten der Dependenztheorie untermauert. In technischer Hinsicht waren die Bedenken begründet, denn da fast die gesamte Ausrüstung aus der BRD geliefert wurde, mussten die teuren Ersatzteile ebenfalls aus Westdeutschland importiert werden. ${ }^{163}$ Die für Tansania ungünstige Entwicklung des Wechselkurses trieb die Kosten zusätzlich in die Höhe. Hinzu kam die Kritik an Aussagen von Bundesdeutschen, die den Aufstiegs- und Modernitätserwartungen der Studierenden entgegenstanden und Tansanias Rolle als abhängige Peripherie festschrieben. So hieß es im offenen Memorandum an den Senat weiter:

The attitudes expressed by some staff members of the faculty are unacceptable as regards our aspirations. Their attitudes are biased against the students' capability to perform any duty or ,create' independently. One workshop instructor told a group of students [...] that ,It is impossible for Tanzanians to manufacture complicated machines. The best we can do is to train the students such that they can maintain and repair these machines and we should prepare them for making spare parts for these machines'. The implication is that such an instructor has a belief that an African student is incapable of performing or pursuing technical jobs or procedures. ${ }^{164}$

162 BArch Koblenz, B 102/86572, Development Assistance to Tanzania - Statement by the Government of the Federal Republic of Germany, 20.4.1970. Die Episode hatte Spuren im kollektiven Gedächtnis akademischer Kreise Tansanias hinterlassen, denn mehrere tansanische InterviewpartnerInnen meinten mit Nachdruck, dass die Nkrumah Hall aufgrund der Anwendung der Hallstein-Doktrin nie ganz fertig gebaut worden sei. Während es sich hier selbst um einen Mythos handelt - die entsprechenden Stellen wurden im Zuge der Verbesserung der tansanischen-Beziehungen in der Brandt-Ära nachgebessert - so belegt dieser Mythos doch das Bewusstsein für die Zweischneidigkeit der „Entwicklungshilfe“ direkt am Campus. Laut dem ehemaligen Rektor Pius Msekwa war die Nkrumah Hall in der Zwischenzeit - mit BRDUnterstützung - bereits fertiggestellt worden (Interview mit Pius Msekwa, Dar es Salaam, 23.11. 2014).

163 BArch Koblenz, B 213/33056, Küper (GTZ), Protokoll einer Besprechung am 26.11.1975 an der Ingenieurfakultät, S. 2; ebd., Protokoll einer Besprechung am 26.11.1975 an der Ingenieurfakultät, Dar es Salaam, 29.11.1975, S. 2. Das Abkommen zwischen der BRD und Tansania hatte vorgesehen, dass diese Unterhaltskosten von Tansania zu bestreiten waren. Da die Fakultät kaum über eigene Devisenreserven verfügte, war sie jedoch darauf angewiesen, die Ersatzteile von der GTZ geliefert zu bekommen.

164 BArch Koblenz, B 213/33043, An Open Memorandum to the Senate Regarding the Faculty of Engineering, 2.4.1974, S. 6. 
Ansichten über die Grenzen tansanischer Leistungsfähigkeit waren, gleich wie sie von den Deutschen begründet wurden, für die Studierenden eine Beleidigung mit rassistischem Gehalt (,belief that an African student is incapable“). Solche Ansichten standen außerdem dem technokratischen Bildungskonzept der Fakultät „to train engineers, who shall be able to solve Tanzania’s problems“, „to instil a capacity for leadership and for independent and creative activity“ - entgegen. ${ }^{165}$

Für die Unzufriedenheit der Studierenden waren aber andere Aspekte vordergründiger, und folglich kamen sie auf den restlichen Seiten ihres Schreibens nicht mehr explizit auf Dependenz und Überlegenheitsdünkel zurück, sondern nannten andere konkrete Faktoren, die die Studienleistung negativ beeinflussten. Projektleiter und Dekan Kreuser meinte, dass die Studierenden ihren „Blick [...] meist auf die individuelle Leistung“ und „persönliche[n] Erfolg“ richteten, der Großteil der Studierenden also nur am eigenen Aufstieg interessiert war. ${ }^{166}$ Die eigene Leistung war dabei oft nicht nur für die Einzelperson ausschlaggebend, sondern auch für Familienmitglieder - gerade für jene, die keinen privilegierten Hintergrund besaßen und nur durch die Ujamaa-Politik den Bildungsaufstieg bis hin zur Universität geschafft hatten. ${ }^{167}$ Bundesdeutsche Lehrkräfte mögen sich dessen bewusst gewesen sein, jedenfalls aber maßen sie diesem Aspekt nicht dieselbe Bedeutung bei wie ihre tansanischen Kollegen. Auf die Frage (gestellt während eines Didaktikseminars der DSE im Jahr des offenen Referendums 1974), welche Probleme die Studierenden im Studium hätten, antworteten deutsche Dozenten in engen, fachbezogenen Kategorien und nannten Defizite aufseiten Studierenden. Die Verbindung zwischen Theorie und Praxis sei unklar; die Fähigkeit zum dreidimensionalen Denken fehle den Studierenden genauso wie analytische und synthetisierende Fähigkeiten. Die eigenen didaktischen Fähigkeiten wurden nicht infrage gestellt. Für die (noch wenigen) angestellten Tansanier hingegen stellten sich soziale und biografische Faktoren wie Familienprobleme, unsichere berufliche Zukunftsperspektiven und schlechte Wohnbedingungen als die Herausforderungen dar, mit denen die meisten Studierenden in erster Linie zu kämpfen hatten. ${ }^{168}$ Vor diesem Hintergrund lassen sich auch die Beschwerden im Memorandum interpretieren: nicht einfach als

165 Ebd., GTZ, University of Dar es Salaam. Faculty of Engineering, Eschborn 1979, 14; ebd., B 213/33074, Report of an International Study Team on the FoE at the UDSM, Mai 1979, S. 52.

166 BArch Koblenz, B 213/7680, Heft „Bericht der Abgeordneten Hofmann (SPD) und Wawrzik (CDU/CSU)“, Wolfgang Kreuser, Aufbau der Ingenieurfakultät Dar es Salaam, Stand 1.10.1974, S. 14.

167 Hydén, Beyond Ujamaa, S. 161.

168 BArch Koblenz, B 213/33043, Hartmut Glimm (DSE), Evaluation of Participants Questionnaire No. 1, S. A2, D2. 
Ausdruck eines „falschen Bewusstseins“ und individualistischer Tendenzen, sondern als kollektive Reaktion auf gesellschaftliche Problemlagen und Missstände an der Universität, die dem eigenen Erfahrungshorizont nahe waren.

Mehrere Vorwürfe im Memorandum richteten sich ausdrücklich gegen Verhaltensweisen von expatriates. Augenscheinlich hatten westdeutsche Dozenten und insbesondere das GTZ-Werkstattpersonal sich im zwischenmenschlichen Umgang einen schlechten Ruf eingehandelt, wie mit einer Reihe von Einzelfällen belegt wurde: Der Werkstattleiter habe einen Studenten verdächtigt, ein Werkstück verlegt zu haben und sich dann geweigert, den Unterricht fortzusetzen, was einer Kollektivbestrafung gleichgekommen sei; ein Werkstattangestellter habe einen Studenten, nachdem ein Werkzeug kaputtgegangen war, als Idioten beschimpft; das gesprochene und geschriebene Englisch mancher Entsandter sei völlig unverständlich. Als umso anmaßender wurde dann die Forderung eines Dozenten empfunden, die Studierenden sollten doch Deutsch lernen, um die Lehrbücher lesen zu können und nicht auf die (als qualitativ minderwertig empfundenen) Handouts angewiesen zu sein. ${ }^{169}$ Derartige Vorwürfe - die Qualität der Englischkenntnisse ausgenommen - hatte es DDR-DozentInnen gegenüber nie gegeben.

Das Fazit des Memorandums war eindeutig. Das Fakultätspersonal, willkürliche Beurteilungsmaßstäbe und der Mangel an Unterrichtsmaterialien waren schuld an den schwachen Leistungen, nicht die Studierenden selbst. Um solchen Missständen entgegentreten zu können, forderten die Unterzeichner eine umfassende, bis dato inexistente studentische Mitbestimmung an der Fakultät. Das Memorandum war keinesfalls das Produkt einer radikalen oder isolierten Minderheit, sondern spiegelte die weitverbreitete Unzufriedenheit unter den Studierenden der Fakultät wider, die sich auch zu späteren Zeitpunkten Luft machten. 1975 etwa mussten mehrere Fakultätsmitglieder einen Vorlesungsboykott über sich ergehen lassen. ${ }^{170}$ Laut einer GTZ-Publikation gingen die Boykotts vor allem auf die ungenügenden Englischkenntnisse der Deutschen zurück. ${ }^{171}$ Einer der GTZ-Experten, Prof. Thelen, erhielt sogar eine anonyme Morddrohung (von der er sich allerdings wenig beeindruckt zeigte; er zog eine frühere Rückreise nicht in

169 Ebd., An Open Memorandum to the Senate Regarding the Faculty of Engineering, 2.4.1974, S. 3-4, 6 .

170 Ebd., Kreuser, Projektbericht Nr. 14, Dar es Salaam, 1.11.1975.

171 GTZ, Bildung und Wissenschaft in Entwicklungsländern. Die Maßnahmen der staatlichen deutschen Bildungs- und Wissenschaftsförderung, Eschborn 1975, S. 190. 
Betracht und ließ lediglich eine Alarmanlage in sein Haus einbauen), die höchstwahrscheinlich im Zusammenhang mit den Boykotts stand. ${ }^{172}$

Auch in den folgenden Jahren beschwerten sich Studierende über Unterrichtsstil, Verhalten und mangelnde Sprachkenntnisse der Lehrkräfte. Eine Umfrage aus dem Jahr 1979 über die Zufriedenheit mit dem Lehrpersonal erbrachte zwar eine ganze Reihe positiver Kommentare („Has improved this time“, „Highly systemized lectures“), kritische Urteile und Änderungsvorschläge überwogen jedoch. Besonders häufig bezogen sie sich auf ungenügende didaktische Fähigkeiten, fehlende Hilfsbereitschaft und falsche bzw. germanozentrische Vorannahmen:

Do not limit to first angle only which is of course in Germany standard!!

Assumes we know things which we do not.

Actually your topics were not well understood. No adequate explanations neither examples which really explain the subject matter.

The lecturer was not co-operative at all. He was not even answering questions.

He is too brief and the notes are also too brief.

Hand-outs are seen to be good, the problem is that we are not explained how to use them. ${ }^{173}$

Andere Kommentare bezogen sich auf den Mangel an Unterrichtsmaterialien, so mussten sich z.B. acht Studierende ein Arbeitsblatt teilen. Gefordert wurden praktischere Beispiele und mehr Möglichkeiten zum individuellen Ausprobieren. Manche Lehrpersonen würden kein Verständnis für die Probleme der Studierenden aufbringen. Wie bereits angedeutet, handelte es sich hier offensichtlich nicht nur um Verständnisschwierigkeiten zwischen Personen verschiedener soziokultureller Provenienz. Der Abschlussbericht eines didaktischen Seminars etwa legt nahe, dass die große Mehrheit der Dozenten den Bildungsprozess als Vermittlung technischen Problemlösungswissens sah. Nur eine kleine Gruppe ausländischer Dozenten zeigte sich von der ,bornierte[n] Wertfreiheits- und Spezialistenattitude [sic]“ an der Fakultät frustriert und hegte sogar Aggressionsgefühle gegen den Technizismus der Mehrheit. ${ }^{174}$ Ein GTZ-Experte, der als einer der wenigen nicht aus dem Kreis der „Kreuser-Mafia“ technikzentrierter Anthroposophen, sondern

172 BArch Koblenz, B 213/7683, Aus- und Fortbildung Heft 2, BRD-Botschaft an AA, Dar es Salaam, 5.12.1975.

173 BArch Koblenz, B 213/33074, Report of an International Study Team on the FoE at the UDSM, Mai 1979, S. $166-169$.

174 BArch Koblenz, B 213/33043, Flechsig, Zur Auswertung des hochschuldidaktischen Werkstattseminars in Daressalaam, S. 7. 
über die „Goldschmidt-Schiene“ (Goldschmidt hatte die bildungswissenschaftliche Komponente im Gutachten von 1970 bedient) rekrutiert worden war, beschrieb sich im Interview als „Exot“ an der Fakultät. Mit seiner nicht nur ingenieurtechnischen, sondern auch soziologischen Ausbildung sei er von seinen „politisch einfach gestrickt[en]“ deutschen Kollegen als „arrogant“ und „Klugscheißer“ wahrgenommen worden, weswegen sie ihn mit seinen Ideen oft „auflaufen“ lieBen. ${ }^{175}$

\section{Expatriates und Tansanisierung}

Zur Eröffnung 1974 waren fast alle Lehrposten und selbst die leitenden Funktionen in der Werkstatt von Westdeutschen besetzt. Später kamen Schweizer und andere expatriates hinzu. Zwar befand Dekan Kreuser 1974, dass „[i]m Vergleich $\mathrm{zu}$ anderen Universitäten in Afrika [...] die Counterpartsituation an der Ingenieurfakultät Dar es Salaam schom im 2. Jahr ihrer Existenz recht günstig“ sei, merkte aber an, dass die Nationalisierung aufgrund politischer Rahmenbedingungen wohl nicht vor 1981 abgeschlossen werden könne: Die manpower-Behörde verteile die Absolventen prioritär auf Industrie und Ministerien, während die Zuteilungsquote an Ingenieuren für die Universität weit unterschritten werde. ${ }^{176}$ Von 69 akademischen Stellen waren 1978 fast zwei Drittel, nämlich 44, von ausländischen Akademikern ${ }^{177}$ besetzt und nur knapp über ein Zehntel (8) von Tansaniern. Das restliche Viertel (17) umfasste vakante Positionen, weil einige einerseits Tansanier noch zur Qualifizierung im Ausland weilte und andererseits die Arbeitsbedingungen und das Prestige der Fakultät nicht attraktiv genug waren, um die Lücken durch Ausschreibungen am internationalen Arbeitsmarkt zu füllen. ${ }^{178}$ Personalmangel war an der Fakultät somit keine Ausnahme, sondern ein Normal- und Dauerzustand. Während sich das Zieljahr für die vollständige „Tansanisierung“ über die Jahre von 1981 immer weiter nach hinten verschob,

175 Interview \#122, GTZ-Experte.

176 BArch Koblenz, B 213/7680, Heft „Bericht der Abgeordneten Hofmann (SPD) und Wawrzik (CDU/CSU)“, Wolfgang Kreuser, Aufbau der Ingenieurfakultät Dar es Salaam, Stand 1.10.1974, S. 10.

177 Die weiteren expatriates kamen laut dem UDSM-Jahresbericht 1979/80 neben der BRD aus der Schweiz (15), Großbritannien, Dänemark, Indien (je 2) und den USA bzw. Trinidad und Tobago (1). UDSM, Annual Report 1979-80 on the Activities of the University of Dar es Salaam, Dar es Salaam 1982.

178 BArch Koblenz, B 213/33066, Meyringer (GTZ), Anlage 1 zu Niesel (DAAD), Das Counterpartausbildungprogramm der FoE der UDSM, Nairobi, 12.2.1978. 
steckte die GTZ immer mehr Millionen in die „Streckung der Personalabbauplanung“. .179

Um die „Tansanisierung“ der Fakultät zu beschleunigen, stellten der DAAD und die Carl Duisberg Gesellschaft Stipendien für die Counterpartausbildung zur Verfügung. Bis 1978 war nur die Hälfte der DAAD-Stipendiaten von M.Sc.- und PhD-Programmen zurückgekommen, der Rest kämpfte mit Prüfungen und Verzögerungen; von einem „Totalausfall“ erhoffte sich die Fakultät sogar, er möge gar nicht erst zurückkommen. ${ }^{180}$ Die BRD war kein von der Fakultätsleitung bevorzugtes Ziel für die Qualifizierungsmaßnahmen, ganz im Gegenteil. Bis auf einen Doktoranden in Warschau mit polnischer Finanzierung und einem Studenten in Finnland weilten alle zur Qualifizierung Entsandten in westlichen Ländern, in denen auf Englisch unterrichtet wurde. Währenddessen lockten Unternehmen der privaten und halbstaatlichen Industrie AbsolventInnen und erfahrene Lehrkräfte, die ihre Mindestvertragszeit bei der Universität absolviert hatten, mit umfangreichen und - angesichts des Reallohnverfalls - immer bedeutender werdenden Lohnnebenleistungen und schnellen Beförderungen, womit sie die egalitäre Lohnpolitik der Regierung unterliefen. ${ }^{181}$

Maßnahmen offizieller Stellen, dieser Abwanderungstendenz entgegenzuwirken, reduzierten die Entscheidungsfreiheit der AbsolventInnen. Jene mit den besten Abschlussergebnissen - „first class“, „second upper class“ - wurden zeitweise direkt von der Fakultät rekrutiert. Ein Professor der Ingenieurwissenschaften, der 1978 zu dieser Leistungsgruppe gehört hatte, erzählte im Interview von seinem Versuch, dieser Zuordnung zu entgehen. Eine Consultingfirma in Arusha hatte ihm bereits ein Jahr vor dem Abschluss seines Studiums ein Angebot unterbreitet und zugesichert, das Dreifache des Einstiegsgehaltes an der Universität zu zahlen. Wie andere Teilnehmer seines Jahrgangs mit guten Leistungen war er allerdings als Teil des zukünftigen Lehrkörpers vorgesehen. Als er die Stelle bei der Consultingfirma trotzdem antrat, habe die Universität die Polizei informiert, diese wiederum habe bei seinen Eltern vorgesprochen, die ihrem Sohn dann geraten hätten, keine Auseinandersetzung mit „der Regierung“ zu riskieren. Wie die Hälfte der Absolventen seines Jahrgangs, meinte dieser noch zum Zeitpunkt des Interviews an der Fakultät unterrichtende Professor, begann er sein Berufsleben nicht freiwillig, sondern zwangsweise ( $k w a$ nguvu) an der Universität. ${ }^{182}$

179 BArch Koblenz, B 213/7680, Wiegmann (BMZ) an Referat 122, Bonn, 25.10.1979.

180 BArch Koblenz, B 213/33066, Meyringer (GTZ), Anlage 4 zu Niesel (DAAD), Das Counterpartausbildungprogramm der FoE der UDSM, Nairobi, 12.2.1978.

181 BArch Koblenz, B 213/33074, Report of an International Study Team on the FoE at the UDSM, Mai 1979, S. 99.

182 Interview \#40, Tansanischer Professor an der Ingenieurwissenschaftlichen Faktultät. 
Wie üblich in entwicklungspolitisch begründeten Interventionen sollten auch an der Universität die ausländischen Fachkräfte baldmöglichst durch einheimischen Nachwuchs ersetzt werden. Wie üblich gab es Probleme in der praktischen Umsetzung und unintendierte Ergebnisse. Ein westdeutscher Dozent, der auch selbst Counterparts und Absolventen in die BRD vermittelte ${ }^{183}$, schilderte, wie gleich zwei Counterparts, die als seine Nachfolger vorgesehen waren, ausfielen. Den ersten Fall stellte er als gleichermaßen tragische wie geradezu karikaturhaft überzeichnete Version des Entfremdungsmotivs dar. Der Counterpart habe sein Arbeitsethos in der BRD dermaßen verändert, dass er unter tansanischen Bedingungen nicht mehr habe überleben können:

Der erste Counterpart, der kam von Deutschland, der war in einem deutschen Ingenieurbüro, und der kam nach Tansania, und der ist leider nach drei Monaten verstorben. Der hat sich wirklich überarbeitet. [...] Der hat so einen deutschen Arbeitsrhythmus gehabt, hat gesagt, „Die machen ja alle nix“, und wollte das alles von heute auf morgen machen. Und da hat er sich irgendwie übernommen. Und das war auch das Klima, muss man alles in Betracht ziehen, und er hatte diese Umstellung von Deutschland schlechter hinbekommen wie ich. So das dann also der Counterpart nicht da war. ${ }^{184}$

Der zweite Counterpart habe aus Karrieregründen - verständlicherweise, wie der Dozent im Interview meinte - bereits nach einem Jahr wieder den Weg ins Ausland angetreten. So blieb von zwei eingeplanten Counterparts mit der entsprechenden Qualifikation kein einziger, der die Position übernehmen konnte. Ein anderer GTZ-Experte wartete laut eigenen Angaben jahrelang auf die Rückkehr des Counterparts aus England; als dieser dann schließlich nach Tansania zurückkam, wurde er erst in einer anderen Abteilung eingesetzt und dann von der Regierung zur Planung von Maßnahmen in der neuen Hauptstadt Dodoma abgezogen. ${ }^{185}$

Als sich die Auslandsaufenthalte der Stipendiaten immer weiter ausdehnten, forderte die GTZ, dass Verlängerungen nicht mehr möglich sein sollten. ${ }^{186} \mathrm{Um}$ individuelle Spielräume zu verringern, setzte die Fakultät - von den Gebern unter Druck gesetzt - zunehmend auf Disziplinierungsmaßnahmen. In mehreren Fällen teilte der Dekan (,very unhappy“) dem DAAD mit, dass die Stipendien nicht verlängert werden sollten, weil die Stipendiaten aus seiner Sicht bummelten, keine Fortschrittsberichte schickten, schwache Leistungen verzeichneten oder

183 Siehe hierzu DAAD-Archiv, B 212/91392/4, BRD-Botschaft an DAAD, Dar es Salaam, 2.6.1980.

184 Interview \#105, BRD-Dozent (Lokaler Vertrag mit GTZ-Gehaltsaufstockung).

185 Interview \#106, GTZ-Experte.

186 BArch Koblenz, B 213/33066, Meyringer (GTZ), Stellungnahme zum Bericht von Niesel (DAAD) über den Verlauf des Stipendienprogramms, o.O., 6.3.1978. 
sich ohne Absprache in andere Spezialisierungen manövriert hatten, die nicht dem Personalentwicklungsplan der Fakultät entsprachen. ${ }^{187}$ Obwohl der akademische Nachwuchs Vorbehalte gegen Entsendungen in nicht-westliche Länder hatte, wurden zunehmend auch Stipendien in Drittländern im globalen Süden wie Indien angeboten: „Etwaige Probleme müssten von den Studierenden durchgestanden werden“, meinte ein Vertreter des DAAD; es ginge „hier um ihre Weiterbildung und nicht um ihre Bequemlichkeit“. ${ }^{188}$ Ein Interviewpartner gehörte zu einer Gruppe von zehn Stipendiaten in Indien und meinte, dass neun von ihnen das Studium abbrachen, weil sie z.B. nicht frei über ihre Unterhaltszahlungen verfügen durften; in anderen Berichten wurden Rassismuserfahrungen beschrieben. ${ }^{189}$

Da die meisten ausländischen Lehrkräfte und das Werkstattpersonal an ihre jeweiligen Institutionen wie die GTZ gebunden waren, bedeutete der „expatriate factor", wie er in einem Bericht genannt wurde, nicht nur eine massive Präsenz, sondern auch einen massiven Einfluss von expatriates (und ihren Institutionen im Hintergrund) an der Fakultät. Einerseits konnte sich das in materiellen und personellen Zuflüssen manifestieren, etwa beim Institut für Geologie, wo ab 1977 eine enge deutsch-tansanische Kooperation etabliert wurde. Hier zeigt sich die Möglichkeit für BRD-Entwicklungspersonal, soziales Kapital aufzubauen und in ökonomisches Kapital für die Universität umzuwandeln, und zwar in einem Volumen, wie es für DDR-Entsandte undenkbar war. ${ }^{190}$

Einige Entsandte, die sich der Nachhaltigkeit und dem Konzept Small is beautiful verpflichtet fühlten, entschieden sich bewusst dafür, ihre Aufgaben ,mit internen Mitteln“ zu erledigen, also z.B. Unterrichtsmaterialien nicht - was unschwer möglich gewesen wäre - durch die GTZ drucken zu lassen, sondern in mühsamer Kleinarbeit mit der Druckerei vor Ort. Das war zwar organisatorisch

187 DAAD-Archiv, B 212/91803/2, Dean Faculty of Engineering an GTZ Team Leader, Dar es Salaam, 24.8.1987.

188 BArch Koblenz, B 213/33066, Niesel (DAAD), Bericht über eine Dienstreise vom 29.1.-4.2. 1978, Nairobi, Februar 1978.

189 Interview \#91, Tansanischer Student in der DDR.

190 Die westdeutsche Institutsleiterin Ingeborg Prasad zeigte sich hier äußerst umtriebig und holte u. a. Finnland als Geber ins Boot, um einen kompletten Gebäudeneubau zu finanzieren und weiteres Lehrpersonal an das Institut zu holen. S. Kapilima, Training and Research and Development Programme in the Geology Department of the University of Dar es Salaam for the Development of Mineral Sector in Tanzania: The Role of DAAD Cooperation, in: University of Dar es Salaam, DAAD Former Scholarship Holders Seminar, Dar es Salaam 1991, S. 33-36; BArch Koblenz, B 213/33066, Armbruster (BMZ), Vermerk, Bonn, 5.5.1977; ebd., B 213/33077, Glimm (DAAD), Vermerk über ein Gespräch mit dem Dekan der Faculty of Science Prof. Nkundiwe am 27.7.1979, o.D., Dar es Salaam. 
aufwendiger, sparte allerdings auch Kosten und zukünftigen Devisenaufwand für Auslandsbestellungen, zumal die Urheberrechte für das Material an die Universität übertragen wurden. ${ }^{191}$

Wenn es in einer Evaluation über den Entwicklungsprozess der Fakultät hieß, „the expatriate [...] has no responsibility for University policy“ ${ }^{192}$ so war das keine Beschreibung der Realität. Es war noch nicht einmal eine von allen akzeptierte Verhaltensrichtlinie. Die bestehenden Abhängigkeiten und damit verbundenen Machtverhältnisse konnten durch die Normvorstellung und den Hinweis auf die tansanische Souveränität zwar problematisiert, aber nicht außer Kraft gesetzt werden. Eine direkte Intervention in die tansanische Entscheidungshoheit erlaubte sich die BRD Mitte der 1970er-Jahre. Die Verabschiedung der Musoma Resolution im Jahr 1974 ließ die GTZ befürchten, dass der Zustrom von SchulabgängerInnen abreißen könnte und die Hörsäle leer bleiben würden. ${ }^{193}$ Die neue Richtlinie griff in die Bildungswege ein: Nach der Sekundarschule folgten $\mathrm{Na}$ tional Service und die „Bewährung“ in der Produktion oder einem anderen Sektor der Arbeitswelt, erst im Anschluss und mit einer entsprechenden Empfehlung des Arbeitgebers sowie der Partei sollte der Studieneinstieg möglich sein. Für erfahrene Werktätige mit niedrigeren Schulabschlüssen wurde durch das Mature Age Entry Scheme der Studieneinstieg an der Universität ebenfalls ermöglicht, aber auch dieser Modus war mit Herausforderungen wie z. B. einer unzureichenden akademischen Vorbildung vieler KandidatInnen verbunden. ${ }^{194}$

1975 begannen als Nachwirkung der Musoma Resolution statt der geplanten 120 nur 65 Erstsemester ihr Studium, darunter nicht nur Tansanier, sondern auch 9 Kenianer, 2 Sudanesen und 1 Ruander. Das BMZ fürchtete, dass diese Zahlen die nahelegten, dass eine Institution gefördert wurde, für die nur wenig Nachfrage bestand - für ernsthafte innenpolitische Legitimations- und in weiterer Folge auch Finanzierungsprobleme standen. Die Beamten zögerten nicht, die Musoma Resolution zu problematisieren und Tansania „moralisch-politisch“ auf eine

191 Interview \#105, BRD-Dozent (Lokaler Vertrag mit GTZ-Gehaltsaufstockung).

192 BArch Koblenz, B 213/33074, Bildungshilfe Technische Fakultät Heft 14, Report of an International Study Team on the FoE at the UDSM, Mai 1979, S. 64.

193 BArch Koblenz, B 213/33056, Küper (GTZ), Interner Vermerk über Gespräche in der Technischen Fakultät Dar es Salaam am 25.11.1975, Eschborn, 4.12.1975, S. 2.

194 Die auf diesem Wege Rekrutierten hatten besonders große theoretische Schwächen in Mathematik und naturwissenschaftlichen Fächern, ihre Studienzeit war für Tansania ein Verlust ihrer Arbeitskraft auf mehrere Jahre und für die BewerberInnen selbst gleichbedeutend damit, mit einem Stipendium von 400 TSh monatlich (anstelle eines Gehalts von 2.000 TSh z. B. in EACInstitutionen, Stand 1976) auskommen zu müssen. BArch Koblenz, B 213/33056, Rösch (Officer for Relations with Industry FoE), Bericht über Besuche bei Ministerien, Parastatals und E.A. Community Institutions in Tanzania, o.O., 5.1.1976. 
Ausnahmeregelung zu drängen. ${ }^{195}$ Die westdeutsche „Öffentlichkeit“ wurde hier als Verhandlungsmasse ins Feld geführt; ihr gegenüber seien die hohen Kosten je Student nicht vertretbar. ${ }^{196}$ Die Forderung nach einer Ausnahme war in diesem Fall noch keine ausdrückliche Drohung einer Finanzierungskürzung, sondern eher der Versuch, „richtiges“ Verhalten zu belohnen. Die BRD schlug vor, offene Studienplätze mit KandidatInnen aus anderen afrikanischen Ländern zu besetzen und dafür 30 zusätzliche DAAD-Stipendien zu finanzieren. Einer der wichtigsten Ansprechpartner neben dem Rektor, der Chief Academic Officer Kimambo, zeigte sich jedoch, so der GTZ-Projektsprecher, „,von unseren Problemen nicht sonderlich berührt“. ${ }^{197}$ Auch Finanzminister Jamal lehnte die Ausnahmeregelung ab. Angesichts dieser kühlen Reaktionen war die BRD-Seite überrascht, als die Ausnahme 1976 doch genehmigt und die Fakultät voll mit tansanischen Studierenden besetzt wurde. ${ }^{198}$ In den folgenden Jahren stimmte dann zwar die Quantität, allerdings fiel der Leistungsdurchschnitt ab.

Einen zweiten Interventionsversuch unternahmen bundesdeutsche Akteure, um die die strikte Trennung des akademischen vom ökonomischen Feld, wie sie an der Universität praktiziert wurde, zu durchbrechen. Laut der bestehenden Regelung sollte das Lehrpersonal lediglich aus Vollzeitlehrkräften bestehen; Lehraufträge für Ingenieure, die in der Wirtschaft tätig waren und entsprechende Praxiserfahrungen mitbrachten, wurden nicht vergeben. GTZ-Projektsprecher Küper sah in dieser Frage wie in der Zulassungspraxis Bedarf für „(politische) Aufklärungsarbeit“. ${ }^{199}$ Ebenfalls eine eindeutig politische Frage war die Höhe der Gehälter. Innerhalb Tansanias war die Tätigkeit in der Industrie deutlich lukrativer als an der Universität, sodass die GTZ-Experten schon bald für eine Sonderregelung an der Fakultät gegenüber dem Rest der Universität eintraten. ${ }^{200}$ Dieser Aspekt wird unten nochmals gesondert behandelt. Festzuhalten ist, dass BRD-Akteure in mehreren Fällen eigene Ansichten durch ihre Position als Re-

195 Ebd., Küper (GTZ), Protokoll einer Besprechung am 28.11.1975 an der Ingenieurfakultät, Dar es Salaam, 29.11.1975, S. 4.

196 Ebd., Küper (GTZ), Vermerk über ein Gespräch mit dem Chief Academic Officer der UDSM Prof. Kimambo am 27.11.1975, Nairobi, 3.12.1975.

197 Ebd., S. 4.

198 Ebd., Kreuser, Projektbericht Nr. 16, Dar es Salaam, 29.4.1976. Eine weitere Ausnahme neben der Ingenieursfakultät wurde auch für Frauen gemacht, deren Anteil an Erstsemestrigen im Zuge der Musoma Resolution noch weiter gesunken war. Hier hatte die Frauenorganisation eine entscheidende Rolle als pressure group gespielte. Siehe Itandala, Response to Musoma Resolution, S. 200.

199 BArch Koblenz, B 213/33056, Küper (GTZ), Interner Vermerk über Gespräche in der Technischen Fakultät Dar es Salaam am 25.11.1975, Eschborn, 4.12.1975, S. 3.

200 Ebd., Küper (GTZ), Protokoll einer Besprechung am 26.11.1975 an der Ingenieurfakultät, S. 1. 
präsentanten der Geldgeber gegenüber der Universitätsleitung durchsetzen wollten - was aber durchaus im Sinne des tansanischen Fakultätspersonals sein konnte.

Die Handlungsspielräume des BRD-Personals waren fraglos groß, schienen sich aber mit den Jahren zu verengen. Der scheidende GTZ-Teamleiter ${ }^{201}$ befand in seinem Abschlussbericht aus dem Jahr 1977, dass er seinen Einfluss vor allem durch seine Positionen in offiziellen und inoffiziellen Gremien an der Universität geltend machen konnte. Dazu sei sein institutionelles Kapital als GTZ-Angestellter („das Gewicht der deutschen Geberorganisation“) äußerst nützlich gewesen. Zunehmend nahm er aber eine Ausgrenzung aus den Informationsflüssen und Entscheidungsfindungen wahr:

Das Gewicht der deutschen Geberorganisation sowie der persönlichen Erfahrungen verhalfen dazu, daß sachlich fundierte und entsprechend vorgetragene Beiträge auch Gehör fanden. Es konnte jedoch nicht ausbleiben, daß gewisse Aktivitäten, etwa des Dekans oder tansanischer Abteilungsleiter sich der Anteilnahme des Teamleiters entzogen. ${ }^{202}$

Offensichtlich nutzte das tansanische Führungspersonal die gewandelten Mehrheitsverhältnisse an der Fakultät und schloss den GTZ-Teamleiter bisweilen bewusst aus; womöglich, um den Gebereinfluss zu verringern und strategisch eigenständiger agieren zu können. Obwohl die daraus resultierenden Initiativen manchmal gegen die „deutsche Position“ gehen würden, so der scheidende Teamleiter, sei die Eigenständigkeit als Zeichen der „Tansanisierung“ zu begrüßen. Ein ehemaliger GTZ-Experte erinnerte sich an diese Jahre als Zeit der verflogenen „Aufbruchsstimmung“, als intensive Kooperation sukzessive durch ein zunehmendes „Nebeneinanderherarbeiten“ ersetzt wurde; auch sein eigener Gestaltungsspielraum habe sich verkleinert. ${ }^{203}$ Manche der westdeutschen Fachkräfte, setzte der scheidende Teamleiter in seinem Bericht fort, hatten augenscheinlich Probleme mit den gewandelten Autoritätsverhältnissen. Aussagen über „,[g]elegentlich unkorrekte Verhaltensweisen von [GTZ-] Mitarbeitern, die einem Tansanier unterstellt waren“, weisen auf Insubordination hin. ${ }^{204}$ Ein Streitpunkt war die Arbeitsdisziplin der expatriates, von denen sich einige nicht

201 Der ranghöchste BRD-Vertreter im Projekt hieß erst Projektleiter, nach der Übernahme des Dekanats durch einen Tansanier dann Projektkoordinator und schließlich Teamleiter.

202 BArch Koblenz, B 213/33066, W., Bericht über die Amtszeit als Projektkoordinator/Teamleiter vom 16.5.1977-30.6.1977, Dreieich, 4.7.1977, S. 4.

203 Interview \#122, GTZ-Experte.

204 BArch Koblenz, B 213/33066, W., Bericht über die Amtszeit als Projektkoordinator/Teamleiter vom 16.5.1977-30.6.1977, Dreieich, 4.7.1977, S. 4. 
damit abfinden wollten, dass zu einer Sechstagewoche im Zuge der Auswirkungen der Ölkrise auch noch ein Sonntagsfahrverbot hinzukam. Als Ausgleich zur dauerhaften Existenz im „Ghetto“, wie der Projektleiter 1974 den Campus bezeichnete, forderten die BRD-Experten die Erhöhung des Urlaubsanspruchs. ${ }^{205}$ Andere entfernten sich an vorlesungsfreien (aber nicht dienstfreien) Samstagen eigenmächtig für Safaris und wurden in der Folge von den mitunter als „sehr strikt“ wahrgenommenen Institutsvorständen zur Erfüllung ihrer vertraglichen Pflichten angehalten. ${ }^{206}$

Etliche Lehrkräfte an der Fakultät - darunter einige aus der BRD - identifizierten sich weder mit Tansanias politischer Ausrichtung noch den allgemeinen Zielvorgaben von Ujamaa; sie hielten nichts von der Wirtschaftspolitik und waren generell der Ansicht, dass Technik politisch neutral sei. ${ }^{207}$ Bisweilen verbargen sich hinter der apolitischen Fassade Haltungen, die gerade in einem Land, das für den Kampf gegen Kolonialismus und Apartheid stand, völlig inakzeptabel waren. Ein GTZ-Experte verlieh seiner rassistischen Einstellung Ausdruck, indem er an eine Toilette ein Schild mit der Aufschrift „For Whites Only“ anbrachte. Die einzige Sanktion für dieses Vergehen war dem damaligen Projektleiter zufolge, dass die GTZ den Vertrag nicht verlängerte. ${ }^{208}$ Ingenieure, die aus einer linken Position heraus politisierten, waren die Ausnahme. Der bereits erwähnte Ingenieur mit Soziologieabschluss, der sich als Achtundsechziger identifizierte, versuchte, die Diskussionen um Mitbestimmung, die er in Westberlin geführt hatte, auch in seinen Unterricht an der Fakultät einfließen zu lassen. Beim Versuch, das Prinzip der Arbeitermitbestimmung zu vermitteln, stieß er allerdings auf den Widerstand der Studierenden, die an derartigen Konzepten kein Interesse zeigten: Das sei „nicht science, das sei arts“, hätten sie gemeint, sodass von seinem politischen Emanzipationsprojekt nur „Ernüchterung“ und „Enttäuschung“ übrig geblieben sei. $^{209}$

Schließlich spielte auch die Wahrnehmung von GTZ-ExpertInnen durch die Zentrale und das BMZ eine Rolle im Einsatz- und Projektverlauf. Blieben die Entsandten nicht nur drei oder vier, sondern fünf, sechs und zehn Jahre im Einsatz, galt ihre Loyalität gegenüber der GTZ und der BRD als gefährdet. Diese Denkweise schlug sich in der feldinternen Terminologie der westdeutschen Ent-

205 BArch Koblenz, B 213/33056, Anlage 1 zu Kreuser, Projektbericht Nr. 14, Dar es Salaam, 13. 2. 1976.

206 Interview \#105, BRD-Dozent (Lokaler Vertrag mit GTZ-Gehaltsaufstockung).

207 BArch Koblenz, B 213/33074, Report of an International Study Team on the FoE at the UDSM, Mai 1979, S. 61.

208 Interview \#101, GTZ-Experte und -Projektleiter.

209 Interview \#122, GTZ-Experte. 
wicklungshilfe nieder. „Verbuschung“ beschrieb nicht nur einen vermeintlichen kulturellen Anpassungsprozess und die zunehmende Distanz $\mathrm{zu}$ formalen Abläufen und „deutschen“ Standards, sondern auch die Verstrickung in lokale Patronagenetzwerke. „Entbuschung“ wiederum stand für das Wiederherauslösen der Experten aus den lokalen soziokulturellen Kontexten. Diese Begriffe bilden eine Kontinuitätslinie zur kolonialen Vokabel der „Verkafferung“, die semantisch ähnlich belegt, aber noch offensichtlicher rassialisiert ist. ${ }^{210}$ Die Begriffe legen nahe, dass es zum erwünschten „Naturzustand“ des entsandten Personals gehörte, eben nicht voll integriert zu sein, um die notwendige - hier wertneutral gemeinte - Ignoranz für eine technische Intervention aufzuweisen und immer in einer imaginierten Außenposition zu verbleibenden. Eine Solidarisierung mit „dem Partner“ und Identifikation mit den Interessen lokaler Gruppierungen wurde vor allem dann als Loyalitätsproblem gedeutet, wenn BMZ bzw. GTZ-Zentrale materielle Kürzungen oder entwicklungspolitische Trendwenden in den Projekten im globalen Süden durchsetzen wollten. So drängte ein BMZ-Beamter 1989 darauf, den GTZ-Teamleiter an der Fakultät abzulösen:

Ich kann mir nicht vorstellen, daß der seit vielen Jahren in dem Vorhaben tätige Experte noch den inneren Abstand zu seiner Arbeit hat und sich persönlichen Beziehungen zu seinen tansanischen Kollegen soweit zu entziehen vermag, um die in vielen Bereichen der FoE [Faculty of Engineering] nötigen Neuorientierungen mitzutragen bzw. durchzusetzen. ${ }^{211}$

In diesem Fall setzte sich die GTZ gegenüber dem BMZ für ihren Angestellten ein und meinte, der Experte habe die Richtungsänderungen sogar selbst mit initiiert und habe dementsprechend auch ein Interesse daran, sie durchzusetzen. In anderen Fällen hingegen war auch die GTZ-Zentrale der Meinung, dass eine „Entbuschung“ angebracht sei und bot keine Vertragsverlängerung an. ${ }^{212}$

\section{Strategische Gruppen: Wirtschaftsinteressen am Campus}

1979, im selben Jahr als Nyerere die IWF-Delegation des Landes verwies, schlug der GTZ-Teamleiter Alarm. Innerhalb kürzester Zeit hatten drei tansanische Lehrkräfte, von denen zwei mit DAAD-Mitteln zur „Tansanisierung“ der Fakultät im Ausland qualifiziert worden waren, die Universität Richtung staatlicher und

210 Rakelmann, Expertenkultur, S. 169; Hüsken, Stamm der Experten, S. 196; Interview \#101, GTZ-Experte und -Projektleiter.

211 BMZ, B 213/48207, Ref. 124 (BMZ) an GTZ, Bonn, 13.11.1989.

212 Interview \#113, GTZ-Experte und -Projektleiter. 
privater Industrie verlassen. Nach Ablauf ihrer obligatorischen, dreijährigen vertraglichen Bindung an die Universität machten sie von ihrer 24-stündigen Kündigungsfrist Gebrauch. An einigen Instituten verblieben kaum noch Tansanier. Die GTZ forderte Maßnahmen von Dekan Mawenya, hatte aber selbst kaum Vorschläge, wie dem „Staff Exodus“ beizukommen sei. ${ }^{213}$ Der GTZ-Teamleiter zeigte sich ebenfalls ratlos, als das „Zuckerbrot, sprich Auslandsstipendium“, die „Zugkraft verloren“ hatte, da Stipendien nun auch standardmäßig in der Industrie vergeben wurden. ${ }^{214}$ Das Problem müsse auf politischer Ebene gelöst und in den nächsten Regierungsverhandlungen auf den Tisch gebracht werden, anderenfalls drohe die Fakultät auf das „Niveau einer Tafel- und Kreide-Lehranstalt“ abzusinken. ${ }^{215}$ Einmal mehr forderten deutsche Fachkräfte also politische Schützenhilfe an - aber auch das tansanische Personal drängte offensichtlich auf diese Änderungen.

Bereits im August 1979 hatte ein fakultätsinternes Komitee - in dem keine expatriates vertreten waren - mehr „Anreize“ gefordert. Dazu zählten höhere Löhne, mehr Aufstiegsmöglichkeiten und Bonuszahlungen für jene, die der Fakultät durch die Übernahme von Consulting-Aufträgen zusätzliches Einkommen verschafften. $^{216}$ Außerdem sollten Mitgliedsbeiträge für internationale Ingenieursvereinigungen, Gelder für Konferenzteilnahmen und Budgets für aktuelle Forschungsliteratur bereitgestellt werden, um auch die Tätigkeit über Tansania hinaus zu gewährleisten; gefordert wurde auch eine Kreditlinie (zusätzlich zu bereits bestehenden Linien für Motorräder, Kühlschränke) für die tansanischen Angestellten, damit diese Häuser bauen und so auch die kritische Unterbringungslage am Campus entlasten konnten. Die Mobilität sollte ebenfalls verbessert werden, denn 1979 verfügte die Fakultät über nur ein eigenes Fahrzeug. Der Rest des Fuhrparks gehörte den Geberorganisationen und durfte nur mit deren Zustimmung genutzt werden. Das Karriereschema, das diesen Empfehlungen beigelegt wurde, verdeutlichte, dass sich das Komitee an den Arbeitsbedingungen und deutlich besseren Gehaltsschemata der Industrie - anstelle der anderen Fakultäten - orientierte. $^{217}$

213 BArch Koblenz, B 213/33077, Küper/Füllenbach (GTZ) an Mawenya (Dekan FoE UDSM), Eschborn, 1.10.1979.

214 Ebd., B 213/33077, H. (GTZ-Teamleiter) an GTZ, 10.10.1979.

215 Ebd., B 213/33088, Füllenbach (GTZ), Stellungnahme zum Bericht Nr. 24, Eschborn, 24.1. 1980.

216 Ebd., B 213/33077, Ad Hoc Committee Report on Measures to Address Dissatisfaction of Tanzania Staff, 23.8.1979.

217 Ebd., Bildungshilfe Technische Fakultät Heft 15, Ad Hoc Committee Report on Measures to Address Dissatisfaction of Tanzania Staff, 23.8.1979, Appendix C. 
Schon im Mai desselben Jahres hatte ein international zusammengesetztes, achtzehnköpfiges Evaluierungsteam in gleicher Weise gefordert, die Konkurrenzsituation mit dem Wirtschaftssektor anzunehmen und damit einen Präzedenzfall an der Universität zu schaffen:

[W]e recognise that some of [the suggested measures for improving the staff situation] might create problems of equity for the University. Nevertheless, in a market situation in which individual employment choices beyond the bonding period are respected, we feel that measures of the general type suggested for managerial teaching staff are probably unavoidable. ${ }^{218}$

Tatsächlich waren kaum andere Optionen denkbar. Eine der wenigen Alternativen, die Verlängerung der bonding period (also Verpflichtung für staatliche Institutionen zu arbeiten) über die Dauer von fünf bzw. drei Jahren hinaus wurde als politisch unklug erachtet, da sie die Unzufriedenheit der Bildungselite und die Wahrscheinlichkeit der Abwanderung noch weiter erhöht hätte. Die GTZ-Zentrale wandte sich für Unterstützung an das BMZ. ${ }^{219}$ Das BMZ inkludierte, der GTZForderung Folge leistend, in den nächsten Regierungsvereinbarungen die maximal unscharfe Klausel: Tansania ,shall undertake special efforts to ensure that the Tanzanian academic and non-academic staff at the Faculty of Engineering remain employed there in line with demand“".220 Rektor Kaduma war geneigt, Nebeneinnahmen aus Beratungstätigkeiten zu genehmigen, wurde aber 1979 abgelöst, bevor die Änderung abgesegnet werden konnte. ${ }^{221}$

Während 1979 die Forderungen stärker auf den individuellen Gewinn zielten, hatte es bereits zuvor Initiativen an der Fakultät gegeben, Profite zu generieren und ihre Mitglieder daran teilhaben zu lassen. Aussagen des ersten tansanischen Dekans Awadhi Mawenya 222, der die Fakultät von 1976 bis 1982 leitete, zeigen die

218 BArch Koblenz, B 213/33074, Report of an International Study Team on the FoE at the UDSM, Mai 1979, S. 100.

219 BArch Koblenz, B 213/33088, Küper/Füllenbach (GTZ) an Lütteken (BMZ), 1.11.1979.

220 Ebd., Entwurf zum Regierungsabkommen, S. 6.

221 Ebd., Füllenbach (GTZ), Stellungnahme zum Bericht Nr. 24, Eschborn, 24.1.1980.

222 Mawenyas Biografie (die biografischen Angaben stammen aus GTZ, University of Dar es Salaam Faculty of Engineering, Eschborn 1979, 25-26) ist in einer Hinsicht untypisch für die postkoloniale (Bildungs-)Elite: Er begann seine Schulkarriere in keiner Missions-, sondern in einer Koranschule, wo er Arabisch lesen und schreiben lernte. Andere biografische Elemente fügen sich eher in das Bild der postkolonialen Bildungselite ein, das aus der Sekundärliteratur bekannt ist: geboren wurde er 1941 in der sozioökonomisch privilegierten Region Kilimanjaro, absolvierte die Sekundarschule in Tabora und erhielt einen Bachelor- und Masterabschluss in Nairobi, jeweils mit herausragenden akademischen Leistungen. Durch praktische Erfahrungen bei der East African Railways Corporation eignete er sich einen Sinn für die Praxis an. Als erste 
Schwierigkeiten und Taktiken in diesen Aushandlungsprozessen. Im Interview beschrieb Mawenya nicht nur, welche Möglichkeiten die landesweit einzigartige Konzentration von Expertise und „modernen“, von deutscher Seite importierten Maschinen an der Fakultät mit sich brachte. Er schilderte auch, wie er sich mit dem Senat und Rektor (die auf den leadership code der Arusha-Deklaration pochten) auseinandersetzen musste, um Ausnahmeregelungen durchzusetzen und in dieser Frage auch die Kooperation mit dem ausländischen Personal suchte. In diesem Fall handelte es sich um einen Schweizer, der den entscheidenden Antrag verfasste, den Mawenya dann in den entscheidenden Universitätsgremien einbrachte und verteidigte. So wurde nicht nur die Institutionalisierung der Dienstleistungsfunktion der Fakultät für die Industrie vorangetrieben, sondern auch die Möglichkeit für Ingenieure, ihr individuelles Einkommen aufzubessern und ihre Tätigkeit zu kommerzialisieren. In dieser Hinsicht verwies Mawenya, wie er sich erinnerte, auf die einzige andere Berufsgruppe, die ebenfalls eine Ausnahmestellung durchgesetzt hatte:

Of course you faced a lot of problems with the university administration because the very concept of getting a second income was not allowed [...]. So I remember, I personally spent a lot of time with the vice chancellor to explain. I said, we are engineers. You should treat us like medical people. You cannot say you are a teaching engineer when you don't practice engineering. Just like a doctor. You cannot teach doctors when you don't have patients. [...] And we were then able to do what other people what call private work. At university. But we didn't see it systematically as private work, it was official, because the income was divided into three portions. One portion which would go directly to the labs or to another part of the university whose facilities were used. Another component will come directly to the Faculty. And one component will then be sub-divided among those people who did the work. And the ratio was ... 30 percent for individuals, 30 percent for the faculty and 40 percent to maintain the facilities which we were using. And it worked very efficiently. And the logic was, if you are doing private work, using official time of the university, then other people must have another work, so that's why the 30 percent must remain in the faculty for everybody [...] Of course, I understand later on, in the nineties, the whole thing was polluted and now you can even take 90 percent and put it in your pocket. ${ }^{223}$

Der Kompromiss, den Gewinn aus privater Arbeit aufzuteilen, wurde dabei nicht unbedingt als Widerspruch zum Entwicklungsmodell Ujamaa dargestellt, da viele

Person überhaupt wurde Mawenya 1971 für die bis dato noch inexistente, aber bereits geplante Fakultät rekrutiert und sogleich zu einem Doktoratsstudium nach Wales geschickt. Direkt nach seiner Rückkehr nahm Mawenya als einziger Tansanier an seinem Institut, mit einem Briten und zwölf Deutschen, die Lehrtätigkeit auf. Mit der Beförderung zum Associate Professor 1976 löste Mawenya den Kreuser als Dekan ab und lenkte für zwei Amtsperioden bis 1982 die Geschicke der Fakultät.

223 Interview mit Awadhi Mawenya, Dar es Salaam, 7.10.2014 
den Aufbau des sozialistischen Tansania und das eigene Vorankommen als zwei Seiten einer Medaille verstanden. ${ }^{224}$ Obwohl Mawenya angab, die Änderungsvorschläge selbst präsentiert und verteidigt zu haben, ist doch die Schutzfunktion nicht zu unterschätzen, die hier durch die Kooperation mit expatriates samt deren institutionellem Kapital gegeben war. Im Gegensatz zur oben erwähnten „Neunergruppe“, die den Sozialismus an der Universität stärker verankern wollte, standen diese expatriates Aufstiegsaspirationen nicht im Weg und waren mit ihrer Repräsentations- und Verbindungsfunktion gen Heimat auch wichtige Fürsprecher für fortgesetzte materielle und personelle Unterstützung. Ein westdeutscher Dozent, von 1978 bis 1982 an der Fakultät, betonte im Interview seine eigene Initiative in diesem Prozess und erinnerte sich an politischen Gegenwind:

\begin{abstract}
Die Fakultät war ja auf der Linie, schwieriger war es, die Gesamt-Unileitung zu überzeugen, weil da die ganzen anderen Fakultäten dann dranhängen, die dann sagen, „Na warum sollen die mehr verdienen als wir?" Das ist klar. Es war ja natürlich aus dem normalen Rahmen dann rausgefallen. Sonst war Lecturer und Senior Lecturer, Gehalt war festgelegt, egal auf welcher Fakultät. Und da sind wir natürlich dann etwas rausgesprungen, weil dann je nach Einsatz von den Einzelnen dann ein bisschen topping up kam. [...] Dass da sozusagen kapitalistische Methoden eingeführt wurden, das war der Anwurf, den ich da bekommen hab. [...] Von der Unileitung wurde ich da zitiert und mir wurden kapitalistische Methoden vorgeworfen, mit dem Aufbau einer Consultancy-Abteilung. Ich konnte aber dann mit Hilfe der Ingenieurfakultät die Leitung überzeugen, dass das sinnvoll ist und tansanische Kollegen mit so ein bisschen Zusatzgeld über Consulting an der Uni zu halten. Das waren damals so ein bisschen zusätzliche Schwierigkeiten, die man noch hatte, von der politischen Seite. Wobei die Ingenieurfakultät eigentlich offen war. Die wurde unterstützt von westlichen Ländern, während die Wirtschaftsfakultät - die war von östlichen, die DDR hat da zum Beispiel unterstützt. Und da gab's so gewisse Animositäten politischer Art zwischen der Ingenieurfakultät, die ja naturgemäß immer eher die Chance haben, Geld parallel Geld zu verdienen durch Consultancy. ${ }^{225}$
\end{abstract}

Bemerkenswert ist neben der Einteilung der Universität in „westlich“ und „östlich“ unterstützte Institutionen (unter Missachtung der gänzlich ungleichen Art der Unterstützung) insbesondere der Hinweis auf die unter Ingenieuren „naturgemäße“ Möglichkeit, Geld dazuzuverdienen. Gerade solche Aneignungsmöglichkeiten und die daraus resultierenden Ungleichheitseffekte hätten durch den leadership code der Arusha-Deklaration und die universitätsweite Angleichung von Gehältern eigentlich der Vergangenheit angehören sollen. Nunmehr agierten tansanische und ausländische Kräfte an der Fakultät in dieser Sache im Sinne des Entwicklungssoziologen Hans-Dieter Evers als eine „strategische Gruppe“, um

224 Ebd.

225 Interview \#105, BRD-Dozent (Lokaler Vertrag mit GTZ-Gehaltsaufstockung). 
eigene Interessen durchzusetzen. ${ }^{226}$ Innerhalb weniger Jahre hatten sie das Vakuum technischer Fachkräfte in Tansania gefüllt, Netzwerke gebildet und arbeiteten nun gemeinsam daran, eine professionell anerkannte Identität zu schaffen, die auch in wirtschaftlichen Gewinn und politischen Einfluss mündete. Ihr spezifisches (ingenieurwissenschaftliches) Wissen bildete die Grundlage für Handlungsstrategien, um sich weitere Ressourcen anzueignen. Durch die verstärkte Industrieberatung konnten Ausschüttungen an alle Fakultätsangestellten ausgezahlt werden, was die Fluktuationsquote etwas verringerte; die Einnahmen wurden zudem auch herangezogen, um einen Teil der laufenden Kosten zu decken. ${ }^{227}$ Diese Ingenieursallianzen, die auf andere Gremien und Institutionen Druck ausübten, waren nationenübergreifend. Es ist wenig zielbringend, den Ursprung oder die Initiative für zunehmende Kapitalisierung bei Schweizer oder GTZ-Experten, BMZ-Beamten oder tansanischen Dozenten zu suchen; vielmehr kamen verschiedene Interessen in einer spezifischen Konstellation zusammen, die es dem Fakultätspersonal ermöglichten, einen Ausnahmestatus und die Lizenz für kommerzielle Tätigkeiten innerhalb der Universität zu erreichen. Diese strategische Gruppe war allerdings kein stabiles Netzwerk. ${ }^{228}$

Gerade die Trennlinie zwischen einheimischem und ausländischem Personal gefährdete die brüchigen Allianzen immer wieder. Manche expatriates agierten mit dem vielfach variierten Argument der „entwicklungspolitischen Wirksamkeit“ gegen die materiellen Interessen des tansanischen Personals. Ein GTZ-Experte war, wie er im Interview erklärte, in dem Komitee vertreten, das über die Verwendung der Consultingeinnahmen entschied. Generell galt hier die Regel, dass die Einnahmen zur Gänze an die Fakultät gehen sollten, was für einheimisches und ausländisches Personal gleichermaßen galt. ${ }^{229}$ Wie der Experte erzählte, votierten tansanische Vertreter im Komitee dafür, Autos anzuschaffen, damit sie mobil sein konnten - kein einziger Tansanier an der ganzen Fakultät besaß ein eigenes Fahrzeug. Seine Präferenz sei hingegen gewesen, die Gelder an den Instituten zu investieren. Er selbst hatte sich - „das war normal“ - vor Ort ein Auto gekauft, „um das herrliche Land zu bereisen“. Diese „Normalität“ bestand aber

226 Evers, Wissen ist Macht.

227 BArch Koblenz, B 213/33099, Füllenbach (GTZ), Fachliche Stellungnahme zu Bericht Nr. 28, Eschborn, 22.1.1982.

228 Vgl. auch für die 1990er Jahre: Tom Hewitt/David Wield, Tanzanian Networks. Networks in Tanzanian Industrialisation, in: Science and Public Policy 24/6 (1997), 395-404.

229 BArch Koblenz, B 213/33074, Report of an International Study Team on the FoE at the UDSM, Mai 1979, S. 75. 
nur für das ausländische Personal, und im Interview meinte er selbstkritisch, dass er die Lage damals „ein bisschen falsch eingeschätzt“ habe. ${ }^{230}$

Generell lässt sich auch der Gegensatz feststellen, dass GTZ und BMZ eher auf Strukturänderungen - hier noch weitgehend auf das direkte Projektumfeld beschränkt und nicht im umfassenden Sinne einer nationalen Umwälzung drängten, während das tansanische Fakultäts- und Universitätspersonal die Probleme eher mit einer Extraversionsstrategie zu überbrücken suchte, die im Wesentlichen auf eine weitere Finanzierung durch die Geber und die Rekrutierung ausländischer Fachkräfte ausgelegt war. ${ }^{231}$ Die BRD lehnte Maßnahmen in diese Richtung, etwa Gehaltsaufschläge (top-ups) für expatriates außerhalb entwicklungspolitischer Arrangements - meist indische Dozenten, die nicht über staatliche Kanäle, sondern in Eigenregie kamen - nicht generell ab, schloss Devisenzuzahlungen für tansanisches Personal allerdings mit den Argumenten der langfristigen Nachhaltigkeit und der vereinbarten Übernahme laufender Kosten durch Tansania aus. ${ }^{232}$ Zumindest in materieller Hinsicht wurde hier die koloniale Hierarchie von Europäern, Indern und Afrikanern wiederbelebt, wobei die Privilegien jetzt durch entwicklungspolitische Argumente rationalisiert wurden.

Die Einführung von Sonderleistungen und leistungsbezogenen Honoraren führte, wie die GTZ 1990 an das BMZ berichtete, zu ,verstärkter Dynamik und Initiative“. ${ }^{233}$ Hier handelte es sich allerdings um ein Schreiben, das mit seinem optimistischen Ton die Finanzierung einer weiteren Projektphase sichern sollte. In internen Besprechungen waren die GTZ und auch die Schweizer Direktion für Entwicklungszusammenarbeit Ende $1989 \mathrm{zu}$ kritischeren Urteilen gekommen. Das Monatseinkommen tansanischer Lehrkräfte reiche nach wie vor kaum, um die Lebenshaltungskosten einer Woche $\mathrm{zu}$ decken, der Großteil des Personals sei unmotiviert, und während die Fakultät zwar 2,5 Millionen TSh durch Beratungsleistungen umsetze, sei die inoffizielle Nebentätigkeit der Dozenten fünf bis zehn Mal umfangreicher. ${ }^{234}$ „Unproduktives“ und „unmotiviertes“ Personal sollte entlassen werden, um das Gehalt für die motivierten Lehrkräfte erhöhen zu können. Im Gegensatz zur BRD zahlte die Schweiz auch dem tansanischem Per-

230 Interview \#106, GTZ-Experte.

231 BArch Koblenz, B 213/33074, Report of an International Study Team on the FoE at the UDSM, Mai 1979, S. $90-91$.

232 BArch Koblenz, B 213/33099, Füllenbach (GTZ), Besprechungsbericht, Dar es Salaam, 13.7. 1982.

233 BMZ, B 213/48212, GTZ, Angebot über die Durchführung des Vorhabens Förderung der Ing.Fakultät der Uni DSM, Eschborn, 12.7.1990, S. 9.

234 BMZ, B 213/48207, Bericht über Besprechung zum Thema Ingenieurfakultät und IPI, Bonn, 30.3.1989. 
sonal Gehaltsaufschläge (allowances), um Abwesenheiten aufgrund von „Schwarzarbeit“ zu verringern. ${ }^{235} 1990$ konnte man auch im BMZ verständnisvollere Stimmen in Bezug auf materielle Anreize vernehmen. Die Bereitstellung von PKWs und Motorrädern seien ein wichtiger Anreiz zu bleiben, angesichts von „völlig unzureichenden Verkehrsmitteln in Daressalam“ sei „diese Haltung rational".236

Dekan Mawenya, Anfang der 1980er zunehmend enttäuscht von Nyereres Wirtschaftspolitik und sich nicht mehr in der Lage sehend, als Familienvater (mit einer werktätigen Ehefrau) mit dem Universitätsgehalt noch länger über die Runden zu kommen, hatte die Fakultät 1984 - wie schon so viele vor ihm - in Richtung Industrie verlassen. ${ }^{237}$ Es herrschte Untergangsstimmung an der Fakultät und Ratlosigkeit in der Regierung: Wenn selbst einer der überzeugten „Pioniere“ die Fakultät verließ - wer sollte dann noch bleiben? ${ }^{238}$ Bereits durch Inflation und die Folgen des Ugandakrieges wirtschaftlich eingeschränkt traf der 1986 nochmals verschärfte Sparkurs die Universität, die zeitweilig bis zu einem Drittel des nationalen Bildungsetats zur Verfügung gehabt hatte, mit voller Härte. Wie in anderen afrikanischen Ländern zwangen die Strukturanpassungsmaßnahmen die Regierung dazu, ihre Ausgaben für tertiäre Bildung zurückzufahren. Die verschiedenen an der Fakultät präsenten Geber koordinierten nunmehr (wie auch in Bezug auf makroökonomische Reformen) ihre Standpunkte und kamen zum Konsens, dass Tansania die strukturellen Bedingungen und die nationale Bildungspolitik ändern müsse, um sich für weitere Leistungen im Rahmen der Entwicklungszusammenarbeit zu qualifizieren. ${ }^{239}$ Diese Änderungen setzten der staatlichen Finanzierung des Bildungswegs bis hin zur Universität ein Ende.

Bis 1990 hatten über 1.300 Studierende einen Bachelor und 21 einen Master in Ingenieurwissenschaften von der Fakultät erhalten, die Nationalisierung des Lehrkörpers war trotz der Probleme weit vorangeschritten. Die BRD kündigte 1988, als Entwicklungshilfemittel zeitweise eingefroren wurden, ihren Rückzug aus dem Projekt an. Die Fakultät argumentierte, diese Entscheidung käme zu einer denkbar ungünstigen Zeit, da die meisten tansanischen Lehrkräfte noch zu jung, die Gerätschaften hingegen schon zu alt seien, um Tansanias Ziel der self-

235 BMZ, B 213/48210, Gesprächsvermerk über Gespräch mit Vertretern der schweizerischen Direktion für EZA und humanitäre Hilfe (DEH), Bonn, 12.12.1989.

236 BArch Koblenz, B 213/48210, Förderung der Ingenieurfakultät Dar es Salaam Heft 27, Dienstreisebericht Referat 124, Konsultationen mit Projektbesuchen, Bonn, 9.3.1990.

237 Interview mit Awadhi Mawenya, Dar es Salaam, 7.10.2014.

238 Interview \#32, Tansanischer Dozent an der Ingenieurwissenschaftlichen Fakultät.

239 BMZ, B 213/48199, GTZ, Report of a meeting of donor agencies which are assisting the university of Dar es Salaam/Tanzania, 13/14 November 1986, Eschborn, März 1987. 
reliance zu erreichen - es brauche noch „post-care“. ${ }^{240}$ Diese in finanzieller wie personeller Hinsicht tatsächlich bescheidenen Maßnahmen, vergleicht man sie mit den vorherigen zwei Jahrzehnten, wurden gewährt. 1999, ein Vierteljahrhundert nach der Eröffnung der Fakultät und siebzehn Jahre später als anfangs erwartet, beendete die GTZ die Intervention - nach Ansicht mancher tansanischer Interviewpartner im Jahr 2014 noch immer verfrüht.

\section{Fazit}

Studentenprotesten gegen die Verschlechterung der Studienbedingungen 1986 folgten weitere Vorlesungsboykotts 1988. Im April und Mai 1990 forderten die Studierenden nicht nur bessere Bedingungen für ihr Studium, sondern - Bezug nehmend auf die Transformationen in Osteuropa und ermutigt von Nyereres Hinweisen auf eine Öffnung in Richtung Mehrparteiendemokratie - politische Reformen, Demokratisierung, die Einführung von Mindestlöhnen und die Zusicherung höherer Produzentenpreise in der Landwirtschaft sowie (die längst ausgesetzten) Einstellungsgarantien für UniversitätsabsolventInnen. ${ }^{241}$ Allgemeine sozialpolitische Forderungen wurden hier mit Aspekten, die für die eigene Laufbahn entscheidend waren, in einem Atemzug genannt. Neu war, dass die StudentInnen auch den Großteil des längst auf Nebentätigkeiten angewiesenen Universitätspersonals auf ihrer Seite wussten. Präsident Mwinyi, Nyereres Nachfolger, unterband weitere Diskussionen. Er kritisierte DozentInnen, die die Proteste unterstützten, scharf und ließ die Universität für mehrere Wochen schließen. ${ }^{242} 1991$ wurde die Universität wiederum für mehrere Monate geschlossen, dieses Mal allerdings, weil der neue Rektor Mmari sich nicht auf Regierungs- und Parteilinie begeben wollte, sondern konziliant auf die Forderungen der Studierenden - die auch immer lautstärker das Ende des Einparteiensystems forderten hatte eingehen wollen. ${ }^{243}$

240 BMZ, B 213/48201, Masuha (Dekan FoE), Continued Cooperation with the FRG - A Brief to the Vice-Chancellor, Januar 1989.

241 Zur Krise siehe die Schilderungen in BMZ, B 213/48210, BRD-Botschaft an AA, Dar es Salaam, 14.5.1990; Matthew L. Luhanga, The Courage for Change: Re-Engineering the University of Dar Es Salaam, Dar es Salaam 2009; Mbwette/ Ishumi, Hg., Managing University Crises.

242 Der letzte Boykott ist detailliert beschrieben im Tätigkeitsbericht eines integrierten Experten: BMZ, B 213/48212, F., Abschlussbericht, Dar es Salaam, 16.6.1990; BMZ, B 213/48210, BRD-Botschaft an AA, Dar es Salaam, 14.5.1990.

243 DAAD-Archiv, B 212/91395/4, BRD-Botschaft an AA, Dar es Salaam, 5. 8.1991. 
Zur Demokratisierung hatten weder BRD- noch DDR-Entsandte viel beigetragen: Sie hatten ihre Hauptaufgabe in den meisten Fällen darin gesehen, die Universität im Sinne einer technokratischen Ausbildungsstätte oder auch national-politischen Kaderschmiede zu unterstützen. Die DDR-Auslandskader konnten aufgrund rivalisierender Sozialismuskonzepte nie eine effektive Allianz mit anderen linken Kräften an der Universität aufbauen; Bündnisse waren aufgrund fehlender materieller Ressourcen auch schwerer zu schmieden. In den hitzigen Debatten am Campus gelang es ihnen kaum, Impulse zu setzen. In den Erinnerungsberichten tansanischer und westlicher AkteurInnen finden DDR-DozentInnen kaum Erwähnung. Nichtsdestoweniger wurden die meisten DDR-Entsandten für die Erfüllung der ihnen angetragenen Aufgaben und ihre Bescheidenheit von Vorgesetzten und KollegInnen sehr geschätzt. In den Interviews sahen sich einige der damaligen DDR-Auslandskader in ideologischer Hinsicht als nachgefragtes Zusatzangebot an der Universität, wo sonst kaum Personal aus anderen sozialistischen Ländern vertreten war. Dieser ideologische Mehrwert, den die Präsenz der DDR-Lehrkräfte bedeutete, war allerdings nicht von allen am Campus erwünscht; bisweilen traf er auf Widerstand.

Während der Einfluss der DDR-Lehrkräfte meist darauf beschränkt blieb, Lehrveranstaltungen und gelegentlich Aufgaben in Gremien zu übernehmen, konnten GTZ-Experten und integrierte DozentInnen aus der BRD an der Ingenieurwissenschaftlichen Fakultät durch ihre Einbindung in einen Projektzusammenhang nicht nur Einfluss auf die Gestaltung von Lehrplänen, sondern auch auf die Arbeitsbedingungen nehmen. Während ostdeutsche Entsandte einen insgesamt geringen Politisierungseffekt erreichten, setzte eine Reihe bundesdeutscher Akteure von Bonn über Eschborn bis Dar es Salaam erfolgreich eine Ökonomisierung an der Ingenieurwissenschaftlichen Fakultät durch - und zwar in einer Allianz mit dem tansanischen Personal, das somit eine Sonderstellung an der Universität erhielt. Der Sonderstatus der Fakultät erwuchs dabei nicht nur aus dem elitären Berufsbild des Ingenieurs und damit verbundenen Karriereerwartungen, sondern auch dem Einfluss westlicher Geber, die ihr materielles und personelles Gewicht nutzten, um kapitalistische und individualistische Logiken zu fördern - weitgehend auch im Interesse und teils sogar auf Initiative des tansanischen Fakultätspersonals. Obwohl es durchaus Grabenkämpfe an der Fakultät gab, lässt sich doch die Bildung einer transnationalen strategischen Gruppe konstatieren, die dafür sorgte, dass die Fakultätsleitung nationale Richtlinien wie den leadership code außer Kraft setzen konnte und eine Kommerzialisierung der Arbeitsformen institutionalisierte. Auch an anderen Fakultäten hatte eine derartige Neuorientierung stattgefunden, das besondere an der Ingenieursfakultät war jedoch die offiziell abgesicherte Institutionalisierung der Änderungen. Der Campus war von einem Zentrum globaler Diskussionen über 
Entwicklungskonzepte und Ungleichheit zu einem Ort der Dienstleistung geworden. Hatte die Universität Anfang der 1970er-Jahre noch selbstbewusst die Forschungsvorhaben ausländischer ForscherInnen in Bezug auf die Nützlichkeit für Tansania untersucht, bestimmten nun Aufträge externer Geber die Forschungstätigkeit. Westliche Geber förderten diese Tendenz durch das Setzen materieller Anreize und die Subventionierung staatlicher Funktionen durch externe Ressourcen. Damit zeigten sich an der Universität Dar es Salaam bereits vor der neoliberalen Umstrukturierung des tertiären Sektors in den 1990er-Jahren Tendenzen einer Entpolitisierung und Ökonomisierung des akademischen Betriebs und einer Vertiefung von Abhängigkeiten, deren Überwindung in den 1970er-Jahren noch der Dreh- und Angelpunkt der Debatten dargestellt hatte. ${ }^{244}$

$244 \mathrm{Zu}$ neoliberalen Reformen im ostafrikanischen Hochschulsektor siehe auch - neben den bereits genannten Werken zur Geschichte der Universität Dar es Salaam - Mahmood Mamdani, Scholars in the Marketplace. The Dilemmas of Neo-Liberal Reform at Makerere University, 19892005, Cape Town 2009. 